\title{
Pacific Northwest Laboratory Annual Report for 1994 to the DOE Office of Energy Research
}

Part 1: Biomedical Sciences April 1995

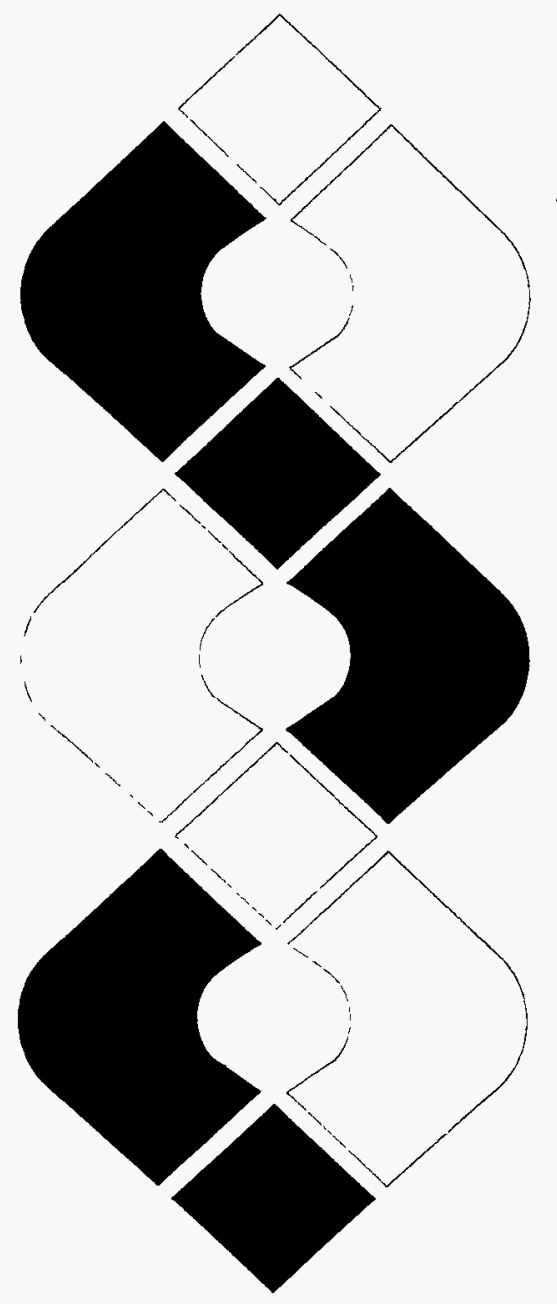

Prepared for the U.S. Department of Energy under Contract DE-AC06-76RLO 1830

Pacific Northwest Laboratory

Operated by Battelle Memorial Institute for the U.S. Department of Energy

\section{\%attelle}




\title{
DISCLAIMER
}

This report was prepared as an account of work sponsored by an agency of the United States Government. Neither the United States Government nor any agency thereof, nor Battelle Memorial Institute, nor any of their employees, makes any warranty, expressed or implied, or assumes any legal liability or responsibility for the accuracy, completeness, or usefulness of any information, apparatus, product, or process disclosed, or represents that its use would not infringe privately owned rights. Reference herein to any specific commercial product, process, or service by trade name, trademark, manufacturer, or otherwise does not necessarily constitute or imply its endorsement, recommendation, or favoring by the United States Government or any agency thereof, or Battelle Memorial Institute. The views and opinions of authors expressed herein do not necessarily state or reflect those of the United States Government or any agency thereof.

\section{PACIFIC NORTHWEST LABORATORY operated by \\ BATTELLE MEMORIAL. INSTITUTE for the UNITED STATES DEPARTMENT OF ENERGY under Contract DE-ACO6-76RLO 1830}

\author{
Printed in the United States of America
}

Available to DOE and DOE contractors from the

Office of Scientific and Technical Information, P.O. Box 62, Oak Ridge, TN 37831; prices available from (615) 576-8401. FTS 626-8401.

Available to the public from the National Technical Information Service, U.S. Department of Commerce, 5285 Port Royal Rd., Springfield, VA 22161. 


\section{DISCLAIMER}

Portions of this document may be illegible in electronic image products. Images are produced from the best available original document. 


\section{Pacific Northwest Laboratory Annual Report for 1994 to the DOE Office of Energy Research}

\section{Part 1: Biomedical Sciences \\ J. F. Park and Staff}

April 1995

Prepared for

the U.S. Department of Energy

under Contract DE-AC06-76RLO 1830

Pacific Northwest Laboratory

Richland, Washington 99352 


\section{Preface}

This 1994 Annual Report from Pacific Northwest Laboratory (PNL) to the U.S. Department of Energy (DOE) describes research in environment and health conducted during fiscal year (FY) 1994. This year, the report consists of two parts, each in a separate volume.

The two parts of the report are oriented to particular segments of the PNL program, describing research performed for the DOE Office of Health and Environmental Research (OHER) in the Office of Energy Research. Each part consists of project reports authored by scientists from several PNL research departments, reflecting the multidisciplinary nature of the research effort.

The parts of the 1994 Annual Report are as follows:

\section{Part 1: Biomedical Sciences}

Part 2: Atmospheric Sciences

\author{
J.F. Park, Program Manager \\ F.T. Cross, Report Coordinator \\ C.C. Lumetta, Editor
}

W.R. Barchet, Program Manager

G.P. O'Connor, Editor

Activities of the scientists whose work is described in this annual report are broader in scope than the articles indicate. PNL staff have responded to numerous requests from DOE during the year for planning, for service on various task groups, and for special assistance.

Credit for this annual report goes to the many scientists who performed the research and wrote the individual project reports, to the program managers who directed the research and coordinated the technical progress reports, to the editors who edited the individual project reports and assembled the two parts, and to Ray Baalman, editor in chief, who directed the total effort. 
Previous Annual Reports in this series:

\begin{tabular}{|c|c|}
\hline 1951 & HW-25021, HW-25709 \\
\hline 1952 & HW-27814, HW-28636 \\
\hline 1953 & HW-30437, HW-30464 \\
\hline 1954 & HW-30306, HW-33128, HW-35905, HW-35917 \\
\hline 1955 & HW-39558, HW-41315, HW-41500 \\
\hline 1956 & $H W-47500$ \\
\hline 1957 & $H W-53500$ \\
\hline 1958 & HW-59500 \\
\hline 1959 & $H W-63824, H W-65500$ \\
\hline 1960 & HW-69500, HW-70050 \\
\hline 1961 & HW-72500, HW-73337 \\
\hline 1962 & HW-76000, HW-77609 \\
\hline 1963 & HW-80500, HW-81746 \\
\hline 1964 & BNWL-122 \\
\hline 1965 & BNWL-280, BNWL-235, Vol. 1-4; BNWL-361 \\
\hline 1966 & BNWL-480, Vol. 1; BNWL-481, Vol. 2, Pt. 1-4 \\
\hline 1967 & BNWL-714, Vol. 1; BNWL-715, Vol. 2, Pt. 1-4 \\
\hline 1968 & BNWL-1050, Vol. 1, Pt. 1-2; BNWL-1051, Vol. 2, Pt. 1-3 \\
\hline 1969 & BNWL-1306, Vol. 1, Pt. 1-2; BNWL-1307, Vol. 2, Pt. 1-3 \\
\hline 1970 & BNWL-1550, Vol. 1, Pt. 1-2; BNWL-1551, Vol. 2, Pt. 1-2 \\
\hline 1971 & BNWL-1650, Vol. 1, Pt. 1-2; BNWL-1651, Vol. 2, Pt. 1-2 \\
\hline 1972 & BNWL-1750, Vol. 1, Pt. 1-2; BNWL-1751, Vol. 2, Pt. 1-2 \\
\hline 1973 & BNWL-1850, Pt. $1-4$ \\
\hline 1974 & BNWL-1950, Pt. 1-4 \\
\hline 1975 & BNWL-2000, Pt. 1-4 \\
\hline 1976 & BNWL-2100, Pt. 1-5 \\
\hline 1977 & PNL-2500, Pt. $1-5$ \\
\hline 1978 & PNL-2850, Pt. 1-5 \\
\hline 1979 & PNL-3300, Pt. 1-5 \\
\hline 1980 & PNL-3700, Pt. $1-5$ \\
\hline 1981 & PNL-4100, Pt. 1-5 \\
\hline 1982 & PNL-4600, Pt. 1-5 \\
\hline 1983 & PNL-5000, Pt. $1-5$ \\
\hline 1984 & PNL-5500, Pt. $1-5$ \\
\hline 1985 & PNL-5750, Pt. 1-5 \\
\hline 1986 & PNL-6100, Pt. 1-5 \\
\hline 1987 & PNL-6500, Pt. 1-5 \\
\hline 1988 & PNL-6800, Pt. 1-5 \\
\hline 1989 & PNL-7200, Pt. 1-5 \\
\hline 1990 & PNL-7600, Pt. 1-5 \\
\hline 1991 & PNL-8000, Pt. $1-5$ \\
\hline 1992 & PNL-8500, Pt. $1-4$ \\
\hline 1993 & PNL-9000, Pt. 1-4 \\
\hline 1994 & PNL-10500, Pt. 1-2 \\
\hline
\end{tabular}




\section{Foreword}

This report summarizes FY 1994 progress in biological and general life sciences research programs conducted for the Department of Energy's Office of Health and Environmental Research (OHER) at Pacific Northwest Laboratory (PNL). This research provides knowledge of fundamental principles necessary to identify, understand, and anticipate the long-term health consequences of exposure to energy-related radiation and chemicals. Our emphasis is to understand the mechanisms involved in radiation- and chemically induced damage. Through this understanding, the health risks associated with exposure to effluents from energy-related technologies can be better defined, and the uncertainty associated with those risks decreased.

The sequence of this report of PNL research reflects the OHER programmatic structure. The Biological Research section contains reports of research including studies of the impact of radiation, radionuclides, and chemicals on biological responses at all levels of biological organization. The General Life Sciences Research section reports research conducted for the OHER human genome program.

\section{Biological Research}

The progress in several life-span studies in rats and dogs on the effects of inhaled radioactive materials including radon, ${ }^{238} \mathrm{PuO}_{2},{ }^{239} \mathrm{PuO}_{2}$, and ${ }^{239} \mathrm{Pu}\left(\mathrm{NO}_{3}\right)_{4}$ is reviewed. Recent progress describes exposure/dose-effect relationships for radon-induced lung tumors and plutonium-induced tumors of the beagle liver and skeleton.

Because many of the life-span studies using experimental animals are in the late phase of completion, it is essential to ensure that we do not lose valuable data or experimental materials generated by these studies. To this end, we have been conducting a comprehensive effort to gather, organize, and catalog data, documents, and tissues related to life-span radiobiology studies for future research and analyses. A related new project reports on progress made toward developing standardized analyses of data from all DOE life-span animal studies.

The animal studies on cancer induction from radon continue to be the core of an extensive research program that characterizes each step in the exposure-dose-response pathway of radon. We are combining in vivo and in vitro methods with up-to-date exposure systems and modern cytogenetic and molecular techniques to understand the mechanisms of radon carcinogenesis, and to reduce the uncertainty in extrapolating molecular/cellular/animal data to risk assessment in mine and home environments.

The relationship between site and type of initial DNA damage and the development of molecular changes, mutations, chromosome damage, and cell transformation contributes to an understanding of the disease process. Chemical- and radiation-effects studies are being conducted using molecular techniques to understand the sites of radiation-induced damage, the types of products produced, and the binding of carcinogenic chemicals to the DNA. The influence that primary, secondary, and tertiary DNA structure has on the induction and location of DNA damage and binding is being determined. 


\section{Laboratory-Wide Effort}

Biomedical research at PNL is an interdisciplinary effort requiring scientific contributions from many research departments throughout the laboratory. Personnel in the Life Sciences Center are the principal contributors to this report.

Additional information on PNL research efforts can be obtained by requesting reprints from the list of publications found at the back of this report. 


\section{Contents}

Preface $\ldots \ldots \ldots \ldots \ldots \ldots \ldots \ldots \ldots \ldots \ldots \ldots \ldots \ldots$ iii

Foreword $\ldots \ldots \ldots \ldots \ldots \ldots \ldots \ldots \ldots \ldots \ldots \ldots \ldots \ldots$

\section{Biological Research}

Inhaled Plutonium in Dogs, J.F. Park . . . . . . . . . . . . . . 1

National Radiobiology Archives, C.R. Watson . . . . . . . . . . . . . . 11

Statistical Analysis of Data from Radiobiologic Animal Studies, E.S. Gilbert . . . . . 19

Genotoxicity of Inhaled Energy Effiuents, A.L. Brooks . . . . . . . . . . . . 23

Molecular Events During Tumor Initiation, D.L. Springer . . . . . . . . . . . . . 29

Biochemistry of Free Radical-Induced DNA Damage, A.F. Fuciarelli . . . . . . . . 35

Radon Hazards in Homes, F.T. Cross . . . . . . . . . . . . . . . 41

Genetics of Radon-Induced Lung Cancer, J.D. Saffer . . . . . . . . . . . . . 47

Mechanisms of Radon Injury, R.F. Jostes . . . . . . . . . . . . . . . 53

In VivolIn Vitro Radon-Induced Cellular Damage, A.L. Brooks . . . . . . . . . . . 57

\section{Publications and Presentations}

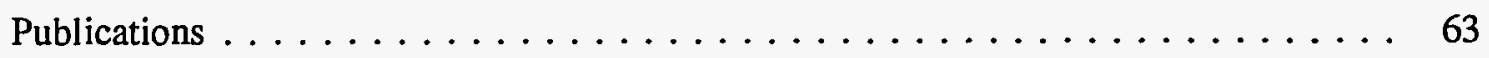

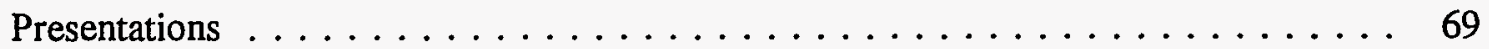

Author Index ........................... 79

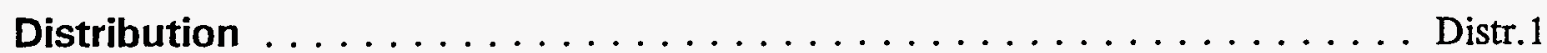


Biological Research

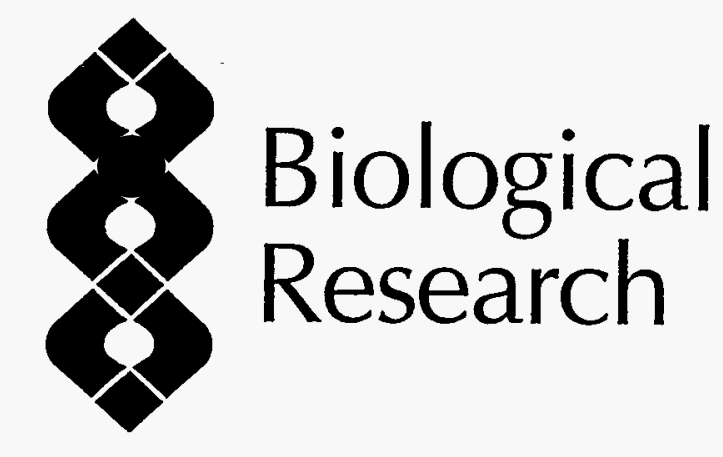




\title{
Inhaled Plutonium in Dogs
}

Principal Investigator: J.F. Park

\author{
Other Investigators: R.L. Buschbom, G.E. Dagle, E.S. Gilbert, C.R. Watson, \\ and R.E. Weller
}

These projects (Inhaled Plutonium Oxide in Dogs, Inhaled Plutonium Nitrate in Dogs) are life-span dose-effects studies of inhaled ${ }^{239} \mathrm{PuO}_{2},{ }^{238} \mathrm{PuO}_{2}$, and ${ }^{239} \mathrm{Pu}\left(\mathrm{NO}_{3}\right)_{4}$ in beagles. This report describes work performed in FY 1994 to study preliminary life-span dose-effect relationships in the skeleton and liver of beagles given single exposures of ${ }^{239} \mathrm{Pu}\left(\mathrm{NO}_{3}\right)_{4}$ aerosols to obtain dose level groups of 20 dogs with initial lung depositions of $63,11,2.2,0.32$, or $0.12 \mathrm{kBq}$. Following life-span observation, the skeleton contained $48 \%$ of the final body deposition of plutonium, and the liver $40 \%$. Significant lifespan shortening was observed in the 3 highest exposure levels, with bone tumors occurring at a group exposure level of $63 \mathrm{~Bq}$ lung deposition, and bone and liver tumors occurring at group average exposure levels of 11 and $2.2 \mathrm{kBq}$ lung deposition. The 37 bone tumors (in 28 dogs) were primarily in the axial skeleton (62\% compared with $38 \%$ for appendicular skeleton). Elevated serum liver enzyme levels were observed in groups with mean liver plutonium concentrations of $1.3 \mathrm{~Bq} \mathrm{~g}^{-1}$ and mean average liver doses of $31 \mathrm{cGy}$ or greater. Adenomatous hyperplasia and bile-duct hyperplasia were also observed. A total of 19 primary liver tumors occurred in 14 plutonium-exposed dogs at lower exposure levels, where life span was not shortened by the occurrence of bone (or lung) tumors.

The life-span biological effects of inhaled plutonium were studied in beagles to help predict risks of effects from accidental exposure in people (Table 1). All the dogs are dead and radioanalysis of tissues completed. Review of dosimetry and dose-effects observations, including histopathology, occurred this year in conjunction with the preparation of manuscripts. The Pacific Northwest Laboratory Annual Report for 1989 to the DOE Office of Energy Research, Part 1, summarized the results of the ${ }^{239} \mathrm{PuO}_{2}$ study, and the results of the ${ }^{238} \mathrm{PuO}_{2}$ study were summarized in the Annual Report for 1990.

These life-span beagle studies are part of a multilaboratory program to evaluate several radionuclides and routes of exposure. In our studies the plutonium was administered by inhalation, and lung tumors were a frequent biological effect. Bone, liver, and lymph node lesions were observed following plutonium translocation to those organs. Preliminary results on the effects of inhaled ${ }^{239} \mathrm{Pu}\left(\mathrm{NO}_{3}\right)_{4}$ on the skeleton and liver are presented in this report.
Life-span shortening was observed in dogs exposed to inhaled ${ }^{239} \mathrm{Pu}\left(\mathrm{NO}_{3}\right)_{4}$ at the 3 highest exposure levels (Figure 1). Dogs at the highest exposure level died early from radiation pneumonitis and are not discussed further in this report. At necropsy of the remaining dogs, the skeleton contained $48 \%$ of the final body deposition of plutonium, and the liver $40 \%$; the liver-toskeleton ratios were similar at each exposure level and time post exposure, and without regard to final body depositions and sex of dog.

Plutonium is translocated to the skeleton (Figure 2) fitting an uptake curve of

$$
\begin{aligned}
S(t)= & 0.350 \mathrm{e}^{-0.000014 t}-0.142 \mathrm{e}^{-0.0022 t} \\
& -0.208 \mathrm{e}^{-0.24 t}
\end{aligned}
$$

where $S(t)$ is the proportion of the initial lung deposition (ILD) in the skeleton at time $t$ (days post exposure). The equation used for calculating dose to the skeleton at time $t$ was 
Table 1. Exposure/Dose Protocols in Life-Span Studies with Inhaled Plutonium in Dogs

\begin{tabular}{|c|c|c|c|c|c|c|c|c|}
\hline \multirow{2}{*}{$\begin{array}{c}\text { Exposure-Level } \\
\text { Group }\end{array}$} & \multicolumn{2}{|c|}{ Number of Dogs } & \multicolumn{6}{|c|}{ Initial Lung Deposition ${ }^{(0)}$} \\
\hline & Male & Female & \multicolumn{3}{|c|}{$\mathrm{kBq}^{(\mathrm{b})}$ (total) } & \multicolumn{3}{|c|}{$\mathrm{Bq} / \mathrm{g}$ Lung $^{(\mathrm{b})}$ (concentration) } \\
\hline \multicolumn{9}{|c|}{${ }^{239} \mathrm{PuO}_{2}$ (Exposed 1970 and 1971) } \\
\hline Control & 10 & 10 & & 0 & & & 0 & \\
\hline 1 & 10 & 11 & 0.12 & \pm & 0.05 & 0.93 & \pm & 0.39 \\
\hline 2 & 11 & 11 & 0.69 & \pm & 0.14 & 6.2 & \pm & 1.3 \\
\hline 3 & 11 & 10 & 2.7 & \pm & 0.05 & 23 & \pm & 4 \\
\hline 4 & 12 & 12 & 11 & \pm & 2 & 95 & \pm & 17 \\
\hline 5 & 10 & 10 & 41 & \pm & 6 & 349 & \pm & 46 \\
\hline 6 & $\frac{3}{67}$ & $\frac{5}{69}$ & 213 & \pm & 120 & 2130 & \pm & 1160 \\
\hline \multicolumn{9}{|c|}{ Inhaled ${ }^{238} \mathrm{PuO}_{2}$ (Exposed 1973 and 1974) } \\
\hline Control & 10 & 10 & & 0 & & & 0 & \\
\hline 1 & 10 & 10 & 0.082 & \pm & 0.031 & 0.65 & \pm & 0.24 \\
\hline 2 & 11 & 10 & 0.67 & \pm & 0.12 & 5.9 & \pm & 1.2 \\
\hline 3 & 12 & 10 & 2.9 & \pm & 0.4 & 24 & \pm & 3 \\
\hline 4 & 10 & 10 & 13 & \pm & 3 & 107 & \pm & 22 \\
\hline 5 & 10 & 10 & 52 & \pm & 10 & 408 & \pm & 72 \\
\hline 6 & $\frac{7}{70}$ & $\frac{6}{66}$ & 203 & \pm & 54 & 1737 & \pm & 440 \\
\hline \multicolumn{9}{|c|}{ Inhaled ${ }^{239} \mathrm{Pu}\left(\mathrm{NO}_{3}\right)_{4}$ (Exposed 1976 and 1977) } \\
\hline Control & 10 & 10 & & 0 & & & 0 & \\
\hline Vehicle & 10 & 10 & & 0 & & & 0 & \\
\hline 1 & 10 & 10 & 0.12 & \pm & 0.04 & 0.97 & \pm & 0.38 \\
\hline 2 & 10 & 10 & 0.32 & \pm & 0.06 & 2.6 & \pm & 0.5 \\
\hline 3 & 10 & 10 & 2.2 & \pm & 0.3 & 19 & \pm & 4 \\
\hline 4 & 10 & 10 & 11 & \pm & 1 & 91 & \pm & 15 \\
\hline 5 & 10 & 10 & 63 & \pm & 11 & 520 & \pm & 107 \\
\hline 6 & $\frac{3}{73}$ & $\frac{2}{72}$ & 202 & \pm & 84 & 1772 & \pm & 747 \\
\hline
\end{tabular}

(a) Estimated from external thorax counts at 2 and 4 weeks after exposure, and from estimated lung weights (0.011 $x$ body weight).

(b) Mean $\pm 95 \%$ confidence intervals around mean.

$$
d_{t}=(K A E / m) \int_{0}^{t} S(t) d t
$$

where $d_{t}$ is the cumulative dose at time $t(G y)$;

$\mathrm{K}$ is $1.38 \times 10^{-5}$, conversion factor for converting $\mathrm{Bq}$ to $\mathrm{Gy}$; $\mathrm{E}$ is $5.15 \mathrm{MeV}$, energy of ${ }^{239} \mathrm{Pu}$ alphaparticle emission; $\mathrm{A}$ is ILD (Bq); $\mathrm{m}$ is skeleton weight $(\mathrm{g})=(0.1)$ [body weight at exposure $(\mathrm{g})]$; $\mathrm{t}$ is time after exposure (d); and $\mathrm{S}(\mathrm{t})$ is skeleton retention function.
The microdistribution of plutonium in bone, using neutron-induced fission tracks, from 1 dog in this study was compared with 1 dog intravenously injected (at the University of Utah) with plutonium citrate at a similar dose. The plutonium concentration on the trabecular and periosteal surfaces was a factor of about 2 higher for the injection route compared to the inhalation route.

Bone tumors were the main cause of death or euthanasia in the 2 highest exposure levels discussed in this report [63 or $11 \mathrm{kBq}$ ILD 


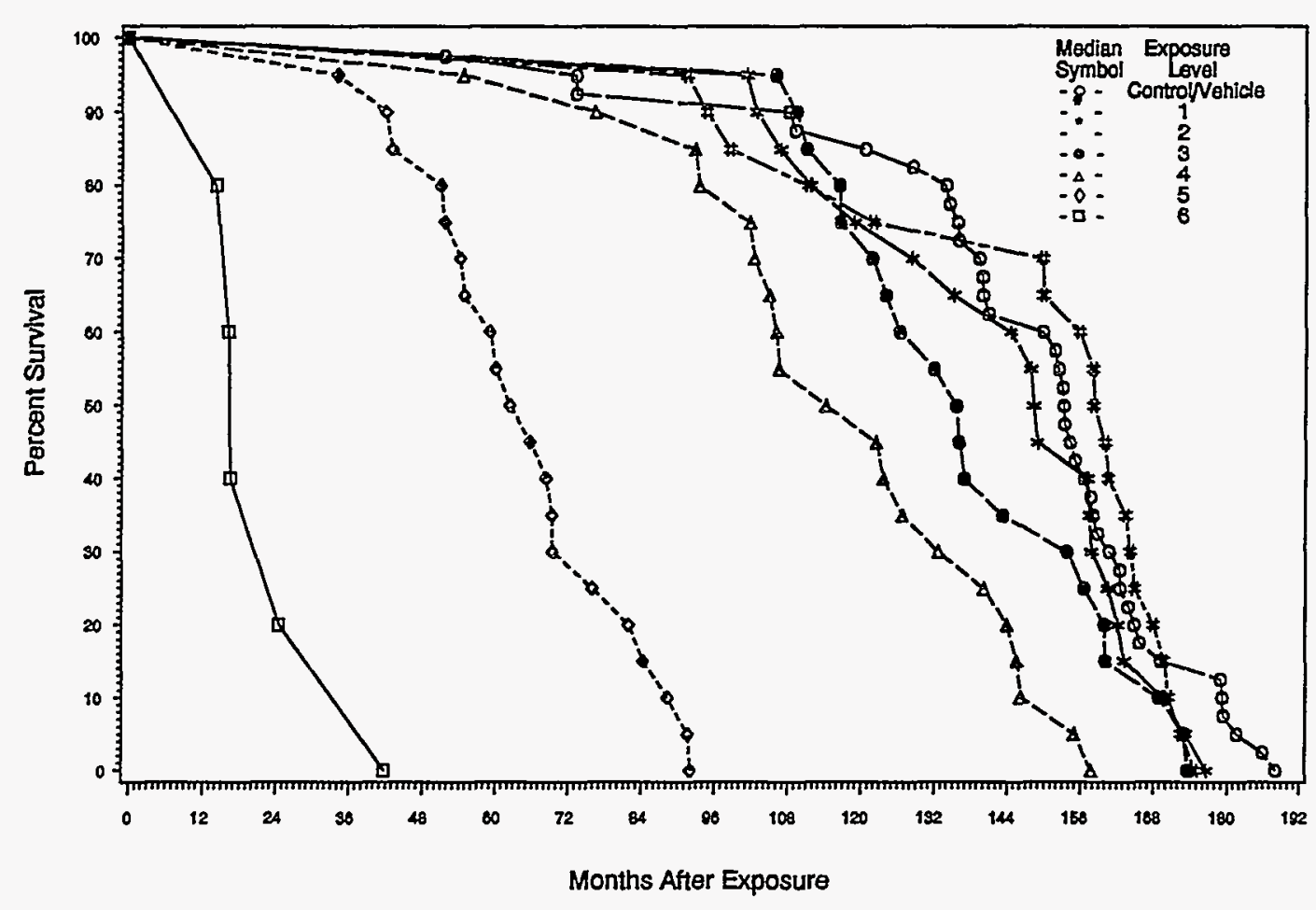

Figure 1. Life-Span Shortening of Dogs Exposed to ${ }^{239} \mathrm{Pu}\left(\mathrm{NO}_{3}\right)_{4}$

(Table 2)]. The tumors were osteogenic sarcomas arising from endosteal surfaces, except for 2 hemangiosarcomas in vertebra of 2 dogs from group 2, and an anaplastic osteosarcoma in the radius of $1 \mathrm{dog}$ from group 3 . Metastases occurred to the lungs of $10 \mathrm{dogs}$, kidneys of 4 dogs, regional lymph nodes of 2 dogs, and occasionally other systemic sites. Peritrabecular fibrosis was observed as a deterministic finding in all groups that produced bone tumors. The tumors arose primarily in the axial skeleton, with a similar distribution of bone tumors as occurred following inhalation of ${ }^{238} \mathrm{PuO}_{2}$ (Table 3). It should be noted that the tumors per estimated number of lining cells was similar for the axial and appendicular skeletons.

Bone-tumor risk was calculated for the purposes of comparing our data with that reported from dogs intravenously injected with plutonium citrate at the University of Utah (Mays et al. 1987). Using only incidence data unadjusted for competing causes of death, our bone-tumor incidence fit the following quadratic curve:

$$
\mathrm{BTI}=(99.3 \pm 4.9) \mathrm{D}-(29.4 \pm 3.3) \mathrm{D}^{2}
$$

where BTI is the bone-tumor incidence and D is the skeletal dose (cGy) 1 year prior to death. Our bone-tumor incidence was similar to that reported at the University of Utah (Figure 3), but it should be noted that we were not addressing the question of threshold or the shape of the dose-response curve at very low exposure levels.

Plutonium accumulations in the liver were described with a 3-compartment model as follows:

$$
\begin{aligned}
L(t) & =0.29 e^{-0.000035 t}-0.165 e^{-0.0029 t} \\
& -0.125 e^{-0.24 t}
\end{aligned}
$$

where $L(t)$ is the proportion of ILD in the liver at time $t$ (days post exposure). The retention curves were not statistically different between exposure levels, or between male or female dogs.

The mean liver doses (Table 2) calculated by integrating from the day of exposure to 1 year prior to death [to compare our findings with those from other beagle studies with intravenously injected plutonium (Taylor et al. 


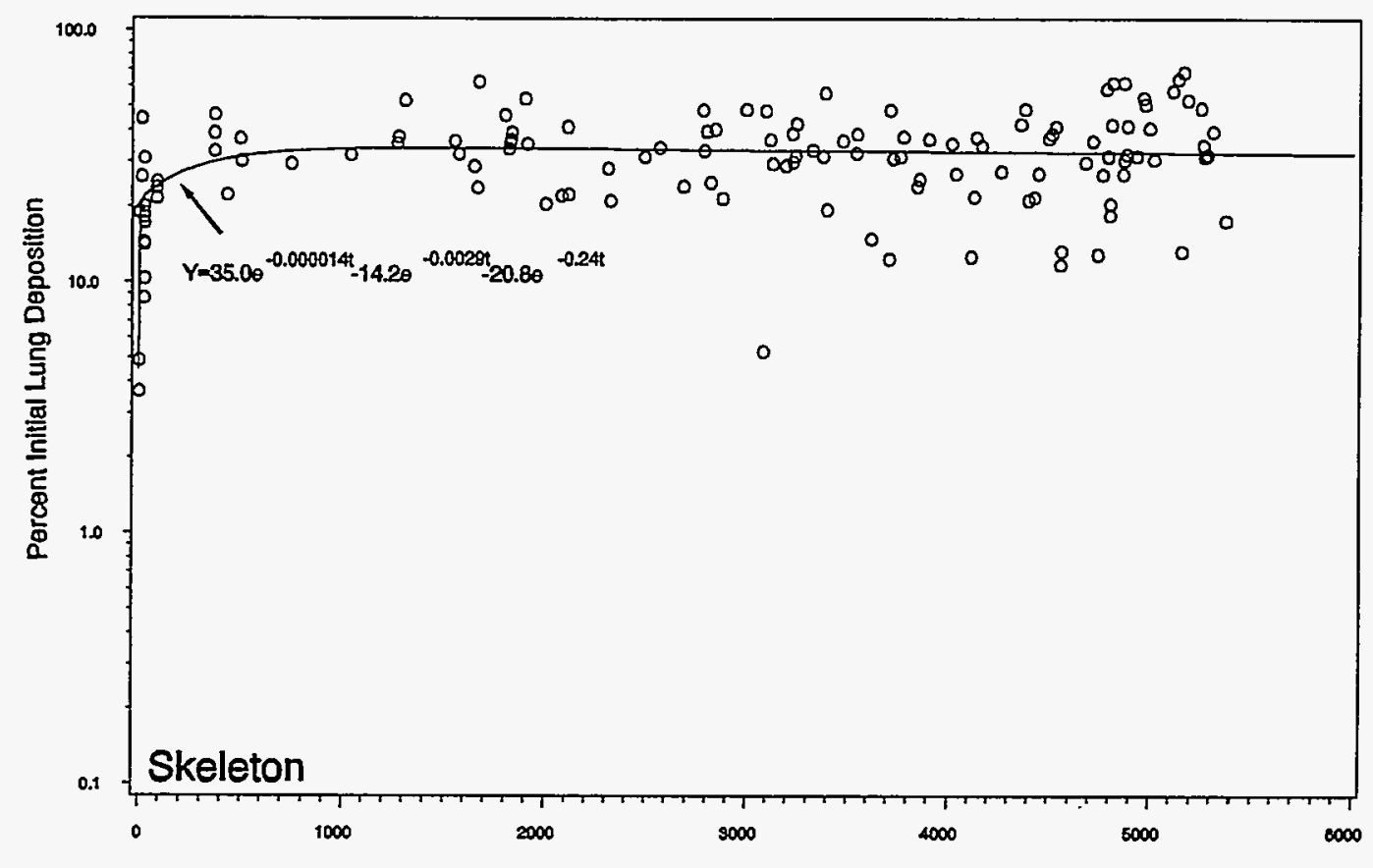

Days After Exposure

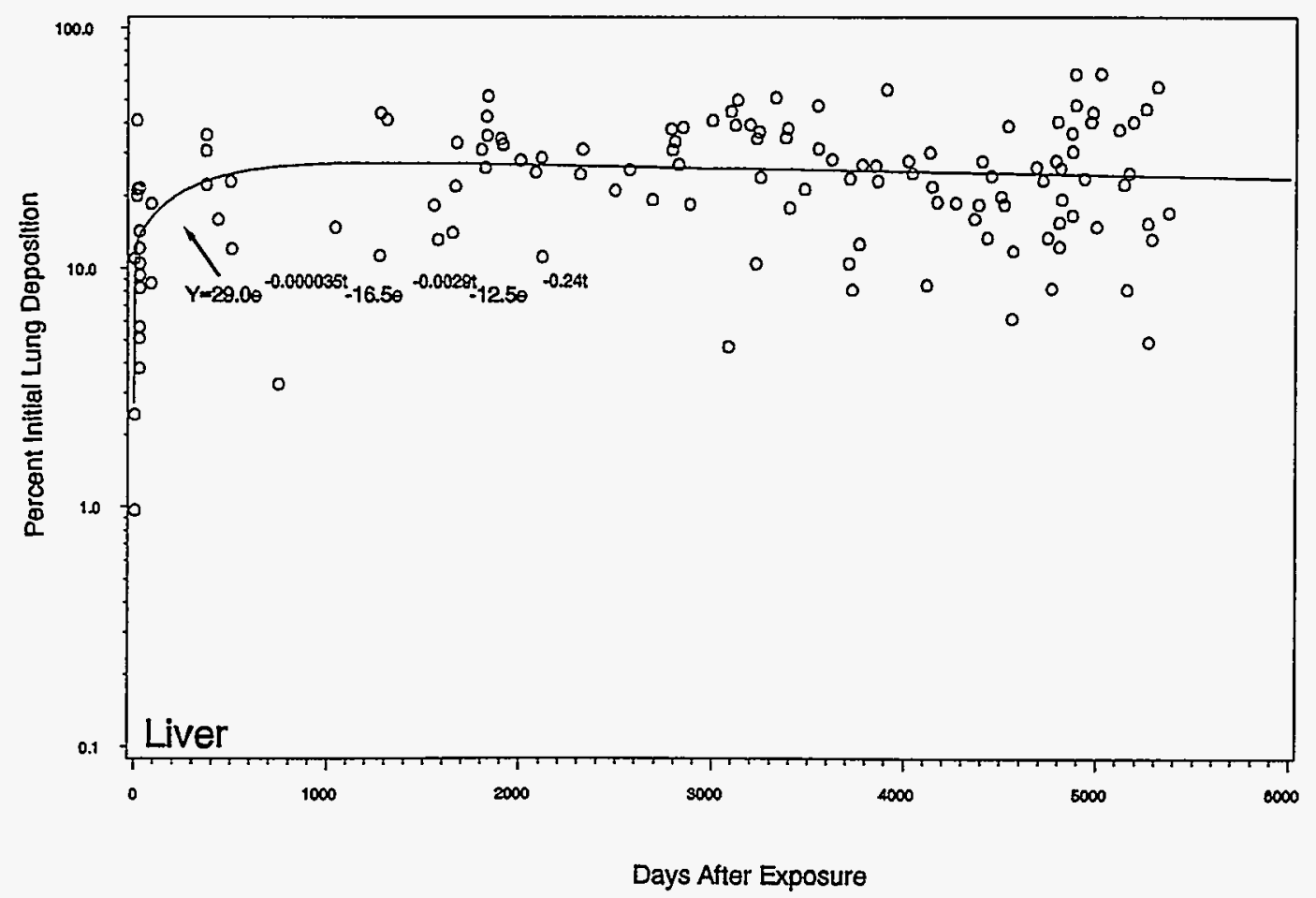

Figure 2. Plutonium Distribution in Dogs Exposed to ${ }^{239} \mathrm{Pu}_{\left(\mathrm{NO}_{3}\right)_{4}}$ 


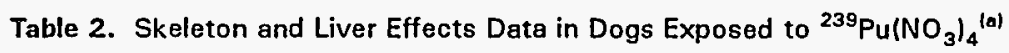

\begin{tabular}{|c|c|c|c|c|c|c|c|}
\hline Exposure Group & 5 & 4 & 3 & 2 & 1 & Vehicle & Control \\
\hline $\begin{array}{r}\text { Study Summary } \\
\text { Number of dogs } \\
\text { Initial lung deposition }(\mathrm{kBq}) \\
\text { Initial lung concentration }(\mathrm{Bq} / \mathrm{g}) \\
\text { Median survival }(\mathrm{mo})\end{array}$ & $\begin{array}{c}20 \\
63 \pm 5 \\
520 \pm 51 \\
62\end{array}$ & $\begin{array}{c}20 \\
11 \pm 1 \\
91 \pm 7 \\
114\end{array}$ & $\begin{array}{c}20 \\
2.2 \pm 0.14 \\
19 \pm 2 \\
135\end{array}$ & $\begin{array}{c}20 \\
0.32 \pm 0.03 \\
2.6 \pm 0.3 \\
157\end{array}$ & $\begin{array}{c}20 \\
0.12 \pm 0.02 \\
0.98 \pm 0.18 \\
150\end{array}$ & $\begin{array}{c}20 \\
-- \\
-- \\
154\end{array}$ & $\begin{array}{c}20 \\
-- \\
139\end{array}$ \\
\hline $\begin{array}{r}\text { Deposition }(\mathrm{kBq}) \\
\text { Concentration }(\mathrm{Bq} / \mathrm{g}) \\
\text { Dose }^{(\mathrm{b})}(\mathrm{cGy}) \\
\text { Tumor incidence }\end{array}$ & $\begin{array}{c}23.4 \pm 3 \\
15.8 \pm 2.1 \\
190 \pm 15 \\
85 \\
\end{array}$ & $\begin{array}{c}3.4 \pm 0.3 \\
2.1 \pm 0.2 \\
71 \pm 5 \\
50 \\
\end{array}$ & $\begin{array}{c}0.72 \pm 0.05 \\
0.49 \pm 0.06 \\
20 \pm 3 \\
5 \\
\end{array}$ & $\begin{array}{c}0.10 \pm 0.01 \\
0.07 \pm 0.01 \\
2.7 \pm 0.3 \\
0 \\
\end{array}$ & $\begin{array}{c}0.05 \pm 0.01 \\
0.03 \pm 0.01 \\
1.1 \pm 0.2 \\
0 \\
\end{array}$ & $\begin{array}{l}-- \\
-- \\
-- \\
0\end{array}$ & $\begin{array}{l}-- \\
-- \\
-- \\
0\end{array}$ \\
\hline $\begin{array}{r}\text { Deposition }(\mathrm{kBq}) \\
\text { Concentration }(\mathrm{Bq} / \mathrm{g}) \\
\operatorname{Dose}^{(b)}(\mathrm{oG} y)\end{array}$ & $\begin{array}{c}16.1 \pm 2 \\
61.0 \pm 8.5 \\
296 \pm 24 \\
\end{array}$ & $\begin{array}{l}2.9 \pm 0.3 \\
6.9 \pm 0.9 \\
111 \pm 7\end{array}$ & $\begin{array}{c}0.49 \pm 0.04 \\
1.3 \pm 0.12 \\
31 \pm 4\end{array}$ & $\begin{array}{c}0.08 \pm 0.01 \\
0.24 \pm 0.04 \\
4.2 \pm 0.5\end{array}$ & $\begin{array}{c}0.04 \pm 0.01 \\
0.12 \pm 0.04 \\
1.7 \pm 0.3\end{array}$ & $\begin{array}{l}-- \\
-- \\
-\end{array}$ & $\begin{array}{l}-- \\
-- \\
-\end{array}$ \\
\hline $\begin{array}{r}\text { Adenomatous Hyperplasia } \\
\text { Incidence } \\
\text { Average severity(c) }\end{array}$ & $\begin{array}{l}17 \\
2.0 \\
\end{array}$ & $\begin{array}{c}18 \\
2.8^{(d)} \\
\end{array}$ & $\begin{array}{c}19 \\
2.7^{|d|} \\
\end{array}$ & $\begin{array}{c}19 \\
2.7^{(d)} \\
\end{array}$ & $\begin{array}{l}16 \\
2.0\end{array}$ & $\begin{array}{l}14 \\
1.8\end{array}$ & $\begin{array}{l}15 \\
1.7\end{array}$ \\
\hline $\begin{array}{r}\text { Bile-Duct Hyperplasia } \\
\qquad \begin{array}{r}\text { Incidence } \\
\text { Average severity }\end{array}\end{array}$ & $\begin{array}{c}1 \\
0.1 \\
\end{array}$ & $\begin{array}{c}8 \\
0.7\end{array}$ & $\begin{array}{l}12 \\
0.9\end{array}$ & $\begin{array}{r}10 \\
0.8\end{array}$ & $\begin{array}{l}15 \\
1.4^{(d)}\end{array}$ & $\begin{array}{c}6 \\
0.4\end{array}$ & $\begin{array}{l}10 \\
0.6\end{array}$ \\
\hline $\begin{array}{r}\text { Liver Tumors } \\
\text { Dogs with liver tumor } \\
\text { Cholangioadenoma } \\
\text { Cholangiocarcinoma } \\
\text { Hepatocellular carcinoma } \\
\text { Leiomyosarcoma }\end{array}$ & $\begin{array}{l}0 \\
0 \\
0 \\
0 \\
0\end{array}$ & $\begin{array}{l}5 \\
4 \\
4 \\
1 \\
1\end{array}$ & $\begin{array}{l}3 \\
2 \\
1 \\
0 \\
0\end{array}$ & $\begin{array}{l}3 \\
0 \\
1 \\
2 \\
0\end{array}$ & $\begin{array}{l}3 \\
0 \\
2 \\
1 \\
0\end{array}$ & $\begin{array}{l}0 \\
0 \\
0 \\
0 \\
0\end{array}$ & $\begin{array}{l}1 \\
0 \\
0 \\
1 \\
0\end{array}$ \\
\hline $\begin{array}{l}\text { Average age at death of dogs with } \\
\text { liver tumors }(\mathrm{mo})\end{array}$ & -. & 136 & 146 & 151 & 171 & - & 162 \\
\hline Percent dogs with liver tumors & 0 & $25^{(0)}$ & 15 & 15 & 15 & 0 & 5 \\
\hline
\end{tabular}

(a) Values shown are mean \pm standard error.

(b) Dose accumulated to 1 year prior to death.

(c) If condition was observed, severity was graded from 1 to 5 , average based on $n=$ incidence

(d) Dose-group mean significantly higher than the control group mean $(P<0.05)$

(e) Dose-group tumor incidence significantly higher than the tumor incidence for vehicle and control combined $(P<0.05)$ 
Table 3. Bone Tumors in Dogs Inhaling Plutonium: Distribution in Different Bones

\begin{tabular}{|c|c|c|c|c|c|c|c|c|c|}
\hline & \multicolumn{2}{|c|}{${ }^{239} \mathrm{Pu}$ Nitrate } & \multicolumn{2}{|c|}{${ }^{238} \mathrm{Pu}$ Oxide } & \multicolumn{2}{|c|}{ Total } & \multirow{2}{*}{$\% \underset{(a)}{\text { Weight }}$} & \multirow{2}{*}{$\begin{array}{c}\text { Lining } \\
\text { Cells } \\
\times 10^{7(b)}\end{array}$} & \multirow{2}{*}{$\begin{array}{r}\text { Tumors } \\
\text { per } 10^{7} \\
\text { Lining Cells }\end{array}$} \\
\hline & No. Tumors & $\%$ Tumors & No. Tumors & $\%$ Tumors & No. Tumors & $\%$ Tumors & & & \\
\hline \multicolumn{10}{|l|}{ Axial Skeleton } \\
\hline Skull and maxilla & 2 & 5 & 1 & 3 & 3 & 4 & 13.4 & 55.1 & 0.05 \\
\hline Mandible & 1 & 3 & 0 & 0 & 1 & 1 & 4.5 & 30.8 & 0.03 \\
\hline Cervical vertebrae & 4 & 11 & 2 & 5 & 6 & 8 & 5.6 & 34.9 & 0.17 \\
\hline Thoracic vertebrae & 4 & 11 & 5 & 13 & 9 & 12 & 6.7 & 48.1 & 0.19 \\
\hline Lumbar vertebrae (including sacrum) & 9 & 24 & 9 & 23 & 18 & 23 & 5.7 & 37.9 & 0.47 \\
\hline Coccygeal vertebrae & 0 & 0 & 0 & 0 & 0 & 0 & 2.8 & -- & -- \\
\hline Sternum & 0 & 0 & 1 & 3 & 1 & 1 & 1.3 & -- & -- \\
\hline Ribs (with cartilage) & 3 & 8 & 5 & 13 & 8 & 10 & 10.4 & 38.1 & 0.21 \\
\hline Total/Average & 23 & 62 & 23 & 58 & 46 & 60 & 50.4 & -. & 0.19 \\
\hline \multicolumn{10}{|l|}{ Appendicular Skeleton } \\
\hline Scapula & 1 & 3 & 5 & 13 & 6 & 8 & 4.3 & 20.3 & 0.30 \\
\hline Humeri & 6 & 16 & 1 & 3 & 7 & 9 & 7 & 43.1 & 0.16 \\
\hline Radii/ulna & 1 & 3 & 0 & 0 & 1 & 1 & 5.7 & 25 & 0.04 \\
\hline Forepaws & 0 & 0 & 0 & 0 & 0 & 0 & 4.4 & -- & -- \\
\hline Pelvis & 4 & 11 & 7 & 18 & 11 & 14 & 6.3 & 26.6 & 0.41 \\
\hline Femora & 2 & 5 & 2 & 5 & 4 & 5 & 7.3 & 45.3 & 0.09 \\
\hline Tibiae/fibulae & 0 & 0 & 2 & 5 & 2 & 3 & 6.9 & 33.4 & 0.06 \\
\hline Hindpaws & 0 & 0 & 0 & 0 & 0 & 0 & 7.7 & -- & -- \\
\hline Total/Average & 14 & 38 & 17 & 43 & 31 & 40 & 49.6 & -- & 0.18 \\
\hline Total & 37 & 100 & 40 & 100 & 77 & 100 & 100 & -. & -- \\
\hline
\end{tabular}

(a) Raabe and Parks 1993.

(b) Polig and Jee 1989. 


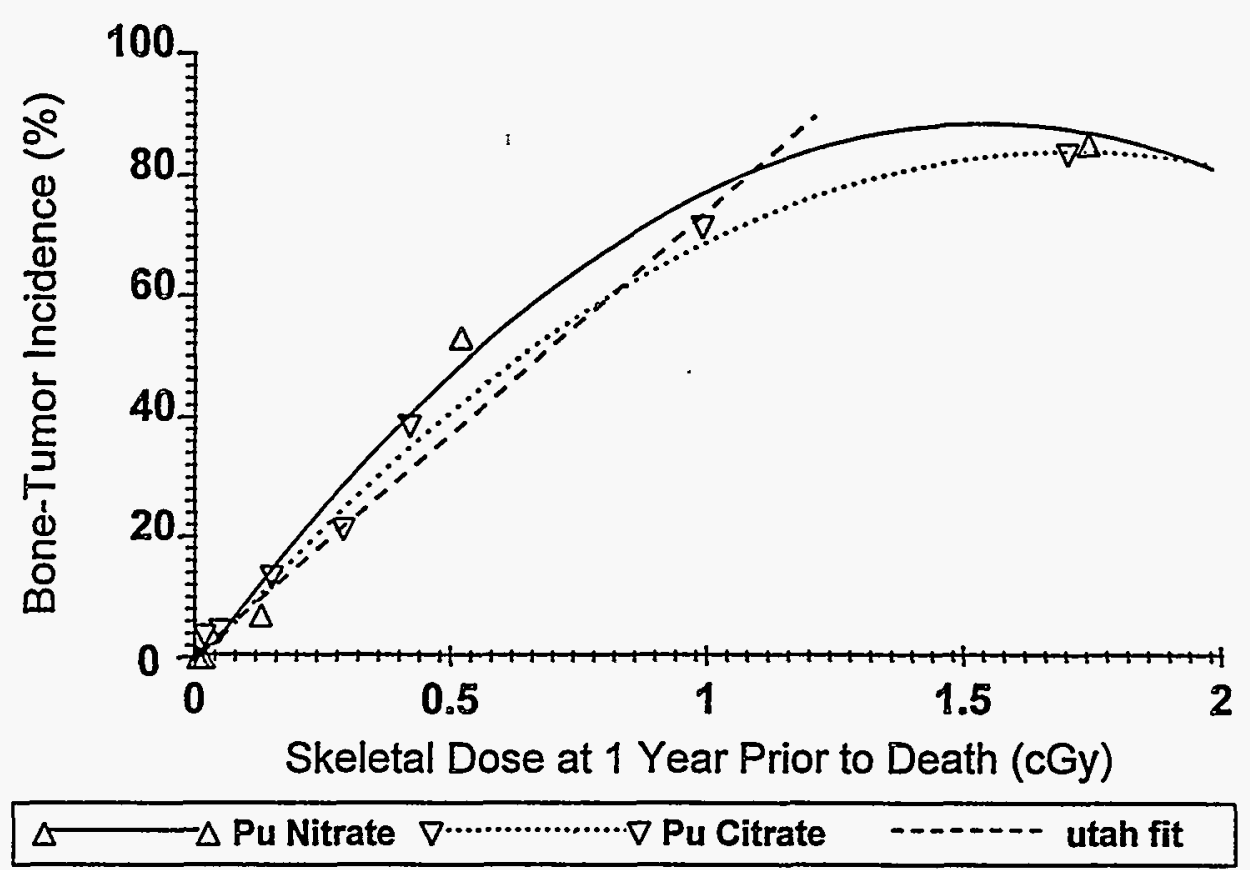

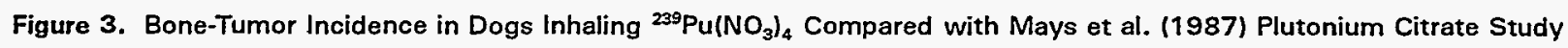

1991)], and multiplying by the appropriate factors to convert to dose in Gy. ILD used in the dose calculation was estimated from external thorax counts at 14 days after exposure; if the estimated ILD was less than the final body deposition, the final body deposition was used. A liver weight (with blood) of $5 \%$ of the dog weight at exposure was used for dose calculations.

Autoradiography of the liver from 3 dogs showed single alpha tracks deposited primarily over liver parenchymal cells and occasionally some aggregates in vacuolated sinusoidal cells. When the location of the tracks were plotted against the relative distance from the portal area to the central vein, there was a tendency for the alpha tracks to be present primarily in the midzonal areas. Calculations (made by counting alpha tracks) of radioactivity concentration in autoradiographs gave about a 2-fold higher activity in the parenchymal (and sinusoidal cells) than determined by radioanalysis of the whole organ, because radioanalysis of the whole organ included tissues without plutonium deposition. The occurrence of plutonium primarily in single tracks in the livers of dogs exposed to ${ }^{239} \mathrm{Pu}\left(\mathrm{NO}_{3}\right)_{4}$ contrasted with the large alpha stars (indicating particles) translocated in the ${ }^{239} \mathrm{PuO}_{2}$ exposed dogs and both single alpha tracks and alpha stars in the ${ }^{238} \mathrm{PuO}_{2}$-exposed dogs.

Liver damage was evaluated by observing serum levels of liver enzymes. Elevated serum chemistry values first occurred at 4.1 years post exposure in group 5 dogs when the group average accumulative liver dose was $2.8 \mathrm{~Gy}$. At this time, the dose rate was 60 to $70 \mathrm{cGy}$ per year. There were biphasic elevations of serum alkaline phosphatase (ALP) and serum glutamic pyruvic transaminase (GPT) in individual dogs. An early increase was followed by a return to control values, and a later effect was characterized by persistent, increased elevations of both ALP and GPT. Values for GPT and ALP in groups 3 and 4 also became significantly higher $(P \leq 0.05)$ than those for the control group (Figure 4).

Degenerative liver lesions became more common as the dogs aged. The group average mean grade of adenomatous hyperplasia of liver parenchymal cells was significantly higher 
$(\mathrm{P} \leq 0.05)$ in groups 2,3 , and 4 dogs relative to control dogs (Table 2). The adenomatous (nodular) hyperplasia consisted of lobules with parenchymal cells of increased size, increased vacuolation, and decreased lipofuscin content relative to surrounding liver lobules. There was a trend towards increased bile-duct hyperplasia consisting of aggregates of bile ducts in periportal areas and, occasionally, bile ducts extending into liver lobules. This finding generally was not significantly different in the plutonium-exposed dogs compared to the control dogs. There were additional changes not clearly related to plutonium exposures, such as the aggregation of vacuolated sinusoidal cells that increased in incidence and group average severity as the dogs became older.

Liver tumors occurred in groups of dogs living longer than the minimal latency period. A total of 10 intrahepatic bile-duct tumors occurred in 5 dogs from group 4: 4 cholangiocarcinomas (1 was fatal), 4 cholangioadenomas, 1 hepatoma, and 1 leiomyosarcoma. Intrahepatic bile-duct tumors were also present in 3 dogs from group 3,1 dog from group 2, and 2 dogs from group 1 ; these consisted of 4 cholangiocarcinomas and 2 cholangioadenomas. In addition, fatal hepatocellular carcinomas occurred in 2 dogs from group 2 and nonfatal hepatocellular carcinomas were present in 1 dog each from group 1 and the control group. The first liver tumor occurred in a group-4 dog 123 months following exposure, and the mean average time from exposure to death for the dogs with liver tumors was lowest in the group- 4 dogs. Metastases occurred only with the cholangiocarcinomas; they were widespread in 1 dog from group 4 and found in the hepatic lymph nodes or spleen of 1 dog each from groups 3 and 4 . Of the 14 plutoniumexposed dogs with liver tumors, 9 were males and 5 were females; the control dog was a female. When comparing the groups of dogs exposed to plutonium with the 2 control groups, the tumor incidence was significantly $(P \leq 0.05)$ higher in dogs from group 4 than the tumor incidence for vehicle and control dogs combined.

The liver-cancer risk was difficult to assess due to the low number of tumors and the competing risks of life shortening from lung and bone tumors. We estimated approximately
900 liver tumors per $10^{4}$ dogs per Gy accumulative dose determined from radioanalysis of tissues, assuming a linear dose response in the lower exposure levels. At these lower exposure levels (1 through 4) the liver-tumor doseresponse curve that best fit the data was

$$
y=(14.01 \pm 1.04)+(0.094 \pm 0.018) x
$$

where $\mathrm{y}=$ liver-tumor incidence $(\%)$ and $\mathrm{x}=$ liver dose at 1 year prior to death (cGy). We assumed a linear dose response for these calculations in order to compare our data with the liver tumor risks estimated from dogs intravenously injected with plutonium citrate, where a liver risk estimate of approximately 2000 total liver malignancies per $10^{4}$ dogs per Gy was reported (Taylor et al. 1991).

Caution is in order when inferring the risk of exposure to 1 radionuclide to that of another. While human data are available from Thorotrast patients, it would be inappropriate to derive a plutonium exposure risk from these data, because there are differences in tissue dose distribution for the 2 radionuclides.

\section{References}

Dagle, G.E., E.P. Moen, R.R. Adee, T.E. Hui, A.C. James, R.E. Filipy, and R.L. Kathren. 1992. Microdistribution and microdosimetry of thorium deposited in the liver. Health Phys. 63:41-45.

Mays, C.W., R.D. Lloyd, G.N. Taylor, and M.E. Wrenn. 1987. Cancer incidence and lifespan vs. $\alpha$-particle dose in beagles. Health Phys. 52:617-124.

Polig, E., and W.S.S. Jee. 1989. Bone structural parameters, dosimetry, and relative radiation risk in the beagle skeleton. Radiat. Res. 120(1):83-101.

Raabe, O.G., and N.J. Parks. 1993. Skeletal uptake and lifetime retention of ${ }^{90} \mathrm{Sr}$ and ${ }^{226} \mathrm{Ra}$ in beagles. Radiat. Res. 133(2):204-218.

Taylor, G.N., R.D. Lloyd, C.W. Mays, W. Angus, S.C. Miller, L. Shagestari, and L.F. Hahn. 1991. Plutonium- and americiuminduced liver tumors and lesions in beagles. Health Phys. 61:337-347. 

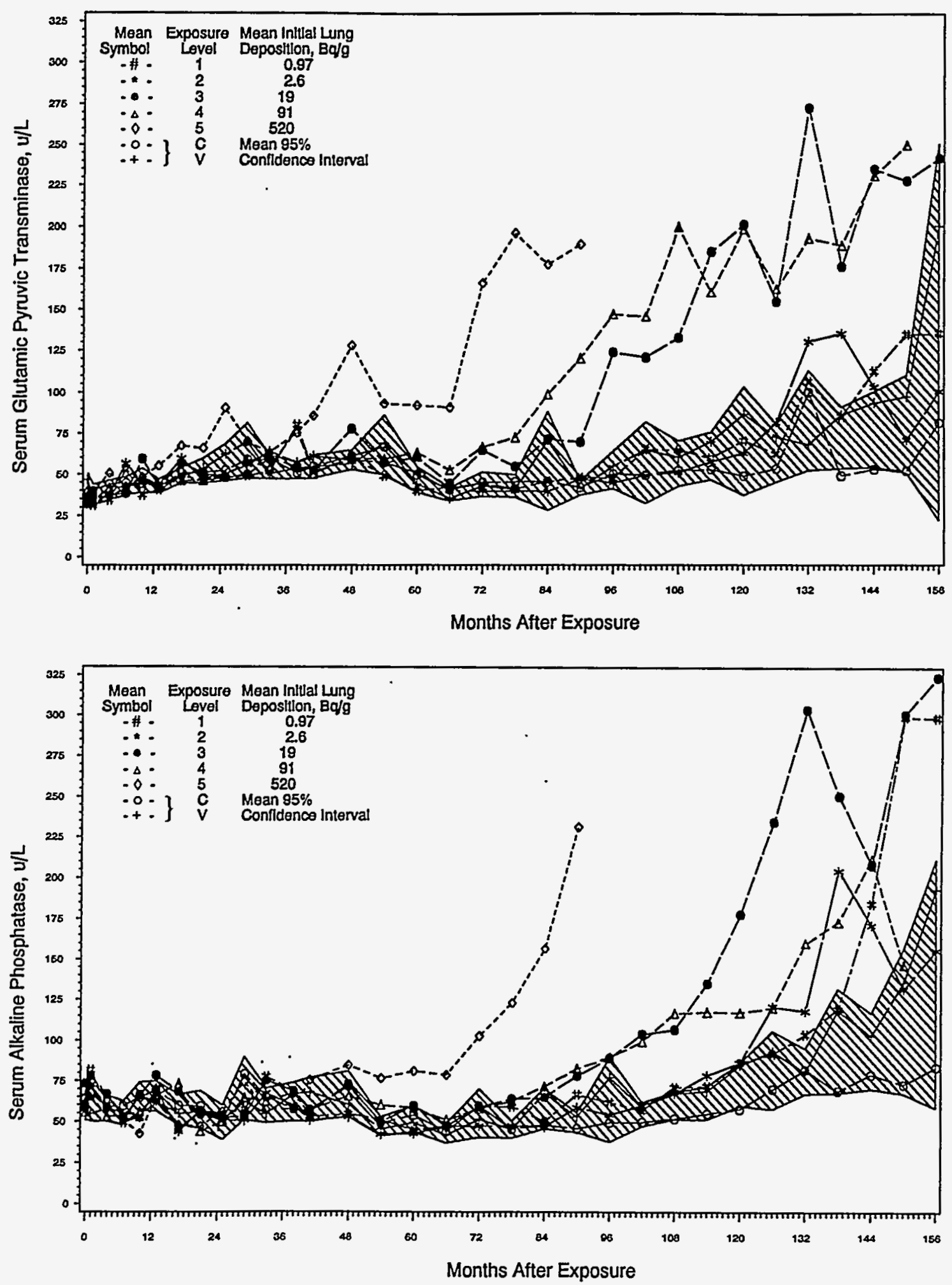

Figure 4. Serum Enzyme Levels in Dogs After Inhaling ${ }^{239} \mathrm{Pu}\left(\mathrm{NO}_{3}\right)_{4}$ 



\title{
National Radiobiology Archives
}

\author{
Principal Investigator: C.R. Watson
}

\author{
Other Investigators: S.K. Smith, E.K. Ligotke, J.C. Prather, \\ L.G. Smith, and M.T. Karagianes
}

The National Radiobiology Archives (NRA) project is a comprehensive effort to gather, organize, and catalog data, documents, and tissues related to completed radiobiology studies. This archiving activity will provide researchers with information for statistical analyses to compare results of these and other studies. The NRA also will provide materials for application of advanced molecular biology techniques to address questions, such as those related to DNA modification, that could not have been considered when these studies were performed. The NRA has a collaborative relationship with the Eurpean Radiobiological Archive (ERA) and the Japanese Low Dose Information Project. The NRA and ERA databases are compatible and can be integrated.

Many investigations have been conducted into the biological effects of ionizing radiation. The focus has been on understanding the nature of human health effects and on quantifying dose-response relationships. When acute effects of large doses had been adequately characterized, attention shifted to effects of lower doses and lower dose rates. This focus led to initiation of life-span studies of experimental animals in several laboratories supported by the US Atomic Energy Commission (AEC), now the Department of Energy (DOE). As DOE radiobiology studies are completed, the National Radiobiology Archives (NRA) will continue to integrate and preserve this unique body of information and materials, and will continue to encourage and simplify its use.

The NRA project concentrated initially on studies of beagle dogs exposed to ionizing radiation at $5 \mathrm{DOE}$-supported laboratories. The project now includes similar studies using other species and at other laboratories. Three major activities are associated with this project:

1. NRA implements an interlaboratory, computerized information system containing a summarized dose-and-effects database, a collection inventory database, and a bibliographic database. During the past year, database structures were redesigned to be compatible with the European Radiobiological Archive (ERA). The information system now includes records from 9 laboratories on approximately 7000 beagle dogs (Table 1), 40,000 rats and mice, and more than 200 nonhuman primates (Table 2). An electronic introduction to the system is available on DOS diskette.

2. NRA establishes a document archives of original (or "record copy") research materials such as logbooks, clinical notes, radiographic films, and pathologists' observations. The first major collection of documents and radiographs was transferred from the University of California at Davis (UC Davis) in 1992.

3. NRA establishes a specimen archives for research materials such as tissue samples or histopathology blocks and slides. Tissue specimens, histopathology blocks and slides, serial radiographs, and extensive clinical records from more than 1000 dogs from UC Davis are organized and available. Two groups of investigators 
Table 1. Major Life-Span Beagle Studies Being Incorporated into the National Radiobiology Archives

\begin{tabular}{|c|c|c|c|}
\hline NRA Study $1 D^{(0)}$ & $\begin{array}{l}\text { Dates of } \\
\text { Exposures }\end{array}$ & Description of Study & $\begin{array}{c}\text { Number of } \\
\text { Life-Span Animals }\end{array}$ \\
\hline $9-1$ & 1961-1974 & ${ }^{230} \mathrm{Pu}, \mathrm{IV}$ injection & 286 \\
\hline $1-2$ & $1953-1970$ & ${ }^{230} \mathrm{Ra}, \mathrm{IV}$ injection & 164 \\
\hline $1-3$ & $1964-1963$ & ${ }^{270} \mathrm{Ra}$, IV injection & 89 \\
\hline 1.4 & $1954-1963$ & ${ }^{220} \mathrm{Th}$, IV injection & 94 \\
\hline $1-5$ & $1965-1966$ & ${ }^{\infty} \mathrm{Sr}$, IV injection & 99 \\
\hline $1-6$ & $1966-1976$ & ${ }^{24} \mathrm{Am}$, IV injection & 117 \\
\hline 1.7 & 1971-1974 & ${ }^{249} \mathrm{Cf}$. IV injection & 36 \\
\hline $1-8$ & $1971-1973$ & ${ }^{202} \mathrm{Cf}$, IV injection & 3E \\
\hline 3-9 & 1972-1978 & ${ }^{209} \mathrm{Pu}, \mathrm{IV}$ injection (juvenile) & 76 \\
\hline $1-10$ & 1973 & ${ }^{203} \mathrm{Es}, \mathrm{IV}$ injection & 5 \\
\hline $1-11$ & $1975-1978$ & ${ }^{200} \mathrm{Pu}, \mathrm{IV}$ injection (aged) & 34 \\
\hline $1-12$ & 1976-1978 & ${ }^{270} \mathrm{Ra}, \mathrm{IV}$ injection (ivvenile) & 63 \\
\hline 1.13 & $1975-1980$ & ${ }^{220}$ Ra, IV injection (aged) & 33 \\
\hline 1-14 & $1977-1979$ & ${ }^{224}$ Ra, IV injection (multiple) & 128 \\
\hline $2 \cdot 1$ & 1962-1968 & $X$ ray, whole body (fractionated) & 360 \\
\hline $2-2$ & 1961-1969 & ${ }^{\infty} \mathrm{Sr}$, ingested (in utero to 540 days) & 483 \\
\hline $2-3$ & 1964-1969 & ${ }^{\infty} \mathrm{Sr}, \mathrm{IV}$ injection & 45 \\
\hline $2-4$ & 1964-1969 & ${ }^{206} \mathrm{Ra}$, IV injection (multiple) & 335 \\
\hline $3-1$ & 1956 & ${ }^{\infty} \mathrm{Sr}$, Transplacental & 63 \\
\hline $3 \cdot 2$ & 1967 & ${ }^{\infty} \mathrm{Sr}$, SC injection (multiple, various ages) & 98 \\
\hline $3 \cdot 3$ & $1960-1964$ & ${ }^{M} \mathrm{Ce}, \mathrm{IV}$ injection & 49 \\
\hline $3-4$ & $1961-1963$ & ${ }^{13} \mathrm{Cs}$, IV injection & 66 \\
\hline 3-6 & 1968-1978 & Gamma ray, whole body (continuous to death) & 311 \\
\hline $3-6$ & $1968-1977$ & Gamma ray, whole body (continuous to predetermined dose) & 343 \\
\hline 4-1 & 1969-1962 & ${ }^{20} \mathrm{PuO}_{2,}$ inhalation & 35 \\
\hline $4-2$ & 1967 & ${ }^{250} \mathrm{PuO}_{2}$, Inhalation & 22 \\
\hline 4-3 & 1970-1972 & ${ }^{2 \times} \mathrm{PuO}_{2}$, Inhalation & 136 \\
\hline 4-4 & 1972-1975 & ${ }^{200} \mathrm{PuO}_{2}$, Inhalation & 136 \\
\hline 4-5 & $1976-1977$ & ${ }^{230} \mathrm{Pu}\left(\mathrm{NO}_{3}\right)_{4}$, Inhalation & 148 \\
\hline 6-1 & 1965-1967 & ${ }^{\infty} \mathrm{SrCl}_{2}$ Inhalation & 63 \\
\hline $6-2$ & $1966-1967$ & ${ }^{14} \mathrm{CeCl}_{3}$ inhatation & 70 \\
\hline 6.3 & 1966-1967 & 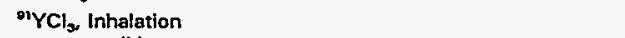 & 64 \\
\hline $5-4$ & $1967-1971$ & ${ }^{14} \mathrm{Ce}$ (FAP) ${ }^{(b)}$, Innalation & 126 \\
\hline $5 \cdot 5$ & 1968-1969 & ${ }^{10} \mathrm{Cscl}, \mathrm{IV}$ injection & 66 \\
\hline $5-6$ & $1969-1971$ & (FAP), Inhalation & 101 \\
\hline $5-7$ & $1970-1971$ & 'Y (FAP), Inhatation & 108 \\
\hline $5-8$ & $1970-1974$ & ${ }^{\infty} \mathrm{Sr}$ (FAP), Inhalation & 124 \\
\hline $6-9$ & 1972-1976 & ${ }^{14} \mathrm{Ce}$ (FAP), Inhalation (juvenile) & 54 \\
\hline $5-10$ & $1972-1975$ & ${ }^{14} \mathrm{Ce}$ (FAP), Inhalation (aged) & 64 \\
\hline 6-11 & $1972-1975$ & ${ }^{148} \mathrm{Ce}$ (FAPI, Inhalation (multiple) & 36 \\
\hline $5-12$ & $1973-1976$ & ${ }^{200} \mathrm{PuO}_{2}$, Inhalation $(3.0 \mu \mathrm{m})$ & 84 \\
\hline 5.13 & 1974-1976 & ${ }^{200} \mathrm{PuO}_{2}$, Inhalation $(1.6 \mu \mathrm{m})$ & 84 \\
\hline $5-14$ & $1977-1979$ & ${ }^{309} \mathrm{PuO}_{2}$, Inhalation $(0.75 \mu \mathrm{m})$ & 60 \\
\hline 6-16 & $1977-1979$ & ${ }^{200} \mathrm{PuO}_{2}$, Inhalation $(1.6 \mu \mathrm{m})$ & 108 \\
\hline 6-16 & $1977-1979$ & ${ }^{200} \mathrm{PuO}_{2}$, Inhalation $(3.0 \mu \mathrm{m})$ & 83 \\
\hline 6.17 & $1977-1978$ & ${ }^{230} \mathrm{PuO}_{2}$, Inhalation (multiple, $0.75 \mu \mathrm{m}$ ) & 72 \\
\hline 6.18 & $1979 \cdot 1983$ & ${ }^{200} \mathrm{PuO}_{2}$, Inhalation (juvenile, $1.6 \mathrm{\mu m}$ ) & 108 \\
\hline 6-19 & $1979-1982$ & ${ }^{209} \mathrm{PuO}_{2}$, Inhalation laged, $1.6 \mu \mathrm{m}$ ) & 60 \\
\hline $8 \cdot 3$ & 1967-1973 & Gamma ray, whole body, $F_{\text {, and }} F_{\text {a generations }}$ & 1680 \\
\hline Total & 1961-1983 & & 7061 \\
\hline
\end{tabular}

(a) Code designations indicate laboratory and study numbers; 3-6, for example, is a code that indicates laboratory 3 (ANL), study 5. Laboratory codes: 1, U of Utah; 2, UC Davis; 3, ANL: 4, PNL; 5, ITRI; 8 CSU. Study numbers: arbitrarily assigned by NRA.

(b) FAP: radionuclide was adsorbed to an insoluble fused aluminosilicate vector aerosol. 
have harvested brain specimens from selected aged dogs to analyze for indicators of Alzheimer's disease, while others have borrowed stomach and mammary carcinoma slides.

\section{Radiobiology Studies}

Nearly 40 years ago, the US AEC began lifespan, radiation-effect studies in beagles; these closely related experiments are now coming to fruition. The studies, conducted at the University of Utah (U of Utah), UC Davis, Argonne National Laboratory (ANL), Pacific Northwest Laboratory (PNL), and the Inhalation Toxicology Research Institute (ITRI) were summarized by Roy Thompson (1989). His book, Life-Span Effects of Ionizing Radiation in the Beagle Dog, became the initial focus of NRA activities. Another multigeneration study in beagles was conducted by the Food and Drug Administration at Colorado State University (CSU). Information from CSU about effects of gamma rays also is being included in the NRA. There also have been many life-span studies of rodents, notably those conducted at Oak Ridge National Laboratory (ORNL), ANL, Brookhaven National Laboratory (BNL), and PNL.

In addition, a series of long-term metabolism studies in nonhuman primates was initiated at the University of Rochester (UR) and continued at Lawrence Berkeley Laboratory (LBL). The most comprehensive description of these studies is given by J. Newell Stannard in Radioactivity and Health, A History (Stannard 1988). An excellent summary of the ANL studies was compiled by Doug Grahn in Studies of Acute and Chronic Radiation Injury at the Biomedical and Medical Research Division, Argonne National Laboratory, 1953-1970: Description of Individual Studies, Data Files, Codes, and Summaries of Significant Findings (Grahn 1994).

The data from beagle experiments currently available from NRA are listed in Table 1, showing the NRA laboratory-study code, the dates of animal exposure, the nature of exposures (includ- ing duration and frequency), and the number of animals held for life-span observation. Table 2 summarizes similar information about rodent and nonhuman primate studies. Information is available on 7061 life-span beagles, 3157 rats, 32,226 mice, and 237 nonhuman primates.

As previously noted, 3 tasks are associated with integrating and preserving information from these studies. The computerized information system provides electronic access to summary data on each animal, to document and specimen collection catalogs, and to bibliographic citations about the studies; the document archives house and preserve nonbiological materials; and the specimen archives house and preserve biological materials.

\section{Advisory Committee}

The NRA is guided by the National Radiobiology Archives Advisory Committee (NRAAC), consisting of 5 external advisors: Stephen A. Benjamin, CSU (dog studies); J.A. Louis Dubeau, University of Southern California (molecular biology); Kenneth L. Jackson, University of Washington (radiobiology); Elizabeth E. Sandager, Peabody Museum (archivist); and Philip R. Watson, Oregon State University (databases).

The committee also includes the following 9 participating (or internal) advisors: Bruce $B$. Boecker, ITRI; Ronald E. Filipy, Washington State University, Tri-Cities; David G. Thomassen, DOE; Bruce A. Carnes, ANL; Scott C. Miller, U of Utah; James F. Park, PNL; Otto G. Raabe, UC Davis; Roy C. Thompson, PNL, and R.J. Michael Fry, ORNL.

\section{Information System}

Computer database technology is essential to integrating this broad and diverse collection of information. The NRA is developing 3 interrelated databases, each of which follows the relational model: the dose-effects summary, the collection inventory, and the bibliography. These 
Table 2. Major Life-Span Studies (Rodents and Nonhuman Primates) Being Incorporated into the National Radiobiology Archives

\begin{tabular}{|c|c|c|c|}
\hline $\begin{array}{l}\text { NRA Study } \\
\text { ID (a) }\end{array}$ & $\begin{array}{l}\text { Dates of } \\
\text { Exposures }\end{array}$ & Description of Study & $\begin{array}{c}\text { Number of } \\
\text { Life-Span Animals }\end{array}$ \\
\hline \multicolumn{4}{|l|}{ Rats: } \\
\hline $4-6$ & $1979-1986$ & Low-level inhaled ${ }^{230} \mathrm{PuO}$, in Wistar rats & 3,167 \\
\hline Total & & & 3,167 \\
\hline \multicolumn{4}{|l|}{ Mice: } \\
\hline 7.1 & 1977 & Gamma ray, single exposure at $10 \mathrm{Wk}, \mathrm{BALB} / \mathrm{c} \& \mathrm{RFM}$ females & 4,728 \\
\hline $7-2$ & 1987 & Gamma ray, single exposure at $10 \mathrm{wk}, \mathrm{C} 3 \mathrm{Hf} \& \mathrm{C} 67 \mathrm{BL} 6$, both sexes & 6,037 \\
\hline $7-3$ & $<1979$ & ${ }^{137} \mathrm{Cs}$, gamma rays, single exposure at 10 wk, RFM, both sexes & 19.200 \\
\hline 9-1 & 1982-1987 & $X$ or gamma rays, fractionated, various ages, C57BL/6 \& CBAVCa males & 3,261 \\
\hline $9-2$ & 1985-1989 & Low-dose neutron leukemogenesis & $\cdot$ \\
\hline To:al & $1977-1989$ & & 32,226 \\
\hline \multicolumn{4}{|c|}{ Nonhuman Primates: } \\
\hline 6-0 & & Controls . & 62 \\
\hline 6-1 & 1954-1982 & ${ }^{\infty} \mathrm{Sr}$ & 124 \\
\hline $6-2$ & 1973-1985 & ${ }^{200} \mathrm{Pu}$ & 28 \\
\hline 6-3 & 1960-1982 & ${ }^{241} \mathrm{Am}$ & 30 \\
\hline $6-4$ & $1985-1986$ & ${ }^{23} \mathrm{~Np}$ & 2 \\
\hline $6-5$ & 1976 & ${ }^{23} \mathrm{Pu}$ & 1 \\
\hline Total & 1954-1986 & & 237 \\
\hline
\end{tabular}

systems are on IBM-compatible PC systems at PNL using the Paradox database management system.

Dose-Effects Summary. The computerized summary database contains dose to and effect on each significant tissue in each animal. The summary database has 6 major tables:

\section{LAB: describing each laboratory}

STUDY: describing each study (as shown in Tables 1 and 2)

GROUP: describing groups of animals within each study

ANIMAL: summarizing each animal TEFFECT: effect (and diagnosis dates) observed in each significant tissue category
TDOSE: dose to each significant tissue category at diagnosis dates in TEFFECT.

The summary database also includes laboratory-specific supporting tables for information such as serial hematological determinations or clinical observations. Progress toward populating the summary database is shown in Table 3.

The TEFFECT summary table is based on standardization of clinicians' and pathologists' terminology through SNODOG, an adaptation of the Systematized Nomenclature of Medicine (SNOMED). Last year, 2 documents were published describing the SNODOG glossary and the frequency of usage of its terms in the beagle studies (Watson 1993). 
Collection Inventory. The collection inventory database contains information about each bar-code label affixed to materials (or containers of materials) in NRA collections. The database defines materials and tracks location of items for rapid retrieval. More than 15,000 items related to 4500 animals currently are managed by this system.

Bibliography. The bibliographic database uses the collection inventory database's bar-code label system to identify reference materials. Location information about materials is stored in the collection inventory database, and bibliographic citations are stored in the bibliography system. This system includes more than $\mathbf{3 0 0 0}$ items of a supporting nature, including animalspecific documents.

An introduction to the NRA information system is available as a stand-alone application that can be self-loaded from diskette onto a DOSbased microcomputer. The documentation accompanying the application, National Radiobiology Archives Distributed Access User's Manual, explains usage and extensively describes fields (Watson et al. 1991; Smith et al. 1992). This document and software provide an important summary of the meta-data (informationdescribing data) collected. The introductory subset diskettes are distributed in response to requests for information about the NRA.

\section{Document Archives}

The research document archives contain detailed, "record copy," research findings associated with each study. Materials include handwritten "raw" data such as exposure logbooks, clinical notes, laboratory analysis forms, hematological profiles, and animal-care observations. A significant class of research documents from these studies comprises photographic film, autoradiographs, radiographs, and photographs. "Summarized" data, usually reduced to computer files or publication reprints, also are included. Each document (or document container such as a folder) is given a bar-coded accession-number label and stored in a controlled environment. Material is catalogued in the bibliographic database for rapid selection and retrieval.

The first contribution to the document archives is the extensive collection of supportive documentation that provided the basis for $R a$ dioactivity and Health: A History (Stannard 1988); 63 boxes have been accessioned (Watson et al. 1994). In addition, 39 lineal feet of clinical records and an extensive collection of radiographic records were transferred from UC Davis in June 1992. In 1990, documents from the $U$ of Utah such as clinical records, radiographs, photographs, and autoradiography preparations, as well as specimens such as organs, histology blocks, and slides, were accessioned; these materials will remain in Utah pending completion of the studies.

\section{Specimen Archives}

The biological specimen archives contain collected research materials such as tissues preserved in formalin or alcohol, tissue samples embedded in paraffin or plastic for histopathological analysis, microscope slides, and radiographic films. Many materials are radioactive and associated with hazardous materials such as formalin, alcohol, or paraffin. A building has been renovated to serve as the repository of these specimens. The building contains a specimenmanipulation laboratory, storage bays, and an automatic fire-suppression system. Materials are nominated for donation to the NRA by an institution which recognizes that specific completed studies are worthy of consideration for archival preservation.

\section{Collaborations and Retrievals}

Cooperation of participating institutions and investigators is essential to achieve goals of the NRA project. Collaboration has been excellent with the 9 institutions that have donated 
Table 3. Progress Toward Populating the Summary Database

Status of NRA Database Tables ${ }^{(b)}$

\begin{tabular}{|c|c|c|c|c|c|c|c|}
\hline $\begin{array}{l}\text { NRA Lab and } \\
\text { Study ID(a) }\end{array}$ & LAB & STUDY & GROUP & ANIMAL & TEFFECT & TDOSE & LAB SPECIFIC \\
\hline $1-1$ to $1-14$ & $\mathrm{~F}$ & c & c & C & C & c & c \\
\hline $2-1$ & $\mathrm{~F}$ & c & c & $P$ & & & \\
\hline $2-2$ to $2-04$ & $\mathrm{~F}$ & c & c & c & C & c & C \\
\hline $3-1$ to $3-03$ & $\mathrm{~F}$ & c & c & $P$ & & & \\
\hline $3-4$ & $\mathbf{F}$ & c & c & c & C & & c \\
\hline $3-5,3-06$ & $\mathrm{~F}$ & C & c & $P$ & & & \\
\hline $4-1,4-02$ & $F$ & C & c & $P$ & & $P$ & $P$ \\
\hline $4-3$ to $4-05$ & $\mathrm{~F}$ & c & c & c & $\mathbf{P}$ & $P$ & $P$ \\
\hline $5-1$ to $5-19$ & $\mathrm{~F}$ & c & c & c & & & \\
\hline $6-1$ to $6-3$ & $F$ & c & c & & & & \\
\hline $6-4$ to $6-5$ & $\mathrm{~F}$ & c & P & & & & \\
\hline $7-1,7-2$ & $F$ & c & c & C & C & c & c \\
\hline $7-3$ & $\mathbf{F}$ & C & C & 1 & & & \\
\hline $8-3$ & $\mathbf{F}$ & $P$ & $P$ & 1 & 1 & & \\
\hline $9-1$ & $\mathbf{F}$ & C & c & $\mathbf{P}$ & & & \\
\hline $9-2$ & $F$ & c & & & & & \\
\hline $10-1$ to $10-51$ & 1 & 1 & $\begin{array}{l}\text { Detailed informatiti } \\
\text { study definition reo }\end{array}$ & $\begin{array}{l}\text { was discurded b } \\
\text { is only.l }\end{array}$ & University of Roc & ter; NRA has & ts of results and \\
\hline
\end{tabular}

(a) Laboratory Codes: 1, U of Utah; 2, UC Davis; 3, ANL; 4, PNL; 5, ITRI; 6, LBL; 7, ORNL; 8, CSU; 9, BNL; 10, University of Rochester. Study numbers are defined in Tables 1 and 2.

(b) Status Codes:

C, Complete: database records are complete; all significant fields have complete information.

F, Final: database records are complete and reviewed by investigator.

1, Incomplete: database tables are partially filled with representative rows.

$P$, Partial: database records are partially complete; some fields have no information.

information and materials. NRA staff have participated in, or have been invited to participate in, several site visits; collaborative projects were initiated, and these laboratory directors serve on the NRAAC.

The NRA encourages analysis of studies that examine previous information from a new perspective by applying different analytical approaches, or by comparing results of studies performed at different institutions. The NRA collaborated with investigators at UC Davis to obtain brain specimens of dogs whose clinical records indicated Alzheimer-like symptoms. NRA staff retrieved tissues and provided laboratory facilities, and the UC Davis team prepared histopathology slides for staining and interpretation (Russell et al. 1992). In addition, the NRA specimen archives supplied histopathology slides of control-beagle stomach tissue to the veterinary school at UC Davis and brain specimens to the University of Tennessee. The information system responded to several requests for detailed data subsets.

A subcommittee of the NRAAC met in December 1991 to plan a collaborative database combining information from 1096 control beagles. The NRA is coordinating publication of this reference set to provide baseline information for comparison with experimental groups. A 
consortium of biostatisticians from ANL, ITRI, and PNL will analyze this control beagle subset.

\section{Collaboration with the Europeans}

A similar archiving task has been initiated by the Commission of European Communities (CEC). The ERA is being developed for the European Late Effects Program (EULEP) by Dr. Georg Gerber. The NRA is actively cooperating with Dr. Gerber to coordinate database design, with the goal of eventual integration. Agreement on computer hardware and database management software was reached, and the database structures are being merged. A joint publication of descriptive information is planned for spring of 1995.

\section{Future Activities}

The NRA will continue the orderly accessioning of life-span beagle-study information, and shipment of selected specimens and documents to PNL. While these studies are being completed, NRA will play an increasing role in facilitating analyses that cut across studies and species. For example, NRA will compile and publish a combined data set of control beagles. Because most rodent-based radiobiology studies involved thousands of animals, access to original, unpublished data from them is limited. Therefore, the NRA will continue to solicit details about additional rodent studies, initially those conducted at ANL, BNL, ORNL, and PNL. The NRA will work closely with the interlaboratory consortium of statisticians developing techniques for comparing and combining information from the beagle studies.

\section{References}

Grahn, D. 1994. Studies of Acute and Chronic Radiation Injury at the Biomedical and Medical Research Division, Argonne National Laboratory, 1953-1970: Description of Individual Studies, Data Files, Codes, and Summaries of Significant Findings. ANL-94/26, Argonne National Laboratory, Argonne, Illinois.

Russell, M.J., R. White, E. Patel, W.R. Markesbery, C.R. Watson, and J.W. Geddes.
1992. Familial influence on plaque formation in the beagle brain. NeuroReport 3:1093-1096.

Smith, S.K., J.C. Prather, E.K. Ligotke, and C.R. Watson. 1992. National Radiobiology Archives Distributed Access User's Manual Version 1.1. PNL-7877, Rev. 1, Pacific Northwest Laboratory, Richland, Washington.

Stannard, J.N. 1988. Radioactivity and Health: A History, R.W. Baalman, ed. DOE/RL/10830-T59 (DE88013791), Office of Scientific and Technical Information, Springfield, Virginia.

Thompson, R.C. 1989. Life-Span Effects of Ionizing Radiation in the Beagle Dog: A Summary Account of Four Decades of Research by the U.S. Department of Energy and Its Predecessor Agencies. PNL-6822, Pacific Northwest Laboratory, Richland, Washington.

Watson, C.R., J.C. Prather, and S.K. Smith. 1991. National Radiobiology Archives Distributed Access User's Manual. PNL-7877, Pacific Northwest Laboratory, Richland, Washington.

Watson, C.R. 1993. SNODOG Glossary: Part 1, Introduction, and Part 2, Usage of Terms. PNL-8650, Parts 1 and 2, Pacific Northwest Laboratory, Richland, Washington.

Watson, C.R., E.K. Ligotke, and S.K. Smith. 1994. National Radiobiology Archives Dr. J. Newell Stannard Collection Inventory Listing. PNL-10219, Pacific Northwest Laboratory, Richland, Washington. 



\title{
Statistical Analyses of Data from Radiobiologic Animal Studies
}

\author{
Principal Investigator: E.S. Gilbert
}

\author{
Other Investigators: R.L. Buschbom, R.L. Hill
}

The purpose of this project is to enhance the information extracted from life-span studies in experimental animals, especially those conducted in beagles, by providing statistical methods and analyses that are as unbiased and informative as possible for assessing human health risks. Statisticians from Pacific Northwest Laboratory (PNL), Argonne National Laboratory (ANL), and the Inhalation Toxicology Research Institute (ITRI) are applying state-of-the-art statistical methods to past and current data generated by scientists involved in the U.S. Department of Energy (DOE) experimental radiobiology program. The project also involves developing statistical methods and software to meet special challenges posed by these radiobiology studies, and improving methods for estimating organ-specific doses from internally deposited radionuclides. A major objective is to establish an integrated approach for synthesizing data across DOE laboratories. This approach includes both standardized analyses, in which estimates of risk comparable across studies and across exposure groups will be obtained for all studies meeting specified criteria, and more extensive and specialized analyses based on combined data from selected studies. In combination, the standardized and combined analyses are expected to provide the best possible overall assessment of DOE radiobiologic data, and to allow these data to be used in an optimal way for assessing human risks.

\section{Introduction}

A wide variety of radiobiologic animal experiments, primarily in rodents and beagles, have been conducted for the DOE at several laboratories. Most of the DOE radiobiologic studies in laboratory animals were designed to obtain information for exposure situations in which adequate human data are unavailable, and particularly to provide information on how dose, dose rate, dose distribution, LET, and other factors modify risks. Radiation exposures from both external sources and internal emitters have been studied. In this project, we hope to increase the understanding of radiation-related human health risks by developing and implementing a plan for analyzing and integrating the extensive data that have been generated from DOE life-span animal experimental studies. To extend statistical analyses now being conducted at individual laboratories, project researchers apply common approaches to data from different studies, conduct analyses that directly combine and compare data from related studies, and further develop the statistical methods and computer software needed to meet special challenges posed by these data. The laboratory animal data from DOE radiobiologic experiments represent an extremely important resource of information on radiation exposures for which human data are unavailable, and the recent development of powerful statistical tools and software for analyzing survival data now makes it feasible to provide a more rigorous and informative assessment of these data than has been possible in the past.

The objectives of statistical analyses con-. ducted under this project are to provide measures of carcinogenic risk that can be appropriately compared across studies, to quantify differences in risks produced by various radionuclides and exposure conditions, to compare risks across species, to investigate the shapes of doseresponse functions in a consistent manner, and to evaluate the consistency of results with models that have been used for human radiation risk assessment. These analyses will provide information needed for estimating risks in man, and will thus decrease the uncertainty in risk estimates, especially for exposure situations not represented by human data. 


\section{Approach}

Statisticians and experimenters from PNL, ITRI, and ANL are collaborating to develop an integrated approach to analyze data from past and present DOE radiobiological studies, especially those conducted in beagles. The project includes regular meetings of the 3 principal investigators (statisticians from PNL, ITRI, and ANL), with participation of radiobiologists, dosimetrists, pathologists, representatives from the National Radiological Archives (NRA), and others who are involved in the studies. The project includes both standardized and combined analyses, as described below.

Standardized analyses of each experiment include calculating a measure of lifetime risk and its uncertainty using specifically recommended procedures for each group of animals defined by dose level, type of radiation exposure, and possibly other factors. These analyses also include the fitting of specified dose-response functions. Such standardized analyses do not preclude other types of analyses that might be appropriate for particular studies, but allow use of these data for human risk assessment in ways that may not be currently anticipated.

In addition to the standardized analyses, we are working with the investigators who conducted the experiments to determine areas in which further combined analyses are needed. These more detailed analyses combine data from selected radiobiologic studies to address specific questions of interest, and they give careful consideration to comparability of (1) dose estimates and their uncertainties; (2) data on health endpoints, including pathologists' judgments in identifying types of tumors and assigning cause of death; and (3) baseline risks. Used carefully, analyses based on combined data permit the development of combined risk estimates, and provide an assessment of differences in risks from various types of exposure that is more rigorous than could be obtained if only analyses based on data from individual studies were available.

\section{Progress in FY 1994}

This summary focuses on activities in which PNL researchers participated, and excludes activities primarily conducted by ITRI or ANL researchers. Three meetings of the principal investigators were held (December 1993 at ITRI, April 1994 at ANL, and November 1994 at PNL), and the following tasks were accomplished.

Draft protocols for standardized analyses and for statistical methods have been prepared. The protocol for standardized analyses discusses factors such as: statistical methods and models; how dose groups are to be defined; treatment of variables such as sex; health endpoints that will be evaluated; dosimetry; context of observation, including the use of radiographic data; baseline risks; and measures to be used to summarize data. Because many statistical methods used to analyze experimental data are common to both standardized and combined analyses, a separate document on statistical methods has been prepared. This document describes models for the hazard or age-specific risk, and gives special attention to appropriately accounting for the context in which tumors are observed (e.g., fatal or incidental to the death of the animal).

Wh have begun using analyses of control dogs as the first example of combined analyses, and to test the use of the NRA for obtaining data. These analyses will bring together in one place descriptive information on the control populations, including simple information on the number of animals, number of tumors of various types, average life span, etc. The analyses also will include a rigorous statistical assessment of differences in several health endpoints by laboratory, sex, and individual studies within laboratories. Based on these results, it may be possible to identify groups of control animals that can be appropriately used for a variety of specific purposes.

Initial analyses of data on rats exposed to inhaled ${ }^{239} \mathrm{PuO}_{2}$ in studies at PNL and ITRI have been conducted. Further work addressing 
comparability of both pathology and dosimetry in the 2 studies is underway, and will be followed by additional analyses. To implement the effort conducted at PNL, we developed software for conducting analyses that account for information provided by the pathologist on whether tumors were fatal or incidental to the death of the animal. The software is sufficiently flexible to (1) fit a variety of dose-response functions, such as linear-quadratic and power functions; (2) quantify estimates of both the hazard and lifetime risks; (3) assess the dependence of risks on dose rate, type of exposure, and other factors; and (4) investigate changes in the hazard as animals are followed over time. Initial documentation of this software has been prepared and provided to statisticians at ANL and ITRI.

Analyses of rats exposed to radon at $P N L$ also have been conducted, and a draft paper describing these analyses prepared. Although these data have been analyzed previously (Gilbert 1989), additional data on studies of low exposures and exposure rates have since become available. Moreover, earlier analyses did not utilize pathologists' judgments on whether tumors were fatal or incidental. Combined analyses of epidemiologic data from 11 cohorts of underground miners recently have been published (Lubin et al. 1994), and have provided new models, particularly for evaluating the effect of dose rate on risks. It is of interest to test these models in experimental animals.

Efforts have begun in dosimetry, an important component of this project, particularly for animals exposed to inhaled radionuclides. Initial work in this area involves dogs exposed to inhaled ${ }^{238} \mathrm{PuO}_{2}$ at PNL and ITRI, with particular attention to ensure that methods being used to estimate organ doses in this study are comparable for the 2 laboratories. These efforts will be extended to estimate lung dose in rats exposed to particles of ${ }^{239} \mathrm{PuO}_{2}$ at PNL and ITRI.

To estimate the temporal accumulation of dose in inhalation studies, work has been initiated to evaluate several quantities: (1) initial lung deposition (ILD), which is the initial amount of material deposited at each exposure in the deeplung, not including rapidly cleared material in upper airways; (2) tissue weight, ideally temporally based to allow for growth of the animal after exposure; (3) parameters describing the radioisotope's temporal distribution in the tissues for which dosimetry estimates are desired; and (4) the fraction of the energy absorbed in the target tissue. Data available for estimating these quantities include information on the tissue-specific distribution of material in each animal at the time of death, and, in some studies, one-time or periodic whole body counts, excreta data, or weights (usually body weight and weights of selected tissues at necropsy).

\section{The Future}

Standardized analyses of data from all DOE life-span animal studies meeting specified criteria will be completed. The results of these analyses and a description of the methods used to obtain them will be published in a summary report, and will be submitted in an abbreviated form to a peer-reviewed journal. Comparable summary statistics and estimates of their uncertainty will be provided for each group of animals within each qualifying study. These statistics will then be available for use by those interested in radiation risk assessment, and by those interested in a general understanding of the radiationcarcinogenesis process. The summary measures could be used in analyses ("meta-analyses") to address questions that may arise in the future.

Further combined analyses of data from selected studies will be conducted, and will address certain issues in more detail than the standardized analyses. These analyses will give careful attention to comparability of dosimetry, pathology, and other aspects of the experimental protocol. Methodological problems posed by these analyses will be explored, and adequate statistical approaches for addressing them will be developed.

In combination, the standardized analyses and the combined analyses are expected to provide the best possible overall assessment of $\mathrm{DOE}$ experimental data, and to allow these data to be used in an optimal way for assessing human risks. 


\section{References}

Gilbert, E.S. 1989. Lung cancer risk models from experimental animals. In: Proceedings of the 24th Annual Meeting of the NCRP, Naomi H. Harley, ed., pp. 141-155. National Council on Radiation Protection and Measurements, Bethesda, Maryland.
Lubin, J.H., J.D. Boice, C. Edling, R.W. Hornung, G. Howe, E. Kunz, R.A. Kusiak, H.I. Morrison, E.P. Radford, J.M. Samet, M. Tirmarche, A. Woodward, S.X. Yao, and D.A. Pierce. 1994. Radon and Lung Cancer Risk: A Joint Analysis of 11 Underground Miners Studies. National Institutes of Health, National Cancer Institute. NIH Publication No. 94-3644. U.S. Department of Health and Human Services, Washington, D.C. 


\title{
Genotoxicity of Inhaled Energy Effluents
}

\author{
Principal Investigator: A.L. Brooks
}

\section{Other Investigators: K.M. Groch, B. Wood, and R.F. Jostes}

This project focuses on 2 major areas of research. First, we are evaluating the use of cellular and molecular techniques to help understand risks associated with inhalation of complex mixtures. These studies required development of a model system to expose cells directly to the vapor-phase materials in complex mixtures. Second, studies are being conducted to evaluate chromosome aberrations as an indicator of early change in carcinogenesis. Previous mechanistic studies employed human chromosome probes in $A_{L}$ cells to compare dose-response relationships for the induction of chromosome aberrations (measured as color switches) following high-LET (radon) and low-LET $\left({ }^{60} \mathrm{Co}\right)$ irradiation. We determined that the color switches are adequate to describe these dose-response relationships. In a continuation of the mechanistic studies associated with chromosome aberrations, we have used probes that "paint" the chromosomes of rat cells via fluorescent in situ hybridization (FISH). Dose-response curves have been developed for low-LET irradiation in primary rat-skin fibroblasts using chromosome 1 probes. In other experiments with $\mathrm{X}$ and $\mathrm{Y}$ probes in the rat, it was demonstrated that it is possible to determine the sex of rodent cells during the interphase stage of the cell cycle. This research was very useful in leukemia transplant studies conducted in rats, and could have application in other studies that require the evaluation of the sex of interphase cells.

\section{Methods \\ Model Exposure Systems for Airway Epithelium}

We have developed an exposure system with a controlled rocker arm to irradiate cells of the airway epithelium. This rocker arm allows cells in half the flask to be covered with medium at all times while cells in the other half of the flask are exposed directly to vapor-phase materials. The system makes it possible to conduct studies on cell survival and on genotoxicity as measured by induced chromosome aberrations, micronuclei, sister chromatid exchanges (SCEs), and mutations. The Pacific Northwest Laboratory (PNL) is currently working with Westinghouse Hanford Company to evaluate the biological activity of vapor-phase samples from waste tanks with this system.

\section{Mechanisms Involved in Chromosome- Aberration Production}

$\mathrm{A}_{\mathrm{L}}$ cells were exposed to ${ }^{60} \mathrm{Co}$ at a dose rate of $0.5 \mathrm{~Gy} / \mathrm{min}$ and total doses of $0.0,1.0,4.0$, 8.0 , and $10.0 \mathrm{~Gy}$ to generate dose-response relationships for color switches (a measure of induced aberrations) between human and rodent chromosomes. Additional cells were exposed to 0.0 or 1.2 Gy from radon using the in vitro exposure system described by Jostes et al. (1991). Radon-exposed cells, and cells exposed to $4.0 \mathrm{~Gy}$ of ${ }^{60} \mathrm{Co}$ gamma rays, were harvested at $1,3,9$, and 15 days after exposure. During the time between exposure and harvest, cells were maintained in exponential growth by subculturing every 4 days. The chromosomes were painted using the technique published by Pinkel et al. (1986), and the number of color junctions were scored. Color junctions are defined as the interface between a yellow-stained human chromosome 11 and a red-stained propidium iodide-labeled Chinese hamster ovary (CHO) chromosome. Aberrations in other chromosomes were not recorded.

Molecular probes were developed in collaboration with Lawrence Livermore National Laboratory (LLNL), Livermore, California, to paint selected rat chromosomes. These probes were designed, using in situ methods previously developed for mouse chromosomes (Breneman et al. 1993), to label enough rat genome to determine dose and induced chromosome translocations during tumor development, and to identify 
$\mathrm{X}$ and $\mathrm{Y}$ chromosomes for gender identification of rat cells in tumors.

Interphase cells from the spleen of healthy male and female mice, and from the spleen of female mice that had leukemia induced by injection with male leukemia cells, were evaluated for copies of X chromosome. These studies tested the hypotheses that the injected cells undergo clonal expansion and are of male origin. The dose-response relationships for the induction of chromosome aberrations were evaluated using fluorescent in situ hybridization (FISH) in primary cultures of skin fibroblasts established from female Fischer rats (55 to 60 days old) in Dulbeco's Modified Eagle's Medium (DMEM) containing $10 \%$ fetal bovine serum, $15 \mathrm{mM}$ HEPES (pH 7.4), and $50 \mu \mathrm{g} / \mathrm{ml}$ gentamycin. Briefly, the abdomen of an animal was shaved and washed with iodine, then several $5 \times 5-\mathrm{mm}$ pieces of skin were excised. Three pieces of skin were placed in a 100-mm tissue-culture dish and covered with a sterile glass cover slip. The cover slip was attached to the dish with a small amount of sterile silicon grease. The tissue was incubated at $37^{\circ} \mathrm{C}$ with $5 \% \mathrm{CO}_{2}$ until the dish was $-75 \%$ confluent. The cover slip then was removed and the cells obtained from both surfaces with trypsin. The cells were passed at about $75 \%$ confluency and a dilution of $\sim 1: 10$ into secondary culture using the same medium. After three passes, cells were resuspended in the growth medium described previously, but further supplemented with $15 \%$ dimethyl sulfoxide; aliquots then were cryopreserved in liquid $\mathrm{N}_{2}$. Ninety-six hours before exposure, an ampoule of cryopreserved cells was thawed and cultures were reestablished using the growth medium described previously.

Cell densities were adjusted so that cultures were approximately one-third confluent at the time of irradiation. Twenty-four hours before exposure, the culture medium was replaced with fresh growth medium. The exponentially growing cultures were irradiated in the ${ }^{60} \mathrm{Co}$ gamma cell facility at PNL at an exposure rate of $\sim 1 \mathrm{~Gy} / \mathrm{min}$ and doses of $0.0,1.0,2.0$, and $3.0 \mathrm{~Gy}$. Following exposure, the cultures were returned to the incubator for 18 hours before addition of $70 \mathrm{ng} / \mathrm{ml}$ colcemid; the cultures then were incubated with colcemid for an additional
4 hours. The culture medium containing nonadherent cells was decanted and the adherent cells removed from the dishes with trypsin. The adherent and nonadherent cells were pooled, their suspension adjusted to $10 \%$ fetal bovine serum, and pelleted. The cells then were washed in Hank's Balanced Salt Solution (HBSS), pelleted, and resuspended in hypotonic $75 \mathrm{mM} \mathrm{KCl}$ for 10 minutes, fixed in 3 changes of ice-cold methanol/glacial acetic acid (3/1), resuspended in methanol/acetic acid, and dropped onto cold, wet slides. The slides were allowed to cure for 48 hours at room temperature, then stored at $-20^{\circ} \mathrm{C}$ under $\mathrm{N}_{2}$ until staining.

Slides for staining were denatured in $70 \%$ formamide containing $2 \times$ SSC $(1 \times$ SSC $=0.15$ $M \mathrm{NaCl}, 0.015 M \mathrm{Na}_{3} \mathrm{C}_{6} \mathrm{H}_{5} \mathrm{O}_{7}$ ), at a $\mathrm{pH}$ of 7.0 , for 5 minutes at $70^{\circ} \mathrm{C}$. The slides were then dehydrated in an ascending series of ethanols at $-20^{\circ} \mathrm{C}$ and dried under a jet of $\mathrm{N}_{2}$, then placed on a warmer at $35^{\circ} \mathrm{C}$. A biotinylated DNA probe for chromosome 1 was denatured in $70 \%$ formamide containing $2 \mathrm{xSSC}$ at $\mathrm{pH} 7.0$, $0.5 \mathrm{ng} / \mathrm{ml}$ dextran sulfate, and $0.1 \mathrm{ng} / \mathrm{ml}$ sonicated salmon sperm DNA for 5 minutes at $70^{\circ} \mathrm{C}$. Thirty-five $\mu \mathrm{L}$ of denatured probe was applied to each slide; a $22 \times 50-\mathrm{mm}$ cover slip was applied to the slide and sealed with rubber cement. Hybridization was allowed to proceed at $35^{\circ} \mathrm{C}$ overnight.

Following hybridization, slides were washed 5 times: 3 times with $50 \%$ formamide containing $2 \mathrm{xSSC}$ at $\mathrm{pH} 7.0,1$ time in $2 \mathrm{xSS}$ at $\mathrm{pH} 7.0$, and 1 time in $2 \mathrm{x}$ SSC at $\mathrm{pH} 7.0$ containing $0.05 \% \mathrm{NP}-40$. All post-hybridization washes were at $41^{\circ} \mathrm{C}$. Chromosomes with bound probe were visualized by treating with fluoresceinated avidin $(5 \mu \mathrm{g} / \mathrm{ml})$ followed by an amplification step of biotinylated mouse anti-avidin antibody $(5 \mu \mathrm{g} / \mathrm{ml})$. After a second application of fluoresceinated avidin, the stained slides were washed in distilled water and dried. Metaphases were counterstained with $0.3 \mu \mathrm{g} / \mathrm{ml}$ propidium iodide in $75 \%$ glycerol containing $9 \mathrm{mg} / \mathrm{ml}$ $O$-phenylenediamine $\cdot 2 \mathrm{HCl}$ (anti-fade).

Metaphase spreads were visualized with epifluorescent illumination on a Nikon Optiphot equipped with a 100-watt $\mathrm{Hg}$ lamp and appropriate excitation/barrier filters. Spreads were analyzed in groups of 100 , and photographs of 
any abnormalities were made with 200 ASA

Ektachrome film. Potential aberrations evident in the photographs were scored by at least two independent observers without prior knowledge of the exposure conditions.

Probes for both chromosome 1 and 2 were evaluated for potential use. Because differential staining was best for chromosome 1, cytogenetic evaluations of damage were limited to this chromosome.

\section{Results and Discussion Model Exposure Systems for Airway Epithelium}

Preliminary experiments using this exposure system focused on cell killing and the induction of SCEs in CHO cells. The system can be calibrated to measure a range of cell killing by vapor-phase materials. The frequency of induced SCEs can be measured at levels of exposure where cell killing is minimal.

\section{Mechanisms Involved in Chromosome- Aberration Production}

The goal of the first study employing rat chromosome probes was to assess whether it was possible to determine the sex of leukemia cells in a rat large granulocytic leukemia (LGL) model. Figure 1 illustrates the number of fluorescent labeled spots that represent the $\mathrm{X}$ chromosome in interphase cells from male and female rats. A certain fraction (10 to $20 \%$ ) of the interphase cells do not seem to take up stain on the $X$ chromosome. In males, most of the cells have either no label or a single label; very few cells have two bright spots. Most cells from spleens of female rats have two labels. Some cells in the female show only a single bright spot while others have no label. This phenomenon seems to be related to the way the cells are oriented on the slide; when both bright spots are in close enough proximity, they are scored as a single spot. A female rat that has LGL induced by injection of male rat cells is shown in Figure 2. There is a single bright spot (male cells) in most cells; only one cell in this field has two bright spots (female cell). This finding shows that the cells responsible for the tumor are of male origin. As previously postulated, after injection cells

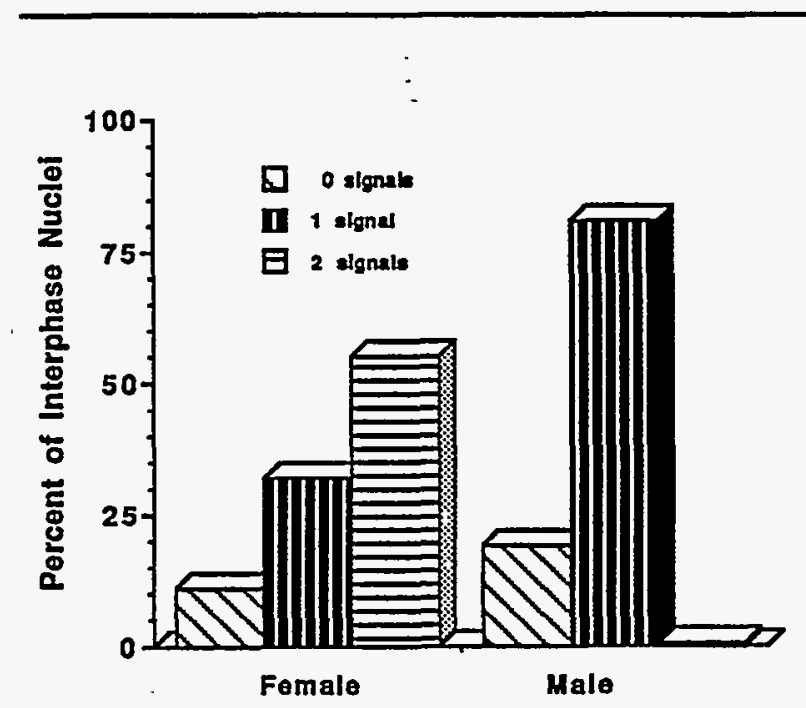

Figure 1. The Frequency of $X$ Chromosomes in Interphase Cells Labeled With Whole Rat Chromosome Probes. The male cells heve a single copy of the $X$ chromosome; the female cells appear to have 1 or 2 copies.

underwent clonal expansion and did not transfer the leukemic phenotype to female cells.

The frequency of color junctions in $A_{L}$ cells was evaluated as a function of dose, time after exposure, and LET. The findings indicated that the increase in color junctions was a nonlinear function of radiation dose (Figure 3), which was described by the following linear-quadratic function: color junctions/cell $=0.027-0.011$ $D+0.0097 D^{2}\left(R^{2}=0.99\right)$. The time course for elimination of cells with color junctions from the population is shown in Figure 4. The graph illustrates that after the initial clearance of cells with damage by ${ }^{60} \mathrm{Co}$, there was a rather constant level of chromosome damage. For radonexposed cells, the level of color junctions remained rather constant. The relative biological effectiveness of radon relative to ${ }^{60} \mathrm{Co}$ in this study was 3.6 when the response was compared at a constant dose (1.2 Gy) and time (24 hours).

The dose-response relationship for the induction of color junctions was evaluated in rat fibroblasts using a chromosome 1 paint. A breakdown of the types of aberrations scored is shown in Figure 5. It was noted that most of the 


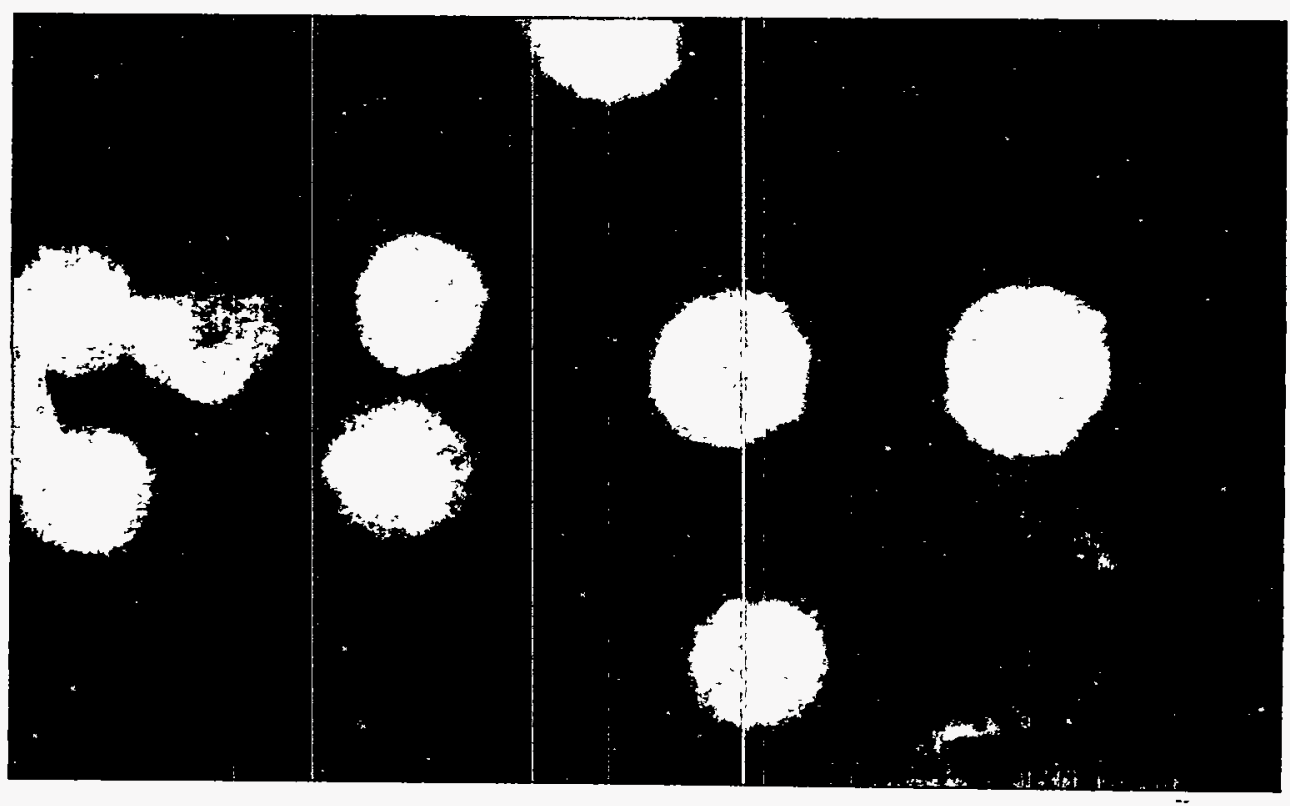

Figure 2. Spleen Cells From a Female Rat Infected With Large Granulytic Leukemia Cells From a Male Rat. The single $X$ chromosome in the interphase cells demonstrates that the leukemia cells are of male origin.

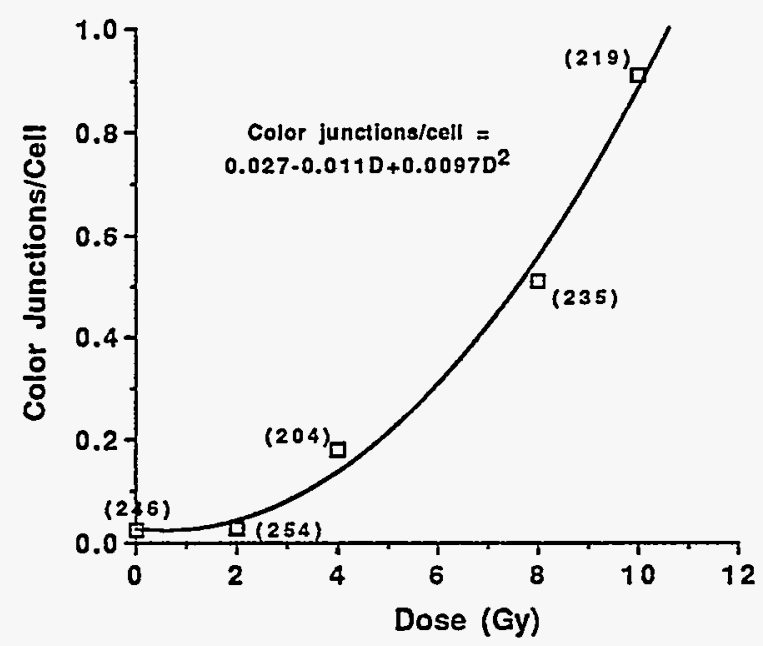

Figure 3. The Dose-Response Relationship for Induction of Color Junctions in $A_{L}$ Cells by ${ }^{60}$ Co Exposure

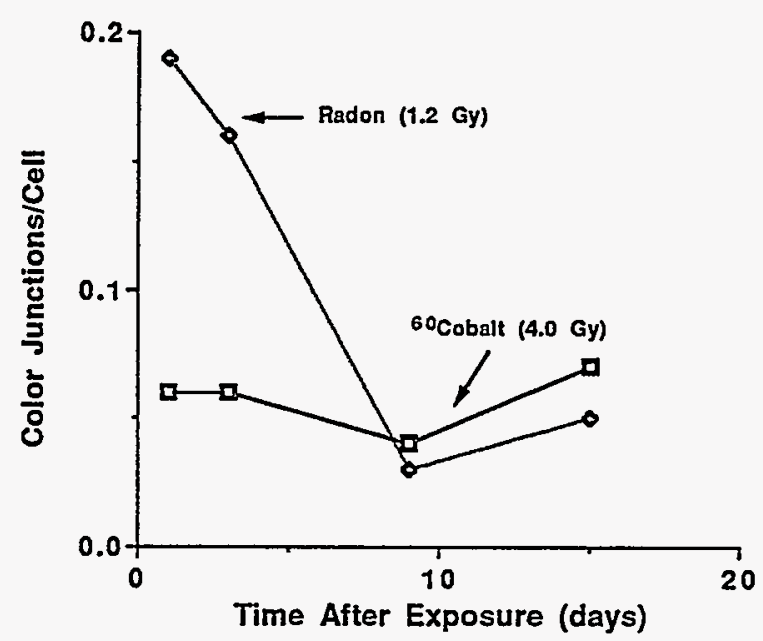

Figure 4. The Time-Response for Survival of Color Junctions in Dividing $A_{1}$ Cell Populations in Culture Following Either $4.0 \mathrm{~Gy}$ of ${ }^{60} \mathrm{Co}$ Gamma Radiation or 1.2 Gy of Alpha Particles from a Radon Source 


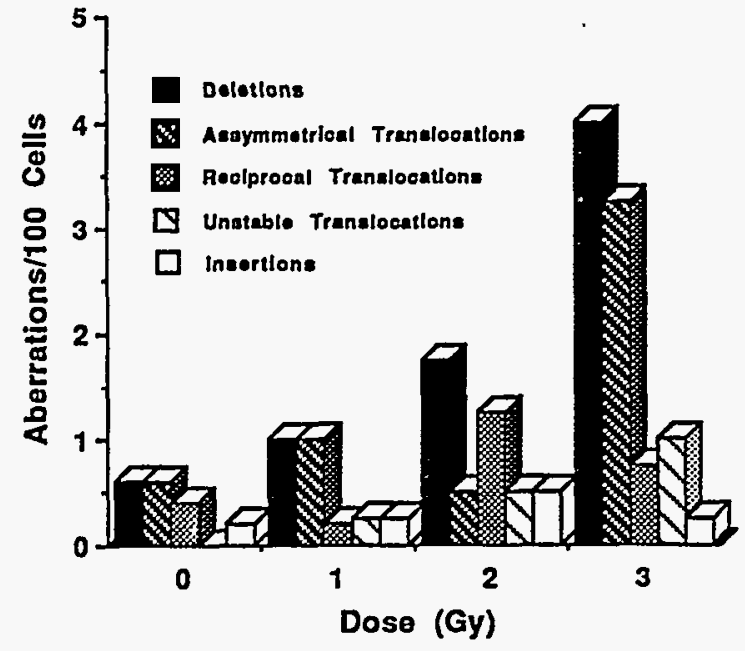

Figure 5. The Distribution of Aberration Types in Primary Rat Skin Fibroblasts Measured by Color Junctions 18 Hours After Exposure to ${ }^{60} \mathrm{Co}$ Gamma Radiation

aberrations scored at 18 hours after exposure were of the chromosome type. The data also suggest that the frequency of asymmetrical translocations was similar to that observed for deletions and was higher than for reciprocal translocations or unstable chromosome translocations (rings + dicentrics). The frequency of reciprocal translocations was not different from that seen for unstable chromosome translocations. The dose-response relationship for total color junctions is illustrated in Figure 6, which illustrates that the frequency of aberrations again increases as a nonlinear function of radiation dose according to the equation color junctions/ cell $=0.02-0.0015 \mathrm{D}+0.0087 \mathrm{D}^{2}\left(\mathrm{R}^{2}=0.99\right)$. This is not significantly different from the doseresponse relationships for the induction of color junctions in $A_{L}$ cells. Color junctions can be used to evaluate dose-response relationships for rodent cells even when there are no probes available to identify centromeres.

These chromosome probe methods will be employed in future studies of induced aberrations in cells following exposure to combinations of well-defined vapor-phase mixtures and ionizing radiation.

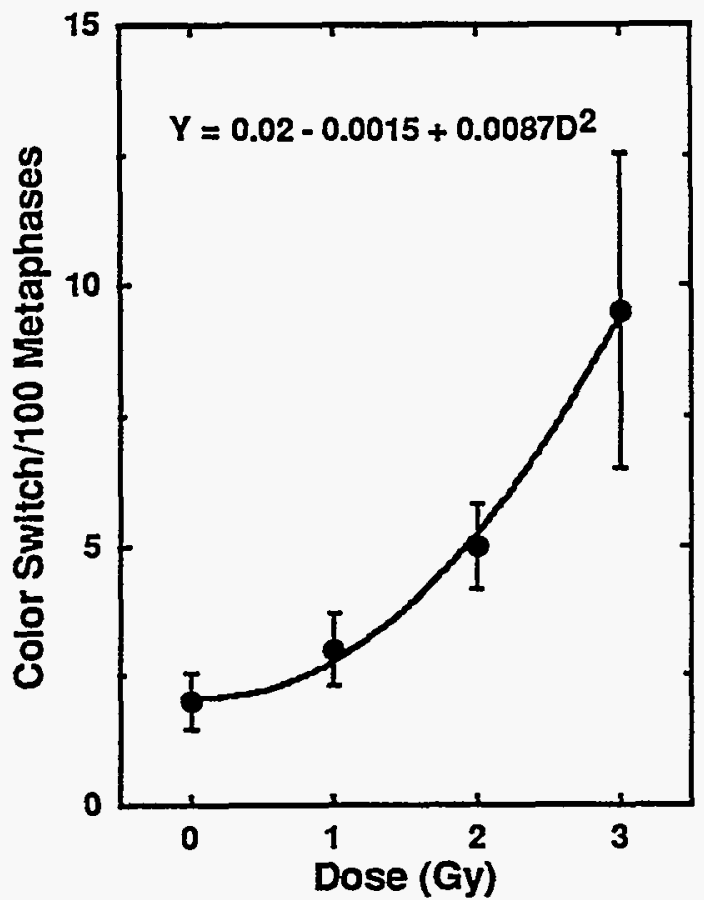

Figure 6. The Dose-Response Relationship for the Induction of Color Junctions in Primary Rat Skin Fibroblasts Exposed to ${ }^{60} \mathrm{Co}$ Gamma Rays. The data is for changes that involve rat chromosome 1 .

\section{References}

Breneman, J.W., J.D. Tucker, G.G. Eveleth, D.A. Lee, J.L. Minkler, M.J. Ramsey, and R.R. Swiger. 1993. The development of chromosome-specific DNA probes for the mouse. Environ. Mol. Mutagen. Suppl. 22:8.

Jostes, R.F., T.E. Hui, A.C. James, F.T. Cross, J. Mencl, J.L. Schwartz, J. Rotmensch, R. Atcher, H.H. Evans, G. Bakale, P.S. Rao. 1991. In vitro radon exposure of mammalian cells: Dosimetric considerations. Radiat. Res. 127:211-219.

Pinkel, D., T. Straume, and J.W. Gray. 1986. Cytogenetic analysis using quantitative, high-sensitivity, fluoresence hybridization. Proc. Natl. Acad. Sci. 83: 2934-2938. 



\section{Molecular Events :During Tumor Initiation}

\section{Principal Investigator: D.L. Springer}

\section{Other Investigators: A.O. Murad and D.B. Mann}

The primary objective of this project is to test the hypothesis that chromatin structure modulates chemical-induced carcinogenesis. Recently, we demonstrated that benzo(a)pyrenediol epoxide (BPDE)induced DNA damage is modulated within nucleosomal DNA. Currently, we are investigating formation of BPDE adducts and their removal from a specific sequence with a well-defined chromatin structure and transcriptional regulation. For this purpose we are using the mouse cell line L1.4-3, with a stably integrated construct consisting of the herpes simplex virus thymidine kinase $(t k)$ gene linked to the mouse mammary tumor virus (MMTV) long terminal repeats (LTR). (This construct is designated LTL.) The $t k$ gene is transcribed from the glucocorticoid-inducible promoter located in the upstream LTR. We have quantitated overall adduct levels and their removal from the genomic DNA in intact cells and in the LTL sequence (as naked DNA) using radiolabeled BPDE and quantitative polymerase chain reaction, respectively. We find that about $50 \%$ of the adducts are removed from genomic DNA in 24 hours. In comparison, indirect measurements using northern blot analysis of the $t k$ gene indicate that transcription from this sequence is inhibited by $>70 \%$ when measured 1 hour after treatment with 4.8 $\mu \mathrm{M}$ BPDE and recovers to $>60 \%$ of control levels (untreated cells) in 24 hours. This inhibition follows single-hit kinetics, suggesting that BPDE adducts to DNA template are directly responsible for this effect.

\section{Introduction}

Benzo[a]pyrene-7,8-diol-9,10-epoxide (BPDE), the ultimate carcinogenic metabolite of benzo[a]pyrene, covalently binds to DNA predominantly at guanine residues. The primary target of covalent modification is through trans addition of ( + -anti-BPDE to the exocyclic amino group of guanines. Covalent adduct formation by BPDE interferes with a number of cellular processes, including DNA replication and transcription, and is thought to be a critical event in tumor initiation. Because most DNA in eukaryotic cells is closely associated with histones, an accurate understanding of carcinogen binding to DNA must consider the role of chromatin structure. Previously, our research was centered around the influence of nucleosome structure on the location and extent of DNA damage. Results from this work demonstrated that the DNA was partially protected from BPDE damage near the center of the nucleosome, and that the rotational setting of the guanines on the helix did not influence carcinogen binding. We now are conducting experiments to investigate the dynamics of adduct formation and the efficiency of their removal from specific genomic sequences for which precise chromatin structure and interaction with transcription factors are known. We are looking at how adduct formation in specific regions of this sequence affects transcription from this sequence, and the time course and mode of removal from these specific regions. For this purpose we have obtained a mouse cell line containing a stably integrated construct derived from mouse mammary tumor virus (MMTV; Zaret and Yamamoto 1984). This construct consists of the MMTV provirus from which most of the viral sequence between the 2 long terminal repeats (LTR) is deleted and replaced by the thymidine kinase $(t k)$ gene from the herpes simplex virus. (The construct is designated LTL; Figure 1.) The mouse L1.4-3 


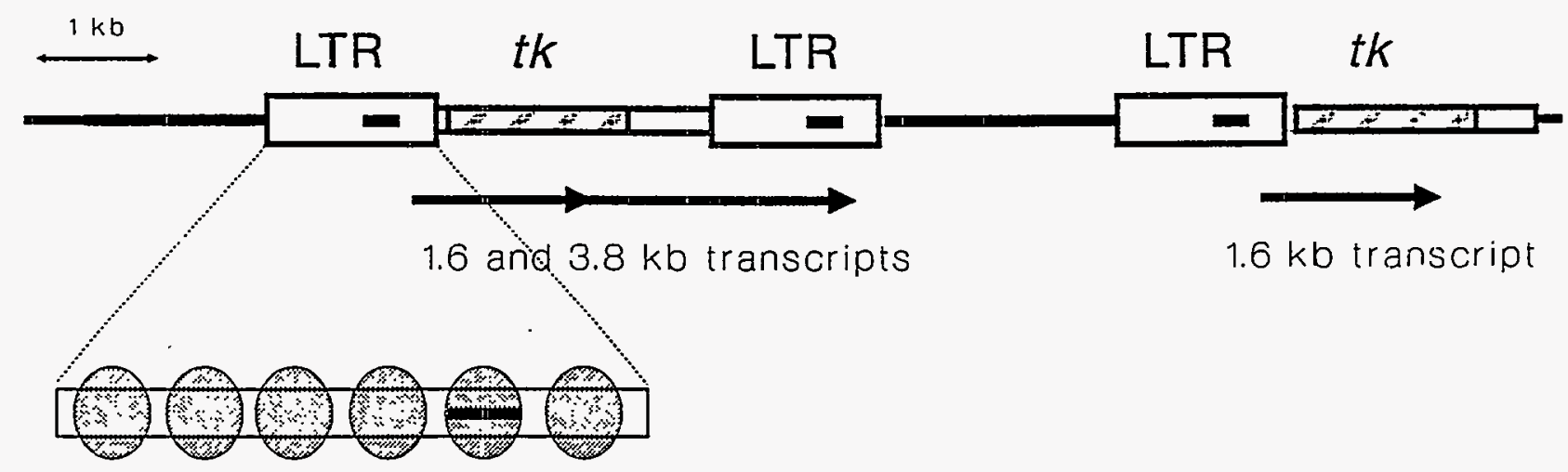

Figure 1. Schematic of the LTL Construct in L1.4-3 Cells. Two transcripts produced from this construct also are shown. The major transcript is the $1.6 \mathrm{~kb}$; the $3.8-\mathrm{kb}$ transcript is a result of a leaky poly $\mathrm{A}$ site in the tk gene. A phased array of 6 nucleosomes is apparent on each of the LTR (Richard-Foy and Hager 1987; Beato et al. 1991).

cell line contains a single $1 \frac{1 / 2}{2}$ tandem copy of this sequence stably integrated into its genome. The $t k$ gene in this construct lacks its own promoter and is transcribed from the glucocorticoid hormone-inducible promoter located in the upstream LTR. Hormone inducibility of transcription from MMTV-LTRs is orchestrated by the precise positioning of 6 nucleosomes (Figure 1) and ensuing changes in chromatin structure in the cells. Structural changes that occur in this sequence after binding of hormone-receptor complex to its cognate sequence have been extensively investigated and reported. It has been shown that one of these nucleosomes is disrupted upon binding the hormone receptor complex. Treatment of cells with the synthetic glucocorticoid hormone, dexamethasone, results in the appearance of a broad DNase-I hypersensitivity and specific DNase-I hypersensitive sites (Zaret and Yamamoto 1984). These results indicate that the chromatin structure actively participates in regulation of transcription. Moreover, features of the chromatin structure that regulate the binding of transcription factors and poise chromatin for different cellular functions may also influence DNA damage and repair processes (Smerdon 1991). While it is known that repair of many genes is coupled to transcription (Selby and Sancar 1994; Smith 1987), recent studies with ultraviolet (UV) photoproducts indicate that the structure the DNA adopts in cells not only influences the damage but also the repair at specific sites and regions (Gao et al. 1994; Lobanenkov et al. 1986; Tornaletti and Pfeifer 1994.). This site- and region-specific repair of damage may not be passive; it may play an important role in maintaining genomic integrity under adverse conditions and, thus, survivability of a cell. Many oncogenes undergo site-specific mutations in order to be activated. The MMTVLTR system provides a unique opportunity to investigate these aspects of DNA damage and repair in the hope of ascertaining the underlying principles governing the mechanism that controls these processes.

\section{Methods/Results}

We determined a useful dose range for BPDE treatment of L1.4-3 cells and the efficiency with which these cells remove resulting adducts from genomic DNA. Cells were incubated with varying concentrations of $\left[{ }^{3} \mathrm{H}\right]-( \pm)$-anti-BPDE in growth medium. After 1 hour of incubation, cells were harvested, lysed in a buffer containing 
sodium dodecyl sulfate (SDS) and treated with proteinase K. DNA was purified by 2 successive ethanol precipitations, and the amount of radioactivity in $50 \mu \mathrm{g}$ of purified DNA from each of the samples was determined by liquid scintillation counting. Exposure of these cells at concentrations from 0 to $10 \mu \mathrm{M}( \pm)$-anti-BPDE produced a linear dose-response curve with a slope of 0.07 adducts $/ \mathrm{kb} / \mu \mathrm{M}$ BPDE (Figure 2A). To determine repair efficiency, cells were treated in a similar manner at BPDE concentrations of 2 and $4 \mu \mathrm{M}$, but they were allowed to repair for various times up to 24 hours in the presence of $2 \mathrm{mM}$ hydroxyurea to suppress replication. We estimate that $>95 \%$ of these cells were able to survive $4 \mu \mathrm{M}$ BPDE treatment in this quiescent state. As can be seen in Figure 2B, at least 50\% of adducts were removed by 24 hours from these cells, in contrast to the repair of UV photoproducts, where only 15 to $20 \%$ were removed from bulk chromatin in 24 hours, as reported by others for rodent cell lines (Smith 1987).

It is important to determine how BPDE adducts that are formed in specific sequences affect the initiation (induction) and elongation of transcription in that sequence. The MMTV model presents an ideal system by providing an "on/off" switch to control transcription externally by addition and removal of glucocorticoid hormone. In the absence of hormone there is a very low level of constitutive transcription (not enough for $t k$ cells to survive in medium containing hypoxanthine, aminopterin, and thymidine), which increases more than 50-fold upon addition of the synthetic glucocorticoid hormone, dexamethasone. Moreover, since $t k$ mRNA belongs to the short-lived class of RNA, with a half-life of only 55 minutes, northern blot analysis of $t k$ mRNA can be used to directly analyze rates of transcription from this sequence. Figure 3 contains the data for one such experiment, in which cells were incubated with various concentrations of (t)-anti-BPDE for 1 hour; then $t k$ mRNA transcription was induced by growing cells in the presence of dexamethasone for an additional 1-hour period. At this time cells were immediately lysed in a guanidine thiocyanate lysis buffer, and total cellular RNA was isolated and analyzed by northern blot analysis. The linearity of dose-dependent
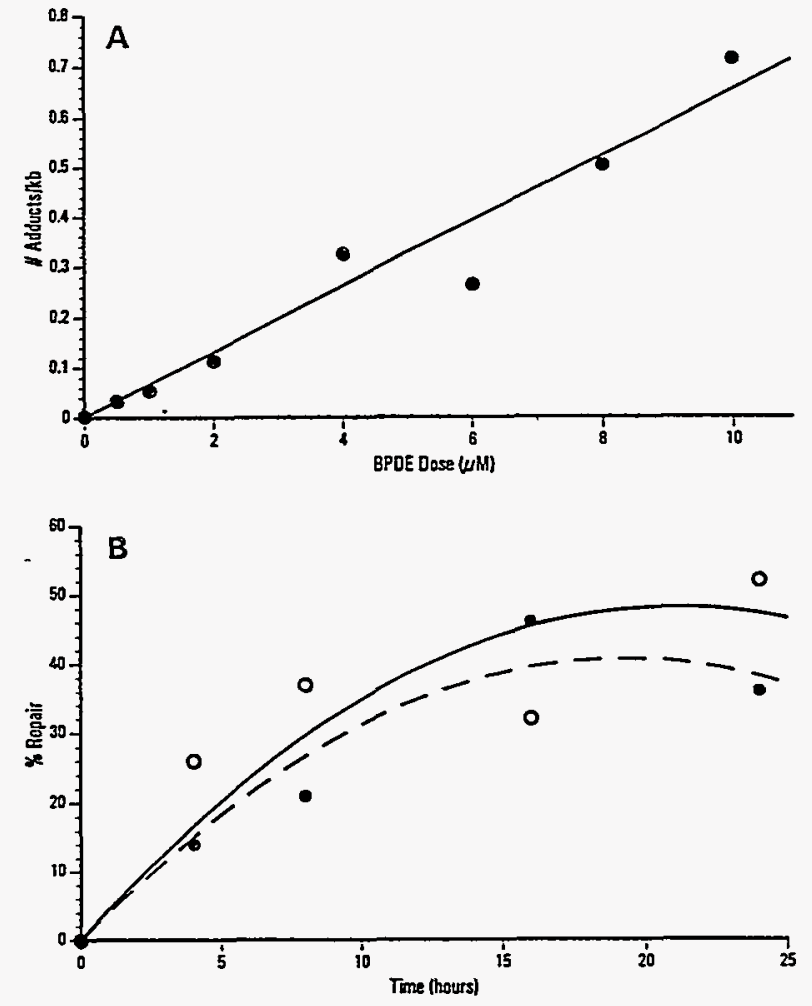

Figure 2. Analysis of Benzo(a)Pyrenediol Epoxide (BPDE) Adducts in Genomic DNA and Overall Rate of Repair. (A) Dose-response curve obtained by incubating cells with varying concentrations of $\left[{ }^{3} \mathrm{H}\right]$-labeled $( \pm)$-anti-BPDE. Amount of radioactivity incorporated in DNA was used to calculate adduct levels in genomic DNA. (B) Time course for removal of these adducts from bulk genomic DNA of cells. Cells were incubated in $2 \mathrm{mM}$ hydroxyurea to block replication during repair incubation.

inhibition of $t k$ mRNA on a log scale is indicative of single-hit kinetics. This suggests that inhibition of transcription of the $t k$ gene is a direct result of adducts formed in the sequence required for transcription and is not due to secondary effects, such as damage to proteins or other factors required for transcription.

When the cells were allowed to repair in a quiescent state, the $t k$ mRNA levels returned to near control level (unadducted) within 24 hours, indicating removal of adducts from the DNA template (Figure 4). This recovery appears to be more rapid than repair to the bulk DNA (see Figure 2B), suggesting that the transcriptionally active $t k$ gene may be repaired preferentially (as 


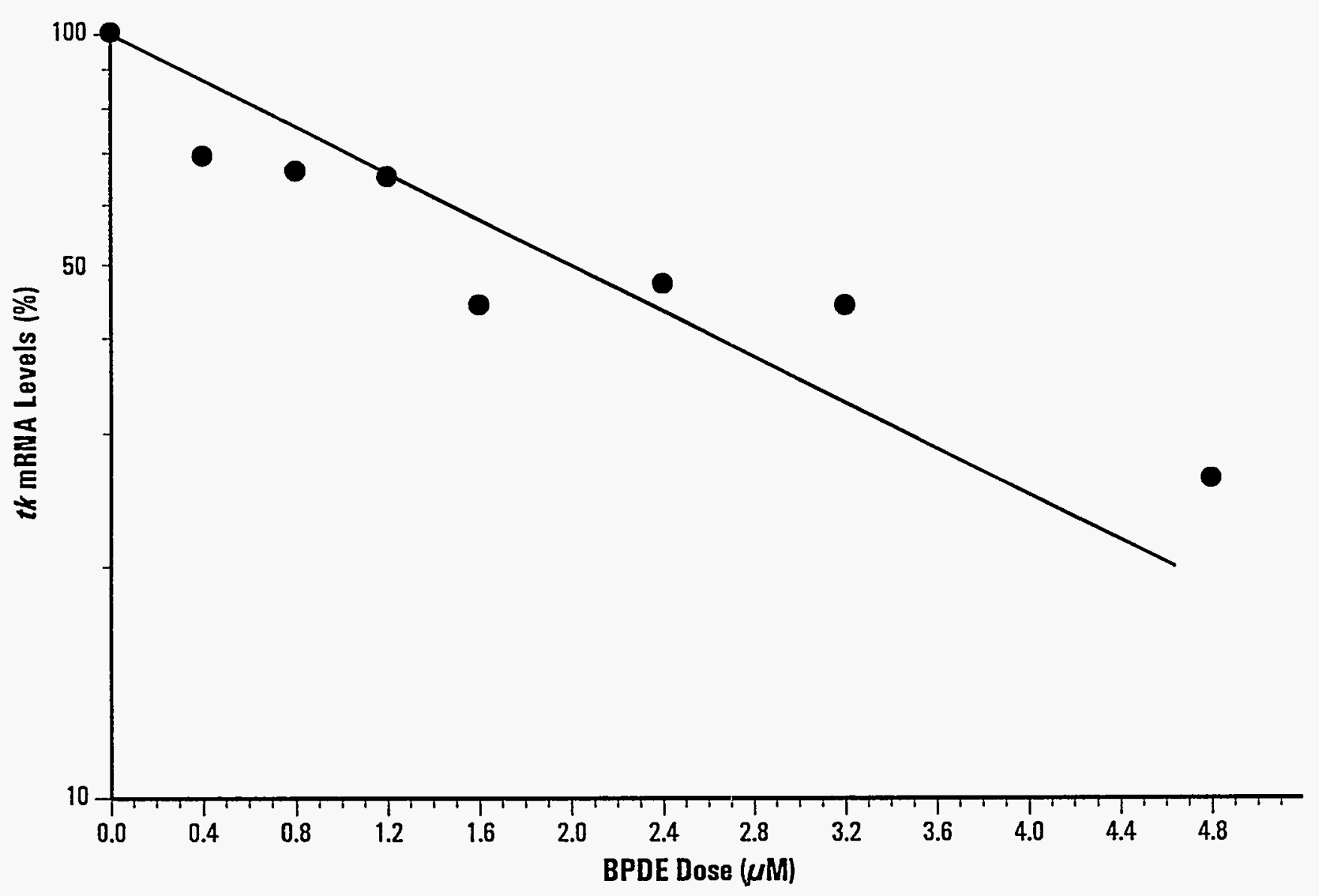

Figure 3. Inhibition of tk Gene Transcription with BPDE Treatment. L1.4-3 cells were incubated with 0-4.8 $\mu M(+)$-antiBPDE for 1 hour. Cells then were washed with phosphate-buffered seline and incubated in growth medium containing $0.1 \mu \mathrm{M}$ dexemethasone for 1 hour to induce transcription. Cells then were immediately lysed in a guanidine thiocyanate lysis buffer on the plate. Total cellular RNA was isolated and analyzed by northern blot analysis using digoxygenin-labeled RNA probe complementary to tk mRNA.

has been shown for UV photoproducts). We currently are adapting quantitative polymerase chain reaction (QPCR) methods to obtain definitive quantitative data on site-specific damage levels and to directly follow removal of adducts from template DNA in the induced and uninduced state after treatment (or in the absence of treatment) with dexamethasone.

Analysis of the sequence for the LTL region indicates that the $t k$ region is highly guanine/ cytosine (GC)-rich (65\%) containing many tracks of Gs. Other investigators have reported that flanking bases modulate the efficiency of BPDE adduct formation at specific sites and have found higher frequencies of adducts at guanines that occur in tracks of Gs (Lobanenkov et al. 1986). It will be interesting to determine if the inhibition of $t k$ transcription is due solely to adducts in the pathway of RNA polymerase on template DNA (elongation), or whether it is influenced by adducts in the promoter region (initiation) required for interaction with the hormonereceptor complex and transcription factors. Initial studies measuring BPDE adducts to DNA in vitro using QPCR indicate higher levels of adducts in the $t k$ region compared to those in the LTR, as predicted from sequence analysis (Figure 5). Studies are in progress to measure adduct levels to LTR and $t k$ regions of the DNA 


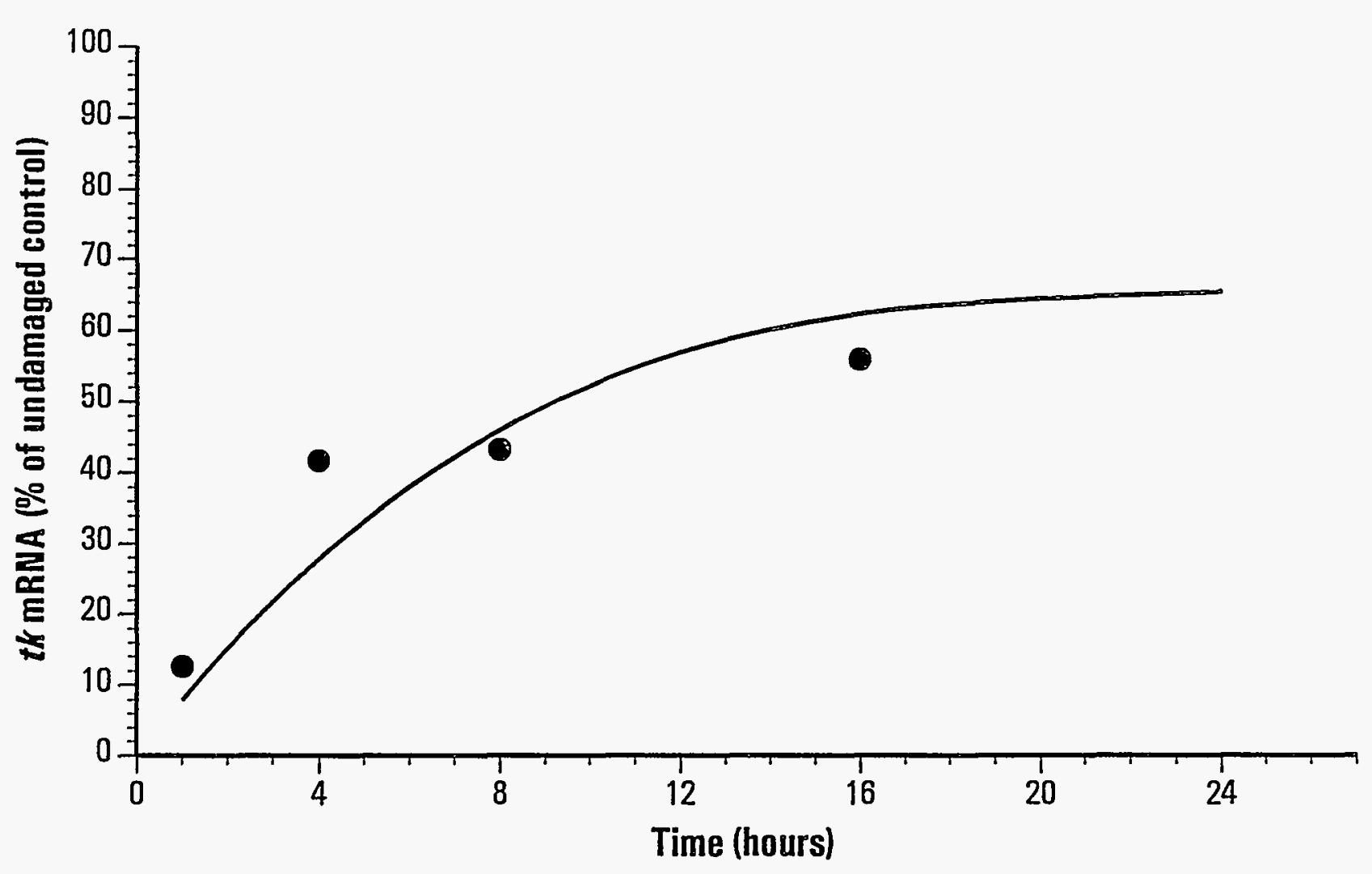

Figure 4. Time Course of Recovery of tk mRNA after Treatment with BPDE. Cells were treated in a manner identical to that described in Figure 3 except that a single concentration of BPDE (4.8 $\mu \mathrm{M}$ ) was used, and cells were allowed to repair for up to 24 hours in the presence of dexamethasone and $2 \mathrm{mM}$ hydroxyurea (to block replicative synthesis).

in intact cells using QPCR. A similar approach will be used to directly determine rates of repair in these regions. In addition, the technique of ligation-mediated PCR is being adapted to measure adducts at specific sites at the nucleotide level of resolution and the rates of their repair under different transcriptional states (i.e., with and without hormonal induction).

\section{References}

Beato, M., B.U. Brüggemeier, G. Chalepakis, R.J.G. Hache, M. Kalff, B. Piña, M. Schauer, E.P. Slater, and M. Truss. 1991. Characterization of DNA receptor interactions. In: Nuclear Hormone Receptors: Molecular Mechanisms, Cellular Functions, Clinical Abnormalities, M.G. Parker (ed), pp. 197-215. Academic Press Inc., San Diego.

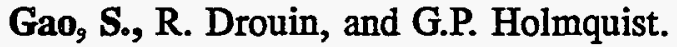
1994. DNA repair rates mapped along human $P G K I$ gene at nucleotide resolution. Science 263:1436-1438.

Lobanenkov, V.V., M. Plumb, G.H. Goodwin, and P.L. Grover. 1986. Effect of neighbouring bases on G-specific DNA cleavage mediated by treatment with the anti-diol epoxide of benzo[a]pyrene in vitro. Carcinogenesis 7:689-1695.

Richard-Foy, H., and G.L. Hager. 1987. Sequence-specific positioning of nucleosomes over the steroid-inducible MMTV promoter. EMBO J. 6:2321-2328.

Selby, S.P., and A. Sancar. 1994. Mechanism of transcription-repair coupling and mutation frequency decline. Microbio. Rev. 58:317-329. 

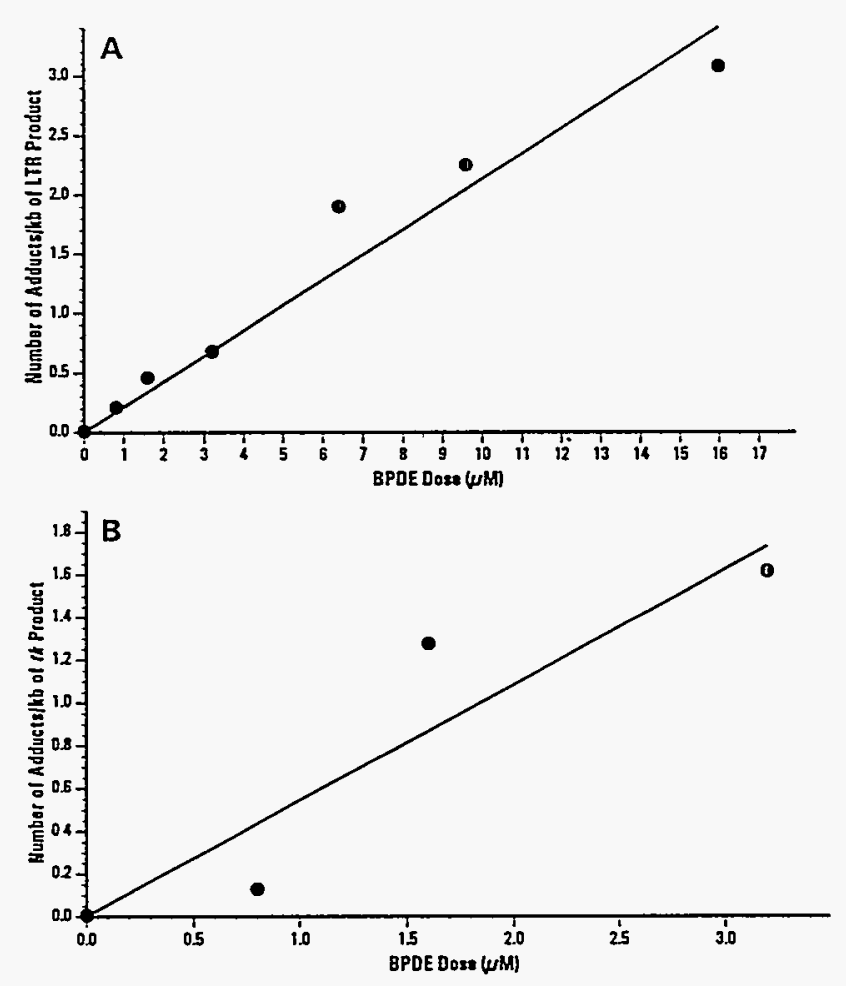

Figure 5. Quantitative Polymerase Chain Reaction (QPCR) Analysis of BPDE Adducts in LTL. Plasmid DNA containing the LTL construct was incubated with various concentrations of $(+)$-anti-BPDE, extracted with phenol/chloroform to remove reaction degradation products, and precipitated with ethanol. Two nanograms of this template were amplified using primers specific to LTR or the tk regions. Unadducted template that amplifies a smaller fragment using the same set of primers was used as an internal control to adjust for efficiency of amplification and gel loading variability. The PCR product was separated on $2 \%$ agarose gels and ethidium staining bands were quantified by video densitometry. (A) PCR with primers specific to the LTR region, resulting in a $1.0-\mathrm{kb}$ product. (B) The same template with primers specific for the tk gene region, resulting in a $1.4 \mathrm{~kb}$ product. (Quantitation of the $t k$ product was not normalized to a control fragment.)
Smerdon, M.J. 1991. DNA repair and the role of chromatin structure. Curr. Opinion Cell Biol. 3:422-428.

Smith, C.A. 1987. DNA repair in specific sequences in mammalian cells. J. Cell Sci. Suppl. 6:225-241.

Tornaletti, S., and G.P. Pfeifer. 1994. Slow repair of pyrimidine dimers at $p 53$ mutation hotspots in skin cancer. Science 263:1436-1438.

Zaret, K.S., and K.R. Yamamoto. 1984. Reversible and persistent changes in chromatin structure accompany activation of glucocorticoiddependent enhancer element. Cell 38:29-38. 


\title{
Biochemistry of Free Radical-Induced DNA Damage
}

\author{
Principal Investigator: A. F. Fuciarelli \\ Other Investigators: E.C. Sisk, J.H. Miller, C.G. Edmonds, R.D. Smith, \\ and D.L. Springer
}

The complementary efforts of characterizing molecular mechanisms underlying free radical-induced DNA damage and developing biochemical methods to examine DNA damage and the rates of repair of such damage in DNA extracted from cells will be important in understanding biological consequences following exposure to energy-related by-products. Differences in levels of DNA damage at critical stages in the cell cycle can result from variations in chromatin structure, in intracellular scavenger and potentiator concentrations, and in rates of repair. Reduced efficiency for repair of damage, whether due to the inability to excise unique types of lesions or due to other factors that modify repair, can result in elevated mutation frequencies which can be correlated with increased tumor incidence. This effort is ultimately aimed at addressing differences in susceptibility of cell populations to energy-related environmental insult, and to uncover the influence of intrinsic or extrinsic factors following such exposure.

\section{Introduction}

Mutagenesis, carcinogenesis, and cell death result from a sequence of events initiated by the deposition of ionizing radiation in living cells. DNA damage is a critical step in this process. Despite extensive work focused on developing analytical methods to assess molecular damage to DNA bases, efforts have revealed little information regarding: (1) the spectrum of modifications to DNA occurring in the irradiated cell at nonlethal doses, (2) the potential for transfer of radiation damage along DNA, (3) the spectrum of damage induced as a function of LET, (4) the removal/repair rates of specific DNA lesions, or (5) the efficiency of these lesions at producing the ultimate biological effect. Little information also exists regarding how DNA damage resulting from exposure to ionizing radiation differs from free radical-induced DNA damage caused by oxidative stress, even though both mechanisms produce identical molecular modifications. In this brief review, two areas of work our laboratory has been involved with will be highlighted: our analysis of the molecular mechanisms underlying free radical-induced DNA damage, and our latest efforts to develop biochemical and analytical methods to examine damage in DNA extracted from cells exposed to ionizing radiation. Both areas of our program complement efforts to achieve analysis of relevant types of DNA damage at low exposure doses and to correlate the spectrum of damage observed with biological inactivation. In future studies, we will search for potential differences in the initial production of damage due to intrinsic factors such as chromatin structure, intracellular scavengers (i.e., sulfydryl-containing compounds and polyamines), and intracellular potentiators (i.e., peroxides and trace metals). We also will examine differences in the rates of repair of selected lesions in repairproficient and repair-deficient cells in an effort to address differences in genetic susceptibility of cell populations to environmental insult.

Highly reactive free radicals are generated by normal metabolic processes in living cells and by exposure to environmental insults such as ionizing radiation. As part of a long-standing effort to understand the mechanistic basis for the biological effects of free radicals on cells, our group continues to be involved in the analysis of free radical-induced DNA damage resulting from exposure to physical (e.g., ionizing radiation and ultrasonic cavitation) and chemical (e.g., hydrogen peroxide) agents. Exposure to ionizing radiation leads to strand breaks (double and single), cross links (DNA-DNA and DNA-protein), and modifications to the deoxyribose and base constituents in DNA and chromatin. We 
have intensively studied the product distribution for base damage (Fuciarelli et al. 1989;

Fuciarelli et al. 1990), intramolecular cross linking (Fuciarelli et al. 1987; Miaskiewicz et al. in press) and intermolecular cross linking with proteins (Fuciarelli et al. 1987; Weir et al. 1994; Weir-Lipton et al. submitted), and the process underlying electron migration along DNA (see below) in an effort to understand the consequences of exposure, and to establish the mechanistic basis for biological consequences. Although modifications to the purine and pyrimidine constituents in DNA by free radical-generating agents are removed/repaired by specific enzymatic mechanisms, it is possible that the rate of removal/repair of such lesions can vary by orders of magnitude. Understanding which lesions persist in biologically active DNA requires a mechanistic understanding of free radical-induced damage to DNA, as well as development of methods to assay specific types of DNA damage at biologically relevant doses in mammalian cells.

\section{Recent Progress in Understanding the Mechanistic Basis of DNA Damage Underlying Potentially Relevant Biological Endpoints}

Free radical-induced damage to DNA following exposure to ionizing radiation is uniquely different in several respects as compared to oxidative DNA damage resulting from normal metabolic processes or from exposure to other physical agents such as ultrasonic cavitation (Fuciarelli et al. 1995) or chemical agents such as hydrogen peroxide (Blakely et al. 1990). The types of free radical species involved are more extensive with ionizing radiation, including both radical $\left(\cdot \mathrm{OH}, \mathrm{e}_{\mathrm{aq}}^{-}, \cdot \mathrm{H}, \mathrm{O}_{2}^{-}\right)$and molecular $\left(\mathrm{H}_{2} \mathrm{O}_{2}\right.$, $\mathrm{H}_{2}$ ) species. Perhaps the most significant difference is related to the spatial distribution underlying radical formation. Ionizing radiation creates locally multiply damaged sites in DNA, where damage is clustered within a distance of less than 20 base pairs. Other types of oxidative stress (e.g., hydrogen peroxide) result in only singly damaged sites, which are spaced at much greater distances along the DNA (Ward 1991). In cells, singly damaged sites on DNA would be much easier to repair by enzymatic processes than multiply damaged sites such as those generated by exposure to ionizing radiation (and, as we suggested in Fuciarelli et al. 1995, ultrasonic cavitation). Multiply damaged sites in DNA demand a significantly more complex form of enzymatic processing. Damage to both strands of DNA can leave areas of DNA without appropriate template for repair synthesis. DNA repair enzymes may also encounter problems, and stall or fall off the damaged strand, as they attempt to read through extensively damaged areas of the genome.

\section{Damage Characterization: Exposure to Ionizing Radiation Leads to Unique Lesions}

Identical DNA base products are formed during normal metabolism (Fuciarelli et al. 1989), and following exposure to ionizing radiation (Fuciarelli et al. 1989, 1990), hydrogen peroxide (Blakely et al. 1990), and ultrasonic cavitation (Fuciarelli et al. 1995). Several different repair enzymes have evolved to eradicate such damage from replicating DNA, thereby preserving genetic integrity. However, DNA damage resulting from exposure to ionizing radiation is also quite unique in two respects. Firstly, classes of DNA damage result from the influence of several different types of radical and molecular products interacting within a very localized area surrounding DNA. Examples of these types of damage include intramolecular cross-linking reactions that lead to $8,5^{\circ}$-cyclodeoxynucleotides (Fuciarelli et al. 1987; Miaskiewicz et al. in press) and intermolecular cross-linking reactions with proteins (Gajewski et al. 1988; Weir et al. 1994; Weir-Lipton et al. submitted) that are characteristically formed following exposure to ionizing radiation and for which repair pathways have not been elucidated. These cross-linking reactions continue to generate interest within our group for three reasons: the mechanism underlying formation of these products is characteristic for exposure to ionizing radiation, the lesions involve structural distortions to the DNA/chromatin complex, and mechanisms for removing/repairing these lesions have not been elucidated.

Secondly, as a result of the high local concentrations of radical and molecular products, DNA 
damage resulting from ionizing radiation occurs in multiply damaged areas. This clustering of damage presents repair enzymes with a complex substrate, which is not characteristic of other types of oxidative processes.

In the case of radiation-induced intramolecular cross-linking reactions in DNA, recent molecular modeling efforts (Miaskiewicz et al. in press) complement experimental efforts, thus establishing preference in the stereochemistry leading to formation of isomeric forms of the lesion in DNA. In the case of intermolecular DNA-protein cross-linking reactions, our recent collaborations have led to application of electrospray ionization mass spectrometry to the detection of thymine-tyrosine cross links (Weir et al. 1994; Weir-Lipton et al. submitted). The notable feature of the intra- and intermolecular crosslinked lesions is exemplified in collaborative research efforts by the ability to detect such damage at doses as low as $0.1 \mathrm{~Gy}$ in irradiated model systems (Weir-Lipton et al. submitted). Unlike the aforementioned hydroxylated DNA base products, detection of these cross-linked products is not encumbered by relatively high levels of background damage present in DNA extracted from cells with no particular attention to minimizing oxidation.

Our efforts to prevent oxidative damage during DNA isolation from cells is described in this report, and this effort will continue, because post-exposure DNA damage represents a major area of concern regarding analysis of damage in exposed cells. Additionally, exploring new analytical techniques for measuring DNA damage remains a significant avenue of investigation; through collaborative efforts, we are exploring on-line liquid chromatography-electrospray ionization mass spectrometry (Weir-Lipton et al. 1994), and on-line capillary zone electrophoresis- and reversed capillary isotachophoresiselectrospray ionization mass spectrometry (Zhao et al. in press).

\section{Mechanistic Processes: Radiation-Induced Electron Migration Along DNA}

Radiation-induced electron migration along DNA is a mechanism by which randomly produced energy deposition events lead to nonrandom types of damage manifested distal to the sites of the initial energy deposition. Solvated and unsolvated electrons, uniquely generated following exposure to ionizing radiation, can be captured by purine and pyrimidine bases in DNA; these electrons subsequently "tunnel" along DNA in the overlapping pi-electron system created by the stacked bases (reviewed by Fuciarelli et al. 1994b).

Our recent work has led to significant advancements in understanding electron migration in DNA. Radiation-induced electron migration in nucleic acids has been examined using DNA and synthetic oligonucleotides containing 5-bromouracil (5-BrU) (Beach et al. 1994; Fuciarelli et al. 1994a; Fuciarelli et al. 1994b; Fuciarelli et al. submitted ${ }^{b}$ ). In aqueous solution, interaction of $5-\mathrm{BrU}$ with solvated electrons results in release of bromide ions and formation of highly reactive uracil-5-yl radicals capable of capturing hydrogen atoms from substrates in the irradiated solution. In irradiated solutions of 5-BrU, stoichiometric release of bromide ion and formation of uracil occurs (Fuciarelli et al. submitted $^{a}$ ); that is, within experimental error all solvated electrons that form during water radiolysis yield bromide ions and uracil. Monitoring either bromide ion release or uracil formation provides an opportunity to study electron migration processes in model nucleic acid systems. Although there is a decrease in reaction rates between electrons and oligonucleotides, as compared to the 5-BrU irradiated as a monomer in solution, $5-\mathrm{BrU}$ is a useful probe of electron interactions in nucleic acids.

Using this approach we have discovered that electron migration along oligonucleotides is significantly influenced by base sequence and strandedness Fuciarelli et al. 1994a). For example, in irradiated single-stranded oligonucleotides the yield of uracil decreased in the following order: $\mathrm{A}>\mathrm{T}>>\mathrm{C} \approx \mathrm{G}$. However, in irradiated double-stranded oligonucleotides, the yield of uracil decreased as follows: $\mathrm{G}>\mathrm{C} \approx \mathrm{T}>\mathrm{A}$. These differences in the ability of electrons to migrate along DNA were attributed to competing proton transfer reactions occurring within DNA base pairs and between DNA and bulk solvent (Fuciarelli et al. 1994a). Migration along 7 base pairs in oligonucleotides containing guanine bases also was observed for oligonucleotides 
irradiated in solution (Fuciarelli et al. 1994a), which compares to average migration distances of 6 to 10 bases for Escherichia coli DNA irradiated in solution and 5.5 base pairs for $E$. coli DNA irradiated in cells (Beach et al. 1994). Evidence also suggests that electron migration occurs preferentially in the $5^{\circ}$ to $3^{\prime}$ direction along a double-stranded oligonucleotide containing a region of purine bases adjacent to the 5-BrU moiety (Fuciarelli et al. submitted ${ }^{b}$ ).

Electron migration is an important process underlying the distribution of radiation damage in DNA, and may be the mechanism causing a nonrandom distribution of DNA damage following energy deposition by stochastic processes. Electron migration at the site of a locally multiply damaged area of DNA can potentiate damage by enhancing the yield of double-strand breaks as a result of migration of radiation damage along one strand of DNA to a position opposite a single-strand break in the complementary strand. Such a mechanism is consistent with the observed enhancement in the radiosensitivity of cells containing 5-BrU-substituted DNA. (For a review see Beach et al. 1994.)

\section{Application of Biochemical and Analytical Techniques for the Assessment of DNA Damage to Cells}

To accurately assess initial levels of DNA damage, it is critical to refine techniques to assay free radical-induced DNA damage, with emphasis on developing methods that limit oxidative damage, and to understand repair processing. Moreover, appropriate protocols must be in place to determine the repairability and repair kinetics of specific radiation-induced products from cellular DNA in an effort to investigate the relationship between DNA damage and genetic susceptibility. Evaluation of several different strategies for isolation of DNA from cells exposed to ionizing radiation is occurring now in our laboratory, and development of efficient protocols that will be used to characterize the influence of intrinsic and extrinsic factors influencing repair rates will ultimately result from this important effort.

Reports have indicated that techniques involving phenol extraction potentiate auto-oxidation of nucleic acids (Mouret et al. 1990). Alternative approaches to nucleic acid isolation are therefore necessary to extend assays of cellular DNA damage into the lower dose region. In an effort to achieve more successful protocols, we have compared DNA/chromatin isolation techniques involving phenol/chloroform (Mouret et al. 1990), salt extraction (Gajewski et al. 1990), and precipitation through Qiagen ${ }^{\text {Th }}$ columns. Whereas phenol/chloroform extractions generally produced significantly higher background levels of hydroxylated bases, and salt extraction remained a very labor-intensive adventure, isolation of cellular DNA through Qiagen ${ }^{\text {tst }}$ columns was rapid (4 hours), consistently quantitative, and potentially the least likely technique for postexposure hydroxylation of DNA bases. Continued work is necessary, however, to refine this protocol for extraction of cellular DNA for mass spectrometric analysis, with necessary improvements in the sequestration of peroxides potentially liberated during the initial disaggregation of the cells. We also believe that maintenance of a controlled nitrogen atmosphere during subsequent DNA handling will aid in reducing hydroxylated DNA bases.

\section{Future Directions: Combining Mechanistic Knowledge and Techno- logical Developments to Evaluate Individual Susceptibility to Energy- Related Environmental Exposures}

Cells deficient in the repair of DNA damage have elevated mutation frequencies; this condition can cause mutated oncogenes or tumor suppressor genes, which potentially leads to increased tumor incidence. The frequency of mutation at any site along DNA is dependent upon damage frequency and the efficiency of repair. Damage frequency is a consequence of (1) physical factors such as energy transfer; (2) chemical factors including intracellular scavengers (e.g., sulfydryl-containing compounds and polyamines) and intracellular potentiators (e.g., peroxides and trace metals); and (3) biological factors such as chromatin structure and repair processing. Our efforts to establish the mechanistic basis for induction of DNA damage and to characterize specific types of 
modifications have laid the groundwork for addressing the biological consequences of exposure. In future studies, we will investigate repair rates of selected lesions in repair-proficient and repair-deficient cells in an effort to address differences in genetic susceptibility of cell populations to environmental insult as a result of intrinsic or extrinsic factors. A major first step, which has yet to be categorically achieved and rigorously tested by any group, is measurement of repairability and repair rates of molecular damage in genomic DNA. Reduced efficiency for DNA repair can be the result of 1) unique free radical-induced lesions which challenge the normal complement of repair enzymes; 2) structural characteristics of the lesion(s); 3) spatial distribution of damage (i.e., formation of locally multiply damaged sites); and 4) biochemical conditions which limit efficient repair activity. Ultimately, our goal is to correlate damage production and differences in the rates of repair of selected lesions in cells in an effort to determine whether there are differences in genetic susceptibility to environmental insult.

\section{References}

Beach, C., A.F. Fuciarelli, and J.D. Zimbrick. 1994. Electron migration along 5-bromouracil-substituted DNA irradiated in solution and in cells. Radiat. Res. 137:385-393.

Blakely, W.F., A.F. Fuciarelli, B.J. Wegher, and M. Dizdaroglu. 1990. Hydrogen peroxide-induced base damage in deoxyribonucleic acid. Radiat. Res. 121:338-343.

Fuciarelli A.F., F.Y. Shum, and J.A. Raleigh. 1987. Intramolecular cyclization in irradiated nucleic acids. Correlation between high-performance liquid chromatography and an immunochemical assay for $8,5^{\prime}$-cycloadenosine in irradiated poly A. Radiat. Res. 110:35-44.

Fuciarelli A.F., B.J. Wegher, E. Gajewski, M. Dizdaroglu, and W.F. Blakely. 1989. Quantitative measurement of DNA base products using gas chromatography-mass spectrometry. Radiat. Res. 119: 219-231.

Fuciarelli A.F., B.J. Wegher, W.F. Blakely, and M. Dizdaroglu. 1990. Yields of radiationinduced base products in DNA: Effects of DNA conformation and gassing conditions. Int. $J$. Radiat. Biol. 58:397-415.
Fuciarelli, A.F., E.C. Sisk, and J.D. Zimbrick. 1994a. Electron migration in oligonucleotides upon gamma-irradiation in solution. Int. J. Radiat. Biol. 65:409-418.

Fuciarelli, A.F., E.C. Sisk, J.H. Miller, and J.D. Zimbrick. 1994b. Radiation-induced electron migration along DNA. Int. J. Radiat. Biol. 66:505-509.

Fuciarelli, A.F., E.C. Sisk, R.J. Thomas, and D.L. Miller. 1995. Induction of base damage in DNA solutions by ultrasonic cavitation. Free Radical Biol. \& Med. 18(2):231-238.

Fuciarelli, A.F., D.A. Jett, J.L. Grady, E.C. Sisk, M.K. Bowman, and J.D. Zimbrick. Hydrogen atom donation in irradiated solutions containing 5-bromouracil and in 5-bromouracilsubstituted oligonucleotides. PNL-SA-23655, Pacific Northwest Laboratory, Richland, Washington. Radiat. Res. (submitted ${ }^{a}$ ).

Fuciarelli, A.F., E.C. Sisk, L.E. Matson, J.H. Miller, and J.D. Zimbrick. Preferential migration of electrons in the $5^{\circ}$ to $3^{\prime}$ direction along DNA. PNL-SA-25316, Pacific Northwest Laboratory, Richland, Washington. Int. J. Radiat. Biol. (submitted ${ }^{b}$ ).

Gajewski, E., A.F. Fuciarelli, and M. Dizdaroglu. 1988. Structure of hydroxyl radical-induced DNA-protein cross-links in calf thymus nucleohistone in vitro. Int. J. Radiat. Biol. 54:445-459.

Gajewski, E., G. Rao, Z. Nackerdien, and M. Dizdarolgu. 1990. Modification of DNA bases in mammalian chromatin by radiationgenerated free radicals. Biochemistry 29:78767882.

Miaskiewicz, K., J.H. Miller, and A.F. Fuciarelli. Theoretical analysis of DNA intrastand cross linking by formation of $8,5^{\circ}$-cyclodeoxyadenosine. Nucleic Acids Res. (in press).

Mouret, J.-F。, M. Polverelli, F. Sarazini, and J. Cadet. 1990. ${ }^{32}$ P-Postlabelling measurement of adenine $\mathrm{N}-1$ oxide in cellular DNA exposed to hydrogen peroxide. Chem. Res. Toxicol. 3:102-110.

Ward, J.F. 1991. Mechanisms of radiation action on DNA in model systems--their relevance to cellular DNA. In: The Early Effects of Radiation on DNA (E.M. Fielden and P. O'Neill, 
eds.) NATO ASI Series Vol. H 54, SpringerVerlag, Berlin.

Weir, M.S., D.L. Springer, A.F. Fuciarelli, B.D. Thrall, and C.G. Edmonds. 1994. Characterization of natural and radiation-induced modifications of histones. Techniques in Protein Chemistry, V, (J. W. Crabb, ed.), pp. 115-122. Academic Press, New York.

Weir-Lipton, M.S., A.F. Fuciarelli, D.L. Springer, and C.G. Edmonds. Radiationinduced nucleobase-amino acid crosslinks in peptide and histone systems. PNL-SA-25743A Pacific Northwest Laboratory, Richland, Washington. Radiat. Res. (submitted).

Zhao, Z., J.H. Wahl, H.R. Udseth, S.A. Hofstadler, A.F. Fuciarelli, and R.D. Smith. On-line capillary electrophoresis-electrospray ionization mass spectrometry of nucleotides. Electrophoresis (in press). 


\title{
Radon Hazards in Homes
}

\section{Principal Investigator: F.T. Cross}

\author{
Other Investigators: R.L. Buschbom, G.E. Dagle, and R.A. Gies
}

\section{Technical Assistance: C.R. Petty}

This project identifies and quantifies, in experimental animals, the major biological effects and factors that produce diseases in the respiratory system and other organs in radon-exposed populations in mines and homes. Histopathological analyses have been completed on rats exposed to 40 working-level months (WLM; see footnote d, Table 1) of radon progeny, at 100-working-level (WL; see footnote d, Table 1) concentrations, in combination with uranium ore dust. Changes related to radon-progeny exposure included a $2.4 \%$ incidence of primary lung tumors; excluding osteosarcomas, which cannot be unequivocally assigned as primary to the lung, the incidence reduced to $2.0 \%$. Other primary tuimors of the respiratory tract were limited to the nose. An updated statistical risk analysis of lung tumors in approximately 2800 exposed rats and 490 controls produced a slightly lower lung-tumor risk coefficient [260 per million rats per WLM (260 per $10^{6}$ WLM)] than reported previously ( 300 per $10^{6}$ WLM), but still comparable to estimated lifetime risks in underground miners. Because cell proliferation is generally accepted to play a vital role in carcinogenesis, cell proliferation rates in the bronchibronchiolar region of Wistar rats were measured following exposure to 174 WLM radon progeny and $0.2-\mu \mathrm{m}$-diameter wax carrier aerosols. Preliminary data showed that labeling indices in thoracic airways of exposed rats can be $1 \frac{1 / 2}{2}$ to 2 times higher than in control rats. The highest ratios occurred in the bronchioles.

Lung cancer incidence and deaths from degenerative lung disease are significant among uranium miners, who often are exposed to high levels of radon, but the cause-effect relationships for these diseases are based on data insufficient to determine risks of public exposures to radon. More recent data on humans suggest that radon also is implicated in other organ diseases, although strong confirmatory data are lacking in animal systems. This project has identified agents or combinations of agents (both chemical and radiological), and their exposure levels, that produced lesions in the respiratory tract and other organs in mine-simulation experiments. The project's current emphiasis is on completion of the historical mine-simulation series of experiments, including the low-exposure experiments that also are relevant to radon exposures in homes.

\section{Wistar Rat Exposure Protocols}

The 6000 and 7000 Series mine-simulation experiments (Table 1) were designed to develop the relationships between response and exposure to radon progeny, at two rates of exposure, and carnotite uranium ore dust. The radon-progeny exposure rate in the 6000 Series was 1000 working levels (WL) and in the 7000 Series, 100 WL. The 8000 Series mine-simulation experiments (100 WL; Table 2) were designed to extend the exposure-response relationships to cumulative exposure levels comparable to current conditions in uranium mines, and to lifetime environmental exposures. This study continues with a histopathological analysis of the remaining low-exposure animals. The 9000 Series minesimulation experiments (Table 3 ) continued the "low-dose" studies at exposure rates comparable to former occupational working levels (10 WL). These experiments help to evaluate the hypothesis that sublinear risk relationships exist at low exposure levels and low exposure rates. In addition, concurrent exposures to varying levels of uranium ore dust also test the hypothesis that irritants (both specific and nonspecific) act synergistically with radiation 
Table 1. High Exposure-Response Relationship Study for Radon-Progeny Carcinogenesis in Rats (6000 and 7000 Series Experiments)

Number of Animals $(a)$

\begin{tabular}{|c|c|c|c|}
\hline 6000 Series & 7000 Series & Exposure Regimen ${ }^{(b, c)}$ & Total Exposure, WLM ${ }^{(d)}$ \\
\hline 64 & 0 & $\begin{array}{l}1000 \mathrm{WL}^{(\mathrm{d})} \text { radon progeny } \\
15 \mathrm{mg} / \mathrm{m}^{3} \text { uranium ore dust }\end{array}$ & 10,240 \\
\hline 56 & 32 & $\begin{array}{l}1000 \mathrm{WL} \text { radon progeny } \\
15 \mathrm{mg} / \mathrm{m}^{3} \text { uranium ore dust }\end{array}$ & 5120 \\
\hline 56 & 32 & $\begin{array}{l}1000 \mathrm{WL} \text { radon progeny } \\
15 \mathrm{mg} / \mathrm{m}^{3} \text { uranium ore dust }\end{array}$ & 2560 \\
\hline 56 & 32 & $\begin{array}{l}1000 \mathrm{WL} \text { radon progeny } \\
15 \mathrm{mg} / \mathrm{m}^{3} \text { uranium ore dust }\end{array}$ & 1280 \\
\hline 88 & 64 & $\begin{array}{l}1000 \mathrm{WL} \text { radon progeny } \\
15 \mathrm{mg} / \mathrm{m}^{3} \text { uranium ore dust }\end{array}$ & 640 \\
\hline 152 & 128 & $\begin{array}{l}1000 \mathrm{WL} \text { radon progeny } \\
15 \mathrm{mg} / \mathrm{m}^{3} \text { uranium ore dust }\end{array}$ & 320 \\
\hline 64 & 96 & Controls & \\
\hline
\end{tabular}

(a) Number of animals is sufficient to detect the predicted incidence of lung tumors at the 0.05 to 0.1 level of significance, assuming linearity of response between 0 and $9200 \mathrm{WLM}$ and $0.13 \%$ spontaneous incidence. Previous exposure at $900 \mathrm{WL}$ for 84 hours/week to 9200 WLM produced an $80 \%$ incidence of carcinoma.

(b) Exposure rate, 90 hours/week; planned periodic sacrifice.

(c) Study is repeated at $100-\mathrm{WL}$ (7000 Series experiments) rate (without periodic sacrifice) to augment previous limited exposure-rate data.

(d) Working level (WL) is defined as any combination of the short-lived radon progeny in 1 liter of air that will result in the ultimate emission of $1.3 \times 10^{5} \mathrm{MeV}$ of potential alpha energy. Working-level month (WLM) is an exposure equivalent to 170 hours at a $1-W L$ concentration.

exposures. The exposures of 6000,7000 , and 8000 Series animals are complete. Exposures of 9000 Series animals were suspended with the $80-\mathrm{WLM}$ and $15-\mathrm{mg} / \mathrm{m}^{3}$ ore-dust exposures to allow analyses of existing data.

Exposures of rats to uranium ore dust alone (10,000 Series experiments; Table 4) are complete. These studies, reported in the Pacific Northwest Laboratory Annual Report for 1992 to the DOE Office of Energy Research, Part 1 , addressed the potential link of silica exposures to lung cancer. Exposures of rats to radon progeny, uranium ore dust, and cigarette-smoke mixtures are complete. This initiationpromotion-initiation (IPI) study $(11,000$ Series experiments; Table 5) continues with a histopathological analysis of the remaining IPI animals. Exposures of female rats $(12,000$ Series experiments; Table 6) are also complete. This study continues with a histopathological comparison to risk data obtained from exposures of male animals using mine-simulation aerosols.

Tables 1 through 6 present the actual numbers of animals (including serially sacrificed animals) used at each exposure level. Because the earlier series of experiments were focused more on understanding the influence on risk of radonprogeny unattached fraction and disequilibrium, their protocols are not reported here.

\section{Rat Respiratory Tract Pathology}

Histopathology was completed on 8000-Series life-span rats exposed to $40 \mathrm{WLM}$ and $15 \mathrm{mg} / \mathrm{m}^{3}$ of uranium ore dust. Changes related to radonprogeny exposure included a $2.4 \%$ average incidence of primary lung tumors; 1 primary lung tumor was found in control rats (Table 7). Excluding osteosarcomas in the 40-WLM group, which are assumed to be primary to the lung but could have originated elsewhere, the incidence of primary lung tumors reduced to $2.0 \%$. Biologic 
Table 2. Low Exposure-Response Relationship Study for Radon Progeny Carcinogenesis in Rats (8000 Series Experiments)

\begin{tabular}{clc} 
Number of Animals $(a)$ & Exposure Regimen $^{(b)}$ & Total Exposure, WLM \\
\hline 96 & $100 \mathrm{WL}^{(c)}$ radon progeny, $15 \mathrm{mg} / \mathrm{m}^{3}$ uranium ore dust & $640^{(\mathrm{d})}$ \\
396 & $100 \mathrm{WL}$ radon progeny, $15 \mathrm{mg} / \mathrm{m}^{3}$ uranium ore dust & $320^{(\mathrm{d})}$ \\
192 & $100 \mathrm{WL}$ radon progeny, $15 \mathrm{mg} / \mathrm{m}^{3}$ uranium ore dust & 160 \\
384 & $100 \mathrm{WL}$ radon progeny, $15 \mathrm{mg} / \mathrm{m}^{3}$ uranium ore dust & 80 \\
480 & $100 \mathrm{WL}$ radon progeny, $15 \mathrm{mg} / \mathrm{m}^{3}$ uranium ore dust & 40 \\
544 & $100 \mathrm{WL}$ radon progeny, $15 \mathrm{mg} / \mathrm{m}^{3}$ uranium ore dust & 20 \\
192 & Controls &
\end{tabular}

(a) Number of animals is sufficient to detect lung tumors at the 0.05 to 0.1 level of significance, assuming linearity of response between 0 and $640 \mathrm{WLM}$ and $0.13 \%$ spontaneous incidence. Previous exposures indicated a tumor incidence of $16 \%$ at 640 WLM.

(b) Exposure rate, 90 hours/week; planned periodic sacrifice.

(c) WL and WLM are defined in footnote d, Table 1.

(d) Repeat exposure is for normalization with Table 1 data.

Table 3. Ultralow Exposure-Rate Study for Radon Progeny Carcinogenesis in Rats (9000 Series Experiments)

\begin{tabular}{clc} 
Number of Animals & $(\mathrm{a})$ & Total Exposure, WLM $^{(\mathrm{c})}$ \\
\hline 64 & $10 \mathrm{WL} \mathrm{L}^{(\mathrm{c})}$ radon progeny, $15 \mathrm{mg} / \mathrm{m}^{3}$ uranium ore dust & 320 \\
64 & $10 \mathrm{WL}$ radon progeny, $3 \mathrm{mg} / \mathrm{m}^{3}$ uranium ore dust & 320 \\
384 & $10 \mathrm{WL}$ radon progeny, $15 \mathrm{mg} / \mathrm{m}^{3}$ uranium ore dust & 80 \\
384 & $10 \mathrm{WL}$ radon progeny, $3 \mathrm{mg} / \mathrm{m}^{3}$ uranium ore dust & 80 \\
512 & $10 \mathrm{WL}$ radon progeny, $15 \mathrm{mg} / \mathrm{m}^{3}$ uranium ore dust & 20 \\
512 & $10 \mathrm{WL}$ radon progeny, $3 \mathrm{mg} / \mathrm{m}^{3}$ uranium ore dust & 20 \\
192 & Controls &
\end{tabular}

(a) Number of animals is sufficient to detect lung tumors at the 0.05 to 0.1 level of significance, assuming linearity of response between 0 and 640 WLM and $0.13 \%$ spontaneous incidence. Previous exposures indicated a tumor incidence of $16 \%$ at 640 WLM.

(b) Exposure rate, 90 hours/week; planned periodic sacrifice.

(c) WL and WLM are defined in footnote d, Table 1.

variability in these low-exposure experiments was reflected in the variation $( \pm 100 \%)$ in primary lung-tumor incidence among the 5 exposure subgroups.

The epidermoid carcinoma in the control rat consisted of numerous large masses of anaplastic squamous epithelium with prominent connective tissue stroma. Although the tumor clearly was potentially fatal, it was not absolutely certain that it originated in the lung; there was, however, no gross description during necropsy that would ascribe its origin to another organ. Other primary respiratory tumors were limited to the nose; 1 exposed rat had an adenocarcinoma and another had a primary malignant lymphoma. No tumors occurred in the larynx or trachea.

Other lesions clearly related to radon progeny and uranium ore-dust exposures included 
Table 4. Control Study for Uranium OreDust Carcinogenesis in Rats (10,000 Series Experiments)

\begin{tabular}{cl}
$\begin{array}{c}\text { Number of } \\
\text { Animals }\end{array}$ & Exposure Regimen \\
\hline 96 & $15 \mathrm{mg} / \mathrm{m}^{3}$ uranium ore dust \\
64 & Sham-exposed controls \\
\hline
\end{tabular}

(a) Exposures, 12 to 18 months at 72

hours/week; planned periodic sacrifice

Table 5. Initiation-Promotion-Initiation (IPI) Protocol for Radon (R), Dust (D), and Cigarette-Smoke (S) Inhalation Exposure of Rats $(11,000$ Series Experiments) ${ }^{(a)}$

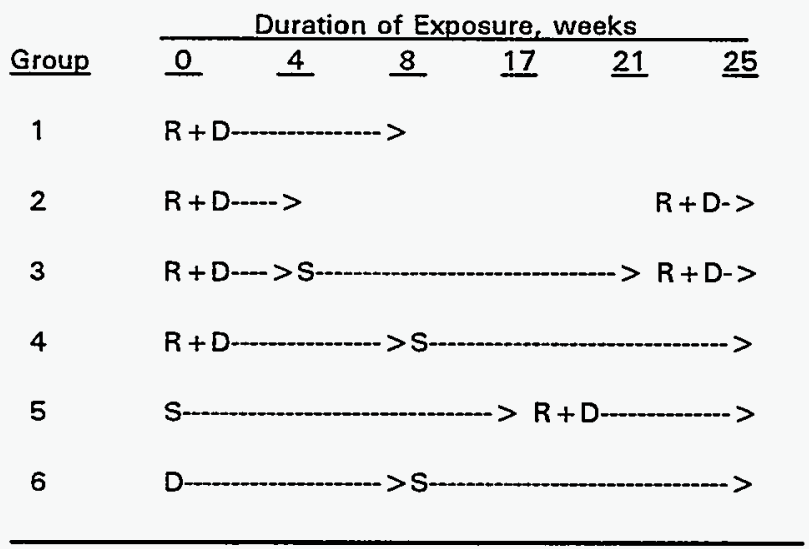

(a) Moderately low concentrations of uranium ore dust accompany radon exposures as the carrier aerosol for radon progeny; sham-exposed control animals (not shown) are included in each exposure group. Ten animals from each exposed or sham-exposed group of 64 rats are killed at 25,52 , and 78 weeks to evaluate developing lesions. Radon-progeny exposures: 100 WL, 320 cumulative WLM; uranium ore-dust concentration: $5 \mathrm{mg} / \mathrm{m}^{3}$; cigarette-smoke exposures from Kentucky 1R4F cigarettes: 1 hour/day, 5 days/week, for 17 weeks.

accumulations of ore dust in macrophages in the lung and tracheobronchial lymph nodes, and reactive hyperplasia of tracheobronchial lymph nodes. A very low incidence of pulmonary adenomatosis was observed in exposed rats while none was found in the control group; however,
Table 6. Exposure of Female Rats to Radon Progeny and Uranium Ore Dust 112,000 Series Experiments)

\begin{tabular}{cl} 
Number of Animals & Exposure Regimen \\
\hline 96 & $100 \mathrm{WL}$ radon progeny; \\
& $640 \mathrm{WLM}$ \\
& $5 \mathrm{mg} / \mathrm{m}^{3}$ uranium ore dust \\
96 & Sham-exposed controls \\
\hline
\end{tabular}

(a) Exposure rate, 72 hours/week; planned periodic sacrifice.

this low incidence was within the range found in control groups of previous studies. Also, a low incidence of acute necrotizing pneumonia was present in both control and radon-exposed rats.

The average number of nonrespiratory malignant tumors was higher in exposed rats than in control rats in contrast to 10,000 Series rats exposed to uranium ore dust alone, in which the incidence of nonrespiratory tumors was lower than in control rats. This finding, in part, could be related to the proportionally smaller ratio of control to exposed rats in the 8000 Series $40-$ WLM rats in contrast to the 10,000 Series uranium ore-dust experiments.

\section{Statistical Risk Modeling}

An updated analysis of lung-tumor risks in approximately 2800 exposed and 490 control rats from the 4000 to 9000 Series experiments was initiated in collaboration with Dr. Ethel Gilbert, PNL. The focus of this analysis is to evaluate the modifying factors of exposure rate, age at risk, and time from exposure. A previous analysis (Gilbert 1989) on approximately 750 exposed and 170 control rats included, for the most part, data only from 6000 and 7000 Series rats, and was based primarily on the assumption that all lung tumors were incidental to the death of the animal.

Preliminary data indicate that the overall linear lung-tumor risk coefficient, accounting for tumor fatality, for 20 to over 10,000 WLM 
Table 7. Summary of Primary Lung Tumors in Control and Life-Span Rats Exposed to 40 WLM (8000 Series Experiments)

\begin{tabular}{|c|c|c|c|c|c|c|c|}
\hline \multirow[b]{3}{*}{ Number of Rats Examined } & \multicolumn{6}{|c|}{ Exposure Subgroups } & \multirow{3}{*}{$\begin{array}{c}\text { Controls } \\
31\end{array}$} \\
\hline & 1 & 2 & 3 & 4 & 5 & Total & \\
\hline & 78 & 96 & 95 & 96 & 96 & 461 & \\
\hline \multicolumn{8}{|l|}{ Tumor Type } \\
\hline Bronchioloalveolar carcinoma & 0 & 0 & 2 & 0 & 1 & 3 & 0 \\
\hline Papillary adenocarcinoma & 1 & 0 & 0 & 0 & 0 & 1 & 0 \\
\hline Epidermoid carcinoma & 0 & 0 & 1 & 0 & 0 & 1 & 1 \\
\hline Adenosquamous carcinoma & 0 & 0 & 0 & 1 & 0 & 1 & 0 \\
\hline Undifferentiated carcinoma & 0 & 0 & 1 & 0 & 0 & 1 & 0 \\
\hline Bronchioloalveolar adenoma & 0 & 0 & 0 & 1 & 0 & 1 & 0 \\
\hline Hemangiopericytoma & 1 & 0 & 0 & 0 & 0 & 1 & 0 \\
\hline Osteosarcoma & 0 & 0 & 0 & 1 & 1 & 2 & 0 \\
\hline Rats with Lung Tumors, \% & 2.6 & 0 & 4.2 & 3.1 & 2.1 & 2.4 & $3.2^{(\theta)}$ \\
\hline
\end{tabular}

(a) SPF Wistar rats typically show less than $1 \%$ spontaneous incidence of lung tumors.

given at exposure rates ranging from 10 to $1000 \mathrm{WL}$, is slightly lower (260 per $\left.10^{6} \mathrm{WLM}\right)$ than the previous value ( 300 per $10^{6}$ WLM); this coefficient is still reasonably comparable to estimated lifetime risks in underground miners (Lubin et al. 1994). A trend was noted for diminishing risks below 320 WLM exposures, but the data were not significant.

\section{Respiratory Tract Cell \\ Proliferation Rates}

Studies suggest that cell proliferation is a key parameter in radiation- and chemically induced lung carcinogenesis. Cell proliferation of the bronchi-bronchiolar region of Wistar rats was measured following exposure to radon progeny and a $0.2-\mu \mathrm{m}$-diameter wax carrier aerosol. Ninety-one young adult male rats were shamexposed or exposed whole body to 174 WLM radon progeny at an average $274 \mathrm{WL}$ in 6 consecutive 18-hour exposures. Two control and 5 exposed rats were periodically sacrificed from day 1 to day 84 after start of exposure. To determine cell proliferation rates, rats were implanted subcutaneously with $50 \mathrm{mg}$ bromodeoxyuridine (BrdU), sacrificed after 4 hours, and necropsied for respiratory tract tissues. The tissues were perfused with Carnoy's solution, fixed in alcohol, processed into slides, and stained for BrdU using the Amersham ${ }^{\otimes}$ cell proliferation kit. The percent of labeled nuclei in airway epithelial cells was quantified using light microscopy. Preliminary data show that labeling indices in thoracic airways of exposed rats can be $1 \frac{1 / 2}{2}$ to 2 times higher than the average in all control rats (Figure 1). Studies to define the kinetics of responses in other damaged regions of the respiratory tract, the regional doses, and the relationships that exist between cell-specific proliferation and cancer induction, are continuing.

\section{References}

Gilbert, E.S. 1989. Lung cancer risk models from experimental animals. In: TwentyFourth Annual Meeting of the National Council on Radiation Protection and Measurements (NCRP), NCRP Publications, August 1, 1989, Washington, DC. NCRP, Bethesda, MD.

Lubin, J.H., J. D. Boice, Jr., C. Edling, R.W. Hornung, G. Howe, E. Kunz, R.A. Kusiak, H.I. Morrison, E.P. Radford, J. M. Samet, M. Tirmarche, A. Woodward, S.X. Yao, and D.A Pierce. 1994. Radon and Lung Cancer 
Risk: A Joint Analysis of 11 Underground

Miners Studies. National Institutes of Health, National Cancer Institute. NIH Publication No. 94-3644, January 1994. U.S. Department of Health and Human Services, Washington, D.C.

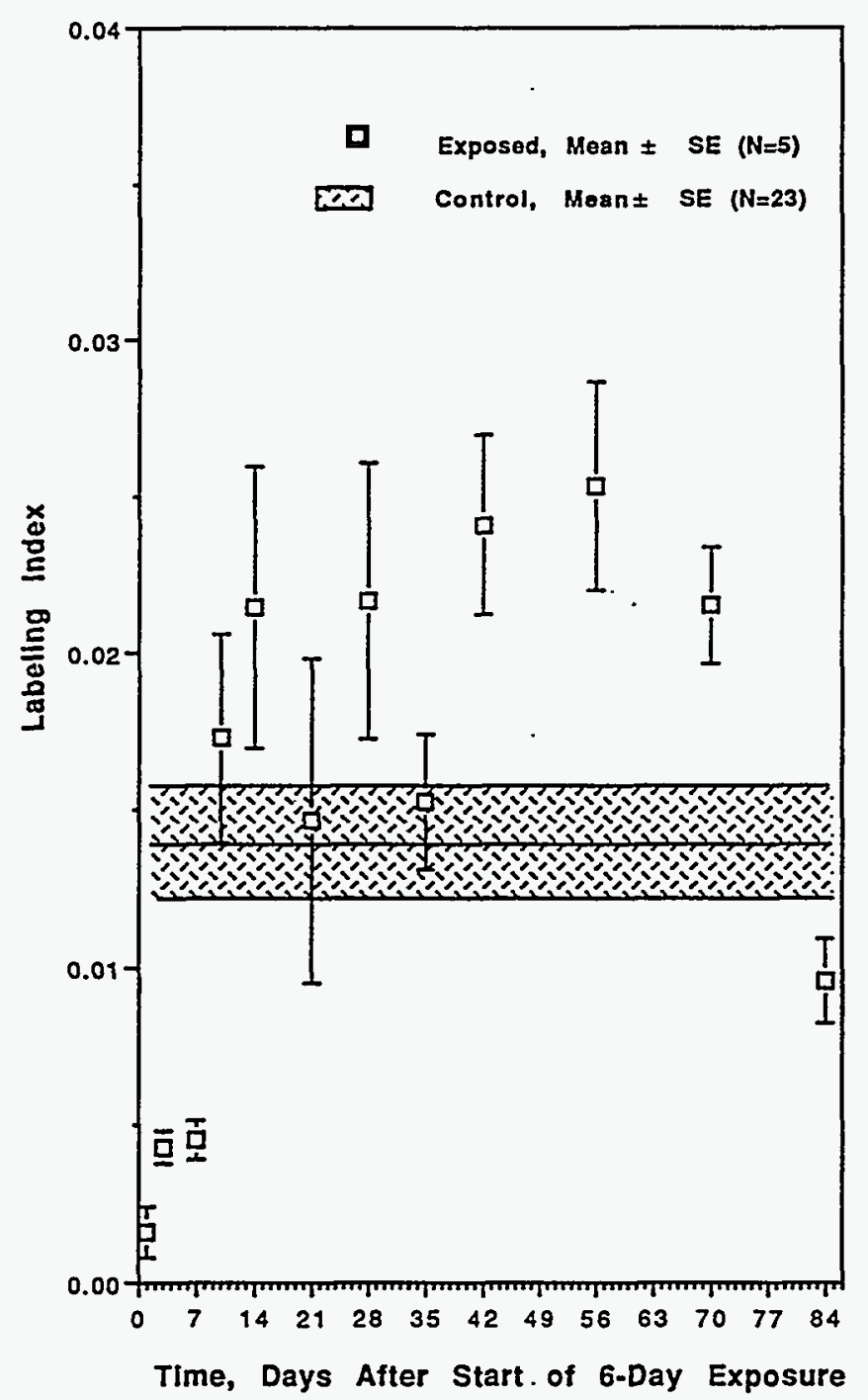

Figure 1. Labeling Index of Rat Bronchial-Bronchiolar Epithelial Cells Following Inhalation Exposure to 174 WLM Radon Progeny and 0.2- $\mu \mathrm{m}$-Diameter Wax Aerosols 


\title{
Genetics of Radon-Induced Lung Cancer
}

\author{
Principal Investigator: J.D. Saffer \\ Other Investigators: K.M. Groch, A.L. Brooks, M.A. Khan, F.T. Cross, \\ R.S. Thrall, ${ }^{(a)}$ and E.M. Eicher ${ }^{(b)}$
}

Technical Assistance: R.A. Gies, L.C. Stillwell

Fully assessing the risk of radon-induced lung cancer to the general population will require a complete understanding of the interactions between exposure and genetic factors influencing lung cancer development. Epidemiological investigations indicate a genetic component in human lung cancer unrelated to cigarette smoking. Similarly, the incidence of spontaneous lung cancer varies among genetically distinct inbred mouse strains. Importantly, (1) the risk of radiogenic lung cancer in mice is relative to the strain-specific spontaneous incidence, and (2) the pathogenesis of spontaneous and chemically induced lung tumors in this species is modulated by at least 3 well-defined loci. A pilot study utilizing 2 inbred strains of mice with differing spontaneous rates of lung tumors was begun to test the hypothesis that genetic background modulates the risk of radon-induced lung cancer. If the hypothesis is confirmed, work will be initiated to map the relevant locus (loci). This effort would provide the foundation for cloning the relevant gene(s) for use in defining molecular mechanisms of radon-induced lung carcinogenesis. Also, these genes possibly could be used as probes for polymorphisms that influence risk in human populations. The work also will provide insights for further defining the appropriate epidemiological risk model (i.e., absolute vs. relative) for extrapolating lung cancer risk in radon-exposed miners to the general population.

\section{Background}

Genetic background and the environment interact in the pathogenesis of human cancer (Knudson 1991). Familial tendencies and specific disease syndromes that predispose people to cancer have been well-defined (Cox 1994), and direct evidence linking genetic predisposition to cancer induced by radiation in humans is beginning to emerge. Mechanistic studies suggest that the excess skin tumors noted in individuals with xeroderma pigmentosum is a consequence of a cellular defect in the repair of ultraviolet-induced lesions (Cleaver, 1990). It has been noted recently that the excess relative risk of breast cancer in Japanese atomic bomb survivors was higher for early-onset disease than that for cancer diagnosed in older women

\footnotetext{
(a) Department of Medicine, University of Connecticut Health Center, Farmington, Connecticut

(b) The Jackson Laboratory, Bar Harbor, Maine
}

(Tokunaga et al. 1994), suggesting interactions between radiation exposure and well-established genetic predisposition to pre-menopausal breast cancer.

Although little is known regarding genetics of radiation- or radon-induced lung cancer, there is epidemiological evidence indicating genetic predisposition to spontaneous disease as well as polymorphisms affecting sensitivity to smokinginduced cancer. Studies have shown that lung cancer risk in particular (Samet et al. 1986; Ooi et al. 1986) or overall risk of cancer in general (Lynch et al. 1986) not related to cigarette smoking is increased in relatives of lung cancer patients. Essentially, all small-cell lung cancer and $\sim 50 \%$ of non-small-cell lung tumors exhibit deletions in chromosome regions $3 p(14-23)$; cytogenetic abnormalities in this region have been shown to co-segregate with renal carcinoma. The region also is believed to contain a fragile site (reviewed in Minna 1990). These 
observations suggest a tumor suppressor gene reminiscent of retinoblastoma.

Molecular studies have shown a germ-line polymorphism in the $p 53$ gene associated with increased lung cancer risk (Kawajiri et al. 1993). The observation is controversial because others have not found a relationship between $p 53$ polymorphisms and lung cancer in other populations (Weston et al. 1992). A variety of polymorphisms in enzymes affecting carcinogen metabolism have been identified; these polymorphisms modulate susceptibility to smoking-induced lung cancer (reviewed in Idle 1991).

Inbred mice provide a powerful tool for characterizing the effects of genetic background on the pathogenesis of lung cancer. The spontaneous incidence of lung tumors in strains varies widely; C57BL/6J (B6) mice infrequently develop lung tumors $(\sim 7 \%)$ whereas essentially all $\mathrm{A} / \mathrm{J}$ (A) mice have multiple lung tumors by 6 months (Hahn 1993). Moreover, exposure to a variety of inhaled or injected chemical carcinogens results in a proportionately greater number of tumors in A mice than in B6 mice (Hahn 1993). These observations suggest that risk of lung neoplasia in this species is relative to the genetically defined spontaneous rate as opposed to a simple increase in the the absolute number of tumors as a function of carcinogen dose.

The risk of spontaneous and chemically induced lung tumors in this species is controlled by 3 loci designated Pas (pulmonary adenoma sensitivity) genes. Through molecular analysis, 1 of these genes has been identified as a polymorphism in the K-ras 2 proto-oncogene (Ryan et al. 1987). Another Pas gene has been found to be closely linked to the mouse H-2 complex (reviewed in Demant et al. 1989). The correlation between increased proliferation indices of lung epithelial cells and cancer susceptibility in inbred mouse strains has led to speculation that the third Pas gene is involved in regulating the growth or differentiation of lung-tumor precursor cells (Malkinson 1991). In addition to the Pas genes, genetic studies indicate the presence of a mouse gene mapping to chromosome 4 that acts as a lung cancer suppressor gene in this species (Herzog et al. 1994).

Mice have been shown to be susceptible to radiogenic lung cancer. Exposure to external
$\mathrm{X}$-rays and neutrons induces lung tumors in inbred BALB/c mice (Ullrich 1983, 1984) and outbred SAS/4 mice (Coggle 1988). More relevant to radon exposure is the observation that alpha particles from inhaled ${ }^{239} \mathrm{PuO}_{2}$ induce lung tumors in $\mathrm{B} 6$ mice, with protraction of the alphaparticle dose increasing the carcinogenic risk (Lundgren et al. 1987). A large-scale analysis of cancer-incidence data obtained using $\mathrm{C} 3 \mathrm{hf} / \mathrm{Bd}$, C57BL/6Bd, BALB/c, and RFM mice exposed to external $\mathrm{X}$-rays and ${ }^{137} \mathrm{Cs}$ gamma rays indicates that (1) the general susceptibility to radiogenic cancers of the lung is correlated with species-specific spontaneous incidences, and (2) the relative risk estimate in mice for radiogenic cancer of the lung and breast as well as for leukemia was not significantly different from that in humans (Storer et al. 1988).

Historically, mice have not been employed extensively in quantifying radon risk. Studies at the University of Rochester in the late 1960s suggested that mice are refractory to radoninduced lung cancer (Morken 1973). However, the animals were exposed to what would now be considered very high cumulative exposures (the lowest estimated to be 18,000 WLM) at very high exposure rates. At roughly the same time, similar results were obtained with $\mathrm{B} 6$ mice exposed to very high radon levels at Pacific Northwest Laboratory (Palmer et al. 1973).

The relevance of these studies is questionable for several reasons. Subsequent studies with rats, which are susceptible to radon-induced lung cancer, have revealed an inverse exposure-rate effect in which carcinogenicity increases with decreasing exposure rate (Cross 1991). Given the very high exposure rates, the significant lifespan shortening, and the amount of radiationinduced cell death of airway epithelium noted in both sets of early studies with mice, it is not surprising that lung tumors were not noted. The current studies were designed to assess tumor incidences at lower cumulative exposures levels comparable to those which have been shown to induce lung cancer in rats.

\section{Experimental Design and Preliminary Results}

The specific aim of this pilot study is to determine if the mouse genes that modulate the patho- 
genesis of spontaneous and chemically induced lung neoplasms also modulate the neoplastic response to inhaled radon and progeny. The $A$ and B6 strains were chosen for the reasons described in the previous section. If genetic background is found to affect radon-induced lung-tumor development, the long-term goal of the project will be to locate and clone the relevant gene(s) using either recombinant inbred strains obtained from A and B6 parent lines or simple sequence length polymorphisms associated with lung neoplasms in backcross progeny of A x B6 F1 animals bred with B6 animals.

For the current study, subgroups from each strain were exposed to 1000 and 2500 WLM (for a definition of WLM, please see the report by Cross, this volume) radon progeny (nominal) using a uranium ore-dust carrier (carnotite, $\sim 5$ $\mathrm{mg} / \mathrm{m}^{3}$ ) at an exposure rate of $\sim 110 \mathrm{WLM} /$ day
(Table 1). The exposures were interrupted daily for routine animal care; they were performed on consecutive days without weekend breaks.

Control animals were exposed to ore dust only. As positive controls, additional animals from each strain were injected intraperitoneally with ethyl carbamate ( $1 \mathrm{mg} / \mathrm{g}$ body weight) using physiological saline as a vehicle.

The primary data to be collected from all groups are lung-tumor incidence and multiplicity as a function of time. Ancillary data will include a complete necropsy for extrapulmonary lesions; histological evaluation of random lung tissue; lung lavage for total cells, differential counts, and total protein; and lung epithelial cell cytodynamics as measured by indices of cell birth and death. The latter will include quantifying in situ the fraction of proliferating deep-lung epithelial cells using Proliferating Cell Nuclear

Table 1. Experimental Design for the Pilot Study to Test the Hypothesis that Genetic Background Modulates the Risk of Radon-Induced Lung Cancer

Sacrifice Schedule (animals/group)

\begin{tabular}{|c|c|c|c|c|c|}
\hline \multirow[b]{2}{*}{ Strain } & \multirow[b]{2}{*}{ Agent } & \multirow[b]{2}{*}{ Exposure } & \\
\hline & & & 30 weeks & 60 weeks & 90 weeks \\
\hline \multirow[t]{6}{*}{$\mathrm{A} / \mathrm{J}$} & none & - & - & - & 15 \\
\hline & ethyl carbamate & $1 \mathrm{mg} / \mathrm{g}$ body wt & 10 & 10 & 15 \\
\hline & radon progeny ${ }^{(8)}$ & $1000 W_{L} M^{(b)}$ & 10 & 10 & 15 \\
\hline & ore dust only ${ }^{(a, c)}$ & - & 10 & 10 & 15 \\
\hline & radon progeny & $2500 \mathrm{WLM}^{(b)}$ & - & - & 15 \\
\hline & ore dust only ${ }^{(d)}$ & - & - & - & 15 \\
\hline \multirow[t]{6}{*}{ C57BL/6J } & none & - & - & - & 15 \\
\hline & ethyl carbamate & $1 \mathrm{mg} / \mathrm{g}$ body wt & 10 & 10 & 15 \\
\hline & radon progeny ${ }^{(a)}$ & $1000 \mathrm{WLM}^{(\mathrm{b})}$ & 10 & 10 & 15 \\
\hline & ore dust only ${ }^{(a, c)}$ & - & 10 & 10 & 15 \\
\hline & radon progeny & $2500 W_{L M}^{(b)}$ & - & - & 15 \\
\hline & ore dust only ${ }^{(d)}$ & - & - & - & 15 \\
\hline
\end{tabular}

(a) Divided between 2 separate exposures.

(b) Nominal cumulative exposure.

(c) Matched for the nominal 1000-WLM cumulative exposures.

(d) Matched for the nominal 2500-WLM cumulative exposure. 
Antigen (PCNA, clone PC10) staining, and quantifying the fraction of cells undergoing apoptosis based on the section of fragmented nuclear DNA using a commercially available apoptosis detection kit (ApopTag ${ }^{\mathrm{TM}}$, Oncor). A collaboration has been established with Dr. Roger Thrall of the University of Connecticut Health Center to evaluate any non-neoplastic changes in the lung epithelium.

To ensure that no subtle anatomical differences between strains affected the dose to the lung epithelium despite equivalent radon and progeny exposure levels, additional animals from each strain were exposed to $\sim 300$ WLM radon and progeny; micronuclei frequency in deep-lung fibroblasts were quantified using the method of Khan et al. (1994). Similar data were obtained for control, ore dust-only, and ethyl carbamateinjected animals. There were no observed differences between strains in the amount of scored, cytogenetic damage in deep-lung fibroblasts obtained from animals from all 4 treatment groups (Figure 1). Interestingly, micronuclei frequency in the cells obtained from animals exposed to $\sim 300$ WLM radon was approximately 3 times that noted for cells obtained from ethyl carbamate-treated animals.

The direction of future work is dependent upon the outcome of the pilot study. As mentioned, if the incidence of radon-induced lung neoplasms is found to be strain-dependent, future work will be aimed at mapping the relevent locus (loci). If the mouse genes influencing the pathogenesis of spontaneous and chemically induced lung tumors are found not to modify the tumorigenic effect of radon, cross-species comparisons between mice and sensitive species as well as in vitro work to identify potential differences will be initiated.

\section{References}

Cleaver, J.E. 1990. Do we know the cause of xeroderma pigmentosum? Carcinogenesis $11: 875-882$.

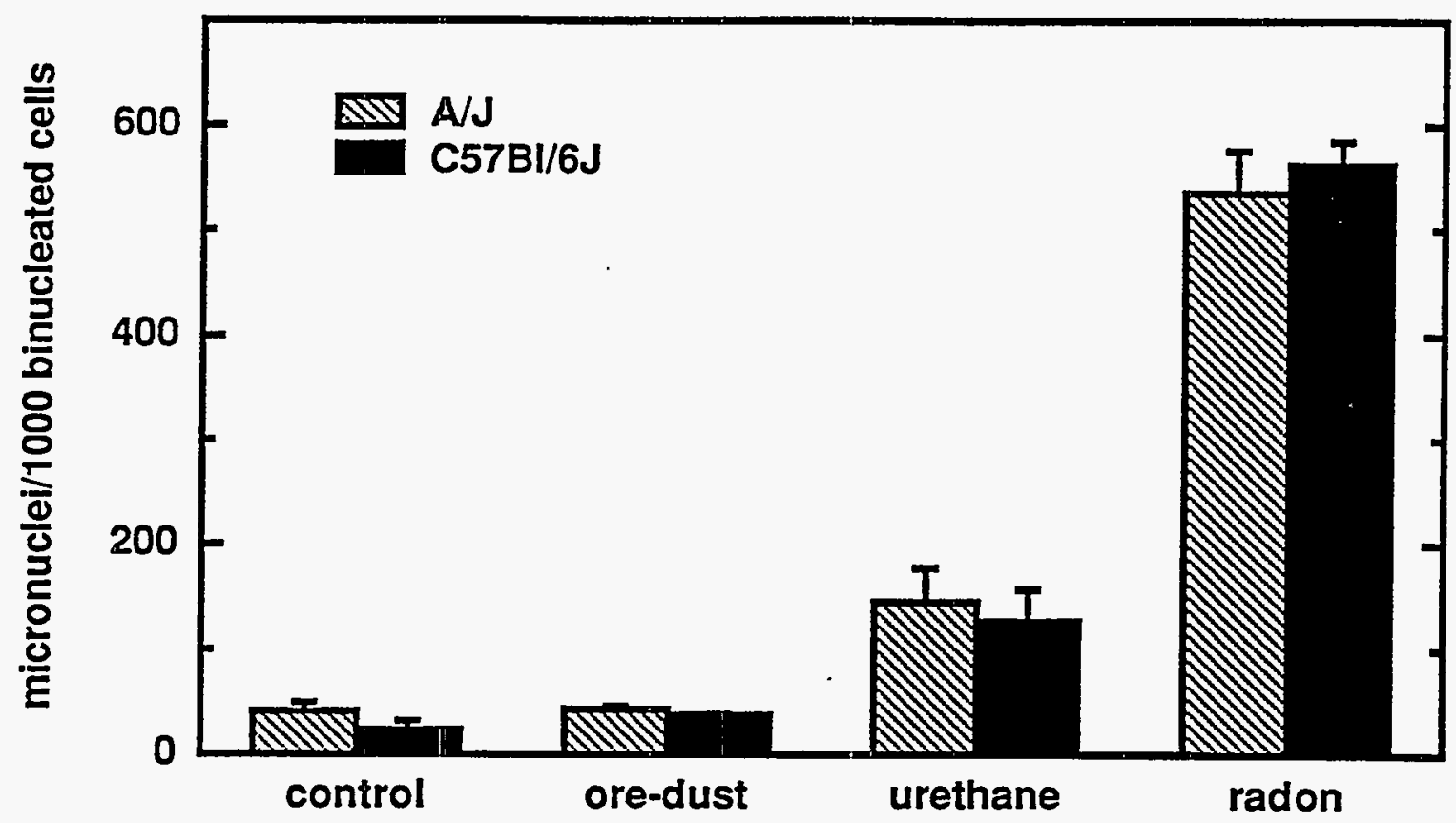

Figure 1. Micronuclei Frequency $( \pm S D)$ in Deep-Lung Fibroblasts Obtained from Mice 24 Hours after Ethyl Carbamate Injection (urethane, $1 \mathrm{mg} / \mathrm{g}$ body weight) or Exposure to $300 \mathrm{WLM}$ (nominal) Radon Progeny 
Coggle, J.E. 1988. Lung tumor induction in mice after X-rays and neutrons. Int. J. Radiat. Biol. 53:585-598.

Cox, R. 1994. Human cancer predisposition and the implications for radiological protection. Int. J. Radiat. Biol. 66:643-647.

Cross, F.T. 1991. Experimental studies on lung carcinogenesis and their relationship to future research on radiation-induced lung cancer in humans. In: The Future of Human Radiation Research (Section 2, Lung Cancer), G.B. Gerber, D.M. Taylor, E. Cardis, and J.W. Thiessen (eds.), pp. 27-35, Report 22, British Institute of Radiology, London. Medical Physics Publishing, Madison, Wisconsin.

Demant, P., L.C.J.M. Oomen, and M. Oudshoorn-Snoek. 1989. Genetics of tumor susceptibility in the mouse: $\mathrm{MHC}$ and non-MHC genes. Adv. Cancer Res. 53:117-179.

Hahn, F.F. 1993. Chronic inhalation bioassays for respiratory tract carcinogenesis. In: Toxicology of the Lung, Second Edition, D.E. Gardner, J.D. Crapo, and R.O. McClellan (eds.), pp. 435-459. Raven Press, New York.

Herzog, C.R., R.W. Wiseman, and M. You. 1994. Deletion mapping of a putative tumor suppressor gene on chromosome 4 in mouse lung tumors. Cancer Res. 54:4007-4010.

Idle, J.R. 1991. Is environmental carcinogenesis modulated by host polymorphisms. Mutat. Res. 247:259-266.

Kawajiri, K., K. Nakachi, K. Imai, J. Watanabe, and S-I. Hayashi. 1993. Germ line polymorphisms of p53 and CYP1A1 genes involved in human lung cancer. Carcinogenesis 14:1085-1089.

Khan, M.A., F.T. Cross, R. Jostes, E. Hui, J.E. Morris, and A.L. Brooks. 1994. Micronuclei induced by radon and its progeny in deeplung fibroblasts of rats in vivo and in vitro. Radiat. Res. 139:53-59.

Knudson, A.G. 1991. Overview: Genes that predispose to cancer. Mutat. Res. 247:185190.

Lundgren D.L., N.A. Gillett, F.F. Hahn, W.C. Griffith, and R.O. McClellan. 1987. Effects of protraction of the $\alpha$ dose to the lungs of mice by repeated inhalation of aerosols of ${ }^{239} \mathrm{PuO}_{2}$. Radiat. Res. 111:201-224.
Lynch, H.T., W.J. Kimberling, S.E. Markvicka, K.A. Biscone, J.F. Lynch, E. Whorton, and J. Mailliard. 1986. Genetics and smoking-associated cancers. Cancer 57:16401646.

Malkinson, A.M. 1991. Genetic studies on lung tumor susceptibility and histogenesis in mice. Environ. Health Perspect. 93:149-159.

Minna, J.D. 1990. Dominant and recessive oncogenes in the pathogenesis of lung cancer. In: Biology, Toxicology, and Carcinogenesis of Respiratory Epithelium, D.G. Thomassen and P. Nettesheim (eds.), pp. 288-305. Hemisphere Publishing, New York.

Morken, D.A. 1973. The biological effects of radon on the lung. In: Noble Gases, R.E. Stanley and A.A. Moghissi (eds.), pp, 501-506. CONF-730915, U.S. Energy Development and Research Agency, National Environmental Research Center, Washington, D.C.

Ooi, W.L., R.C. Elston, V.W. Chen, J.E. Bailey-Wilson, and H. Rothschild. 1986. Increased familial risk for lung cancer. J. Natl. Cancer Inst. 76:217-222.

Palmer, R.F., B.O. Stuart, and R.E. Filipy. 1973. Biological effects of daily inhalation of radon and its short-lived daughters in experimental animals. In: Noble Gases, R.E. Stanley and A.A. Moghissi (eds.), pp. 507-519. CONF-730915, U.S. Energy Development and Research Agency, National Environmental Research Center, Washington, D.C.

Ryan, J., P.E. Barker, M.N. Nesbitt, and F.H. Ruddle. 1987. KRAS2 as a genetic marker for lung tumor susceptibility in inbred mice. J. Natl. Cancer Inst. 79:1351-1357.

Samet, J.M., C.G. Humble, and D.R. Pathak. 1986. Personal and family history of respiratory disease and lung cancer risk. Am. Rev. Respir. Dis. 134:466-470.

Storer, J.B., T.J. Mitchell, and R.J.M. Fry. 1988. Extrapolation of the relative risk of radiogenic neoplasms across mouse strains and to man. Radiat. Res. 114:331-353.

Tokunaga, M., C.E. Land, S. Tokuoka, I. Nishimori, and S. Akiba. 1994. Incidence of female breast cancer among atomic bomb survivors, 1950-1985. Radiat. Res. 138:209-223. 
Ullrich, R.L. 1983. Tumor induction in $\mathrm{BALB} / \mathrm{c}$ mice after fission neutron or gamma irradiation. Radiat. Res. 93:506-515.

Ullrich, R.L. 1984. Tumor induction in $\mathrm{BALB} / \mathrm{c}$ mice after fractionated or protracted exposures to fission-spectrum neutrons. Radiat. Res. 97:587-596.

Weston, A., L.S. Perrin, K. Forrester, R.N. Hoover, B.F. Trump, C.C. Harris, and N.E. Caporaso. 1992. Allelic frequency of a p53 polymorphism in human lung cancer. Cancer Epidemiol. Biomarkers Prev. 1:481-483. 


\title{
Mechanisms of Radon-Induced DNA Damage
}

\section{Principal Investigator: R.F. Jostes}

\author{
Other Investigators: A.L. Brooks, F.T. Cross, T.E. Hui, L.H. Lutze, ${ }^{(a)}$ R.C Miller, ${ }^{(b)}$ \\ J.M. Nelson, and J.P. O'Neill ${ }^{(\mathrm{c})}$
}

\section{Technical Assistance: R.A. Gies, L.C. Stillwell}

In this project, we conduct dosimetric, molecular, cellular, and whole-animal research relevant to understanding the mechanisms of radon and radon-progeny injury to DNA. The work specifically addressed the nature of radon-induced mutations in (1) the Lacl gene obtained from the lung tissue of Big Blue $^{\mathrm{Tn}}$ transgenic mice exposed in vivo; (2) human lymphocytes exposed in the Pacific Northwest Laboratory (PNL) in vitro exposure system for molecular analysis of mutation; and (3) $\mathrm{C} 3 \mathrm{H} 10 \mathrm{~T}^{1 / 2}$ cells exposed in the PNL in vitro exposure system for transformation analysis. Southern blot and polymerase chain reaction (PCR) exon analysis of radon-induced Chinese hamster ovary (CHO)-HPRT mutations were completed and the study published in Radiation Research (Jostes et al. 1994). The gross molecular spectrum of radon-induced mutations showed a marked increase in the frequency of deletions relative to that observed in the spontaneous spectrum, but no difference was noted between the molecular spectra of mutations induced by radon and those induced by $300-c G y \times$ rays. We are currently investigating the fine structure of radon-induced mutations in the LacI gene isolated from lung tissue of a Big Blue ${ }^{\mathrm{TM}}$ transgenic mice.

\section{In Vivo Radon Studies}

We have exposed Stratagene Big Blue ${ }^{\mathrm{Ts}}$ transgenic mice by inhalation to 320,640 , and 960 working-level months (WLM) of radon progeny. Mice were sacrificed after 3,6, and 9 days, the time periods required to obtain the exposures. Control mice also were sacrificed at the same time intervals. Mutations were scored only if they occurred unambiguously in both strands of the mutant gene; the gene then was evaluated in its entirety. Induced mutation frequencies increased with exposure level and were 3 to 4 times spontaneous frequencies. Twelve Lacl mutations were isolated from the lung tissue of a mouse from the 960-WLM group, and the LacI gene has been sequenced. In addition, 16 Lacl mutations were isolated from the lung tissue of a mouse from the 640-WLM group; 7 have been completely sequenced. Nine LacI muta- tions from the lung tissue of unexposed control mice also were sequenced.

Sequence data from the unexposed mice were similar to that found in lung tissue at Stratagene; predominantly $\mathrm{G}: \mathrm{C}$ to $\mathrm{A}: \mathrm{T}$ transitions in the protein-associated region (Table 1). The mutation spectrum from radon-exposed mice was markedly different from that obtained from the control mice. Small deletions and insertions constituted $53 \%$ of the mutations in the radonexposed mice; only 1 was in the proteinassociated region of the gene. Six of the mutations (26\%) obtained from exposed mice exhibited multiple events within the gene. In some, deletions, insertions, and base changes occurred together in the same gene. This observation is consistent with the concept of locally multiply damaged sites after alpha irradiation. No multiple events were noted in the

\footnotetext{
(a) University of California, San Francisco

(b) Columbia University

(c) University of Vermont
} 
Table 1. Types of Mutagenic Events in Spontaneous and Radon-Induced Lac/ Mutants

\begin{tabular}{|c|c|c|c|}
\hline & \multicolumn{2}{|c|}{ Spontaneous Mutants, \% } & \multirow{2}{*}{$\frac{\text { Radon-Induced Mutants, \% }}{\text { PNL }}$} \\
\hline & Stratagene $e^{(a)}$ & PNL & \\
\hline \multicolumn{4}{|l|}{ Transitions } \\
\hline$A: T$ to $G: C$ & $0 \%(0)^{(b)}$ & & $3 \%(1)$ \\
\hline$G: C$ to $A: T$ & $56 \%(5)$ & $67 \%(6)$ & $23 \%(7)$ \\
\hline \multicolumn{4}{|l|}{ Transversions } \\
\hline$G: C$ to $T: A$ & $22 \%(2)$ & $11 \%(1)$ & $10 \%(3)$ \\
\hline$G: C$ to $C: G$ & $11 \%(1)$ & $11 \%(1)$ & $0 \%(0)$ \\
\hline$A: T$ to $C: G$ & $0 \%(0)$ & & $10 \%(3)$ \\
\hline$A: T$ to $T: A$ & $0 \%(0)$ & & $0 \%(0)$ \\
\hline $\begin{array}{l}\text { Other } \\
\quad \text { (insertions \& deletions) }\end{array}$ & $11 \%(1)$ & $11 \%(1)$ & $54 \%(16)$ \\
\hline Total & $100 \%(9)$ & $100 \%(9)$ & $100 \%(30)$ \\
\hline
\end{tabular}

(a) Stratagene 1994.

(b) Numbers in parentheses indicate actual number of mutagenic events in sequenced mutations.

spontaneous mutations evaluated to date. Figure 1 illustrates the shift from predominantly basemispairing events in the spontaneous mutants to deletions and insertions in the radon-exposed mice.

Mutational events in radon-exposed mice are approximately equally distributed throughout the gene, in contrast to the spontaneous mutations, in which half of the mutations are clustered in the protein-associated region of the gene (Figure 2). The break-point rejoining regions of large deletions obtained from radon-exposed mice are being investigated collaboratively with $\mathrm{Dr}$. Louise Lutze at the University of California, San Francisco. These studies will help define the molecular fine structure of mutations induced by high-LET radiation exposure.

\section{In Vitro Radon Studies}

\section{Pacific Northwest Laboratory (PNL)}

Three studies are in progress at PNL:

In vitro cell exposure system. The PNL in vitro radon cell-exposure system was employed in PNL experiments as well as in several collaborative experiments with other laboratories. The collaboration with Dr. E.W. Fleck, Whitman College (Walla Walla,
Washington), on molecular analysis of radoninduced CHO-HPRT mutations using Southern blot and polymerase chain reaction (PCR) exon analysis was completed and published in Radiation Research (Jostes et al. 1994). The gross molecular spectrum of radon-induced mutations showed a marked increase in the frequency of deletions relative to that observed in the spontaneous spectrum, but no difference was noted between the molecular spectra of mutations induced by radon and those induced by $300-c G y$ $\mathrm{x}$ rays. A clustering of deletion breakpoints was noted in the $3^{\circ}$ half of the hprt gene (spontaneous and irradiated).

Fluorescent in situ hybridization. A collaboration with Dr. Brooks at PNL investigating the occurrence of color junctions in chromosomes prepared using fluorescent in situ hybridization after radon and $x$-ray exposures has been completed, and a manuscript has been submitted to Environmental and Molecular Mutagenesis. This work is described in this Annual Report under "Genotoxicity of Inhaled Energy Effluents."

Microbeam. A project investigating chromosome aberration induction using the PNL microbeam has been initiated. A limited number of mitotics from asynchronous $\mathrm{CHO}$ cells given 


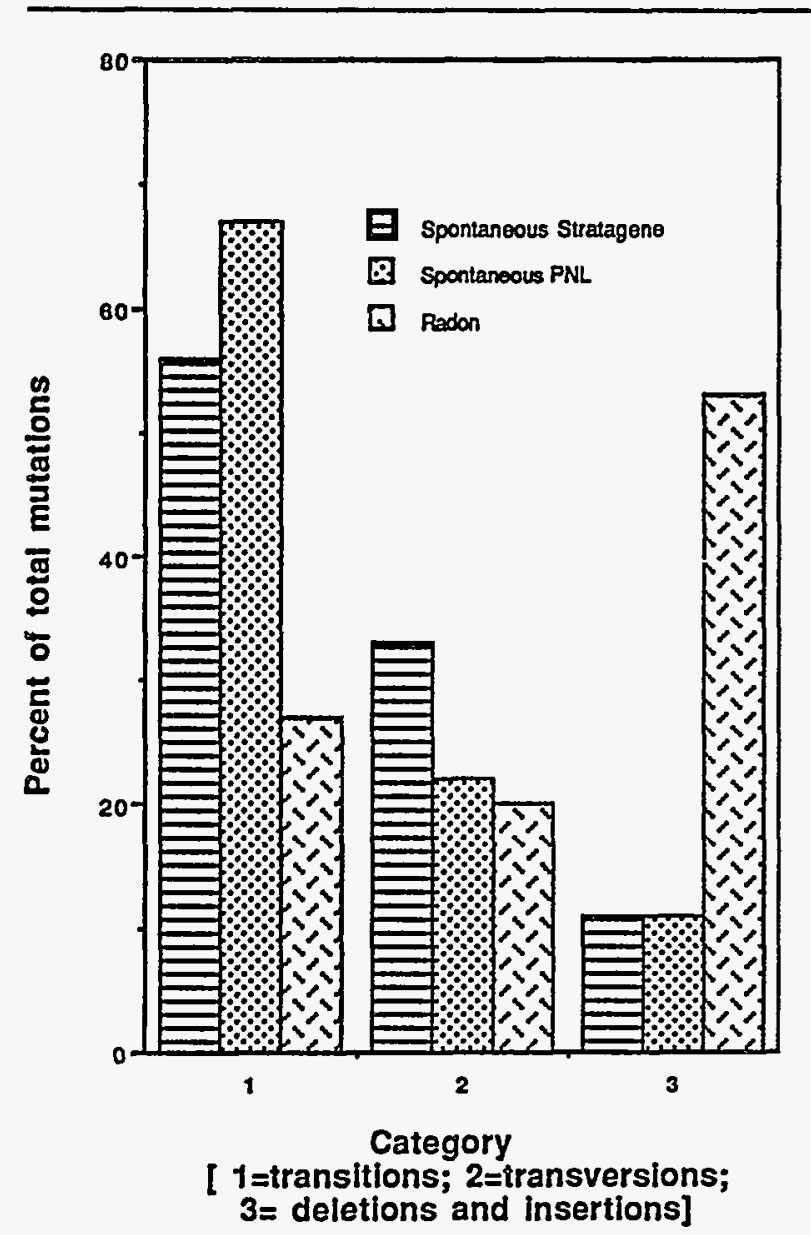

Figure 1. Histogram lllustrating the Relative Frequency of Transitions, Transversions, and Deletions/ Insertions in Spontaneous and Radon-Induced Lacl Mutations

1 alpha particle per nucleus have been scored. These preliminary data indicate that $37 \%$ of the metaphases from the irradiated cells contained aberrations.

\section{PNL/University of Vermont}

In a collaborative study with Drs. J.P. O'Neill and R.J. Albertini at the University of Vermont, we are investigating cell survival and mutation induction in human peripheral blood lympho-cytes after in vitro radon exposure. Dose-response data was evaluated; mutants will be isolated from lymphocytes exposed to a dose between 30 and $40 \mathrm{cGy}$, a range that yields a single alpha traversal probability of 32 to $36 \%$. Two additional exposures were completed in FY 1994, and in the future molecular analysis of isolated mutants will be performed.

\section{PNL/Columbia University}

The collaboration with Drs. Richard Miller and Eric Hall (Columbia University), in which C3H 10T $1 / 2$ cells were exposed in PNL's in vitro radon exposure system, were completed. Cell survival and transformation were evaluated at 3 dose levels in 2 experiments. Technical help for transformation experiments at PNL was provided by Columbia University. The $\mathrm{D}_{0}$ was established at approximately $50 \mathrm{cGy}$ (representing 3 alpha traversals per cell nucleus; $2.1 \times 10^{-3}$ $\mathrm{keV}$ total energy deposited in the nucleus). Transformation frequencies obtained from PNL's in vitro radon exposure system were similar to those obtained from $90-$ and $120-\mathrm{keV} / \mathrm{mM}$ alpha particles generated in the Columbia University Radiological Research Accelerator Facility (RARAF). A manuscript describing this work has been prepared for submission to Radiation Research.

A comparison of suspension-exposure systems versus planar-exposure systems with regard to dose (cell nucleus) was accomplished by calculating the average numbers of alpha traversals at the $\mathrm{D}_{\mathrm{o}}$. We determined that the average traversal number required to achieve $\mathrm{D}_{\mathrm{o}}$ in $\mathrm{C} 3 \mathrm{H}$ $10 \mathrm{~T}^{1} / 2$ cells increased as the average traversal distance decreased (such as from flattened nuclei in the planar irradiation geometry). As expected, the average total energy deposited in the cell nucleus at $D_{0}$ was approximately the same in planar and spherical geometries (1.6 $2.1 \times 10^{-3} \mathrm{keV}$ ). Table 2 presents selected data illustrating this relationship. These findings were presented at the 1994 Annual Meeting of the Health Physics Society.

\section{References}

Jostes, R.F., E.W. Fleck, G.L. Stiegler, T.L. Morgan, and F.T. Cross. 1994. Southern and PCR analysis of HPRT mutations induced by radon and its progeny. Radiat. Res.137:371379.

Lloyd, E.L., M.A. Gemmell, C.B. Henning, D.S. Gemmell, and B.J. Zabransky. 1977. Transformation of mouse embryo (CH3 101/2) cells by alpha particles. In: ANL-77-65, pp. 28-48. Argonne National Laboratory, Argonne, Illinois. 


\section{Region 1}

$-14$

$14 \quad 379$

Region 2

Region 3

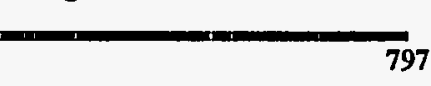

374

RADON

IIIIII III I I II

\section{SPONTANEOUS}

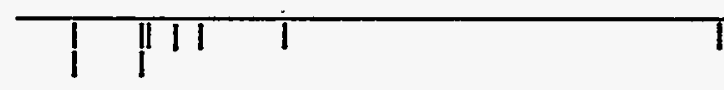

Figure 2. Distribution of Mutations in the Lacl Gene Obtained from Radon-Irradiated and Spontaneous Lung Tissue.

Tick marks indicate the location of mutations; stacked marks indicate the same mutation in the same base pairs.

Table 2. Comparison of Alpha Traversals and Energy Deposited per Nucleus at the $D_{0}$

\begin{tabular}{|c|c|c|c|c|c|c|c|}
\hline Study & Cell & $\begin{array}{l}\text { Exposure } \\
\text { System }\end{array}$ & $\begin{array}{c}D_{0} \\
\text { (cGy) }\end{array}$ & $\begin{array}{c}\text { Track } \\
\text { Length }^{(8)}\end{array}$ & $\begin{array}{c}\text { LET } \\
(\mathrm{keV} / \mu \mathrm{M})\end{array}$ & $\begin{array}{c}\text { Alpha } \\
\text { Traversals } \\
\text { at the } D_{0}\end{array}$ & $\begin{array}{c}\text { Energy } \\
\text { Deposited (b) } \\
\text { (keV) }\end{array}$ \\
\hline $\begin{array}{l}\text { Jostes et al. } \\
\text { (unpublished data) }\end{array}$ & $\mathrm{C} 3 \mathrm{H} 10 \mathrm{~T} 1 / 2$ & Suspension & 50 & 6.6 & 103 & 3.1 & $2.1 \times 10^{3}$ \\
\hline Raju et al. 1991 & $\mathrm{C} 3 \mathrm{H} 10 \mathrm{~T}^{1 / 2}$ & $\begin{array}{l}\text { Collimated } \\
\text { planar }\end{array}$ & 60 & 2.1 & 121 & 6.4 & $1.6 \times 10^{3}$ \\
\hline Lloyd et al. 1977 & C3H 10T $1 / 2$ & $\begin{array}{l}\text { Collimated } \\
\text { planar }\end{array}$ & 60 & $\begin{array}{c}-1.7 \\
\text { (estimated) }\end{array}$ & $\begin{array}{c}-85 \\
\text { (estimated) }\end{array}$ & 13.8 & $2.0 \times 10^{3}$ \\
\hline
\end{tabular}

(a) Average track length (in $\mathrm{mm}$ ) of each alpha traversal of the nucleus.

(b) Average total energy deposited in the cell nucleus at the $D_{0}$.

Raju, M.R., Y. Eisen, S. Carpenter, and W.C. Inkret. 1991. Radiobiology of alpha particles. III. Cell inactivation by alpha-particle traversals of the cell nucleus. Radiat. Res. 128(2):204-209.
Stratagene. 1994. Standardization and validation data summary. In: Big Blue Transgenic Rodent Mutagenesis Assay Systems, p. 28. Stratagene, La Jolla, California. 


\title{
In Vivo/ln Vitro Radon-Induced Cellular Damage
}

\section{Principal Investigator: A.L. Brooks}

\author{
Other Investigators: M.A. Khan, F.T. Cross, K.M. Groch, and R.F. Jostes
}

To understand the health effects of inhaled radon and its progeny, this project provides important links relating the data from mechanistic model studies to those derived from animal studies, and renders both types of data more useful in predicting health hazards from radon-progeny exposure in homes. In this project, we compare cytogenetic damage induced by high-LET alpha particles and lowLET gamma rays given both in vivo and in vitro to define the relationships between working-level months (WLM) from radon-progeny inhalation exposure and radiation dose to cells of the respiratory tract. During FY 1994, we investigated the influence of biological and physical variables on this exposure-to-dose relationship, and determined the radon relative biological effectiveness (RBE) both in vivo and in vitro. Experiments were directed toward (1) understanding the influence of species/strain on the induction of micronuclei by radon-inhalation exposure; (2) evaluating the role of dose rate on chromosome damage from both high- and low-LET radiation exposure; and (3) investigating the influence of radon-progeny aerosol characteristics on respiratory tract deposition, dose, and induced damage.

Animals and cultured cells were exposed to radon and its progeny; cellular damage was determined in deep-lung fibroblasts using the micronucleus assay. The sensitivity of different species or strains to the induction of cancer was not reflected in an increase in the sensitivity to micronuclei induction in primary lung fibroblast cultures. However, marked species differences were observed in the frequency of micronuclei induced per unit of exposure. The frequency of induced micronuclei decreased as a function of dose rate for low-LET radiation exposure but showed an increase with decreasing dose rate for radon exposure. The dose-rate effectiveness factor was 6.0 when comparing the frequency of micronuclei induced following an acute radon exposure with that from a 67-hour protracted exposure. By comparing micronuclei induction at equal doses of ${ }^{60} \mathrm{Co}$ and radon delivered in an equal time period, we obtained a high RBE of about 65 . The damage per WLM exposure from radon associated with wax and uranium ore-dust aerosols was higher than that associated with cigarette smoke aerosols.

This research addresses basic radiobiologic questions associated with radon inhalation (herein taken to mean "radon and its progeny") and helps provide a mechanistic basis for understanding the action of radon on respiratory-tract cells. This information provides the basis for better estimates of risk from indoor radon exposure. Key questions we're addressing are:

1. Is there a relationship between the genetic susceptibility of animals for the induction of lung cancer and the sensitivity of the lung cells to the induction of micronuclei?

2. What is the dose-rate effectiveness factor for protracted low-LET irradiation exposure, and, at low dose-rate exposures, what is the relative biological effectiveness
(RBE) for radon-induced damage with respect to protracted low-LET radiation?

3. How does the radon-progeny carrier aerosol influence the distribution of dose and damage in deep lung fibroblasts?

\section{Experimental Design and Methods}

To evaluate the relationship between the sensitivities of animals to cancer and micronuclei induction, studies were conducted with different rodent species and strains: Wistar rats, Syrian Golden hamsters, Chinese hamsters, C57BL/6J mice, and $A / J$ mice. The rat is very sensitive to radiation-induced lung cancer while the Syrian Golden and Chinese hamsters are not as sensitive. The C57BL/6J mouse is resistant to 
the induction of lung cancer by urethane, whereas the $A / J$ mouse is sensitive to lung cancer induction by this chemical. Our hypothesis is that sensitivity to lung cancer induction by either radiation or chemicals would be reflected by an increase in the frequency of radon-induced micronuclei or by a decrease in radon-induced repair of cytogenetic damage. To evaluate cytogenetic damage and repair, the frequency of induced micronuclei in lung fibroblasts was measured using the methods of Khan and Heddle (1992). Animals were exposed to radon using the in vivo system developed by Cross et al. (1984). This study addressed 2 questions: (1) Is initial damage between species the same? (2) Is the damage handled biologically the same in each species over time? All exposures were conducted with the same carrier aerosol (uranium ore dust) and the dose and fractionation time ( 3 to 5 days) was similar for each species. For the between-species and strain comparisons, animals were sacrificed 4 hours after the end of the radon exposure. Thereafter, at 4 hours and at 15 and 30 days after radon inhalation, additional rats, Syrian Golden hamsters, and Chinese hamsters were sacrificed to evaluate the loss of micronuclei from the cell population. The cells were harvested as described by Khan et al. (1994) and placed in culture for 72 hours. The cultures were treated with cytochalasin B to block cytokinesis, then micronuclei frequency was determined.

In another study, the limiting dose-rate effect for low-LET radiation and the RBE for radon relative to low-LET radiation were evaluated in Wistar rats. Rats were exposed to $0,1,2$, and 4 Gy of ${ }^{60} \mathrm{Co}$ gamma rays delivered over 20 minutes. Two additional groups of animals were exposed to $0,4,8$, and 12 Gy delivered over either 4 or 67 hours. The 2 protracted exposures matched the times required for the radon exposures above. Animals were sacrificed 4 hours after the end of each exposure and the irradiated fibroblast cells evaluated for the induction of micronuclei as described above.

The influence of different carrier aerosols was determined by evaluation of induced micronuclei in rat lung fibroblasts following inhalation of radon progeny attached to wax, uranium-ore dust, or cigarette smoke. In all studies, the cells were scored for micronuclei induction on coded slides.

\section{Results and Discussion Species/Strain Study}

The exposure-response relationships for in vivo induction of micronuclei by radon inhalation in Wistar rats and Syrian Golden hamsters have been reported (Khan et al. in press). The comparison between exposureresponse relationships for Wistar rats and Syrian Golden hamsters is shown in Figure 1. These relationships were fit by the least-squares method to linear equations (micronuclei/1000 binucleated cells $=15.5 \pm 14.4+0.53 \pm 0.06$ WLM for the rat; micronuclei/1000 binucleated cells $=38.1 \pm 15.1+0.80 \pm 0.08$ WLM for the Syrian Golden hamster). There was a single data point at 500 WLM for the Chinese hamster, which resulted in $1.83 \pm 0.02$ micronuclei $/ 1000$ binucleated cells/WLM. These observations are particularly interesting, because the Wistar rat is much more sensitive to radon-induced lung tumors than the Syrian Golden hamster (Cross

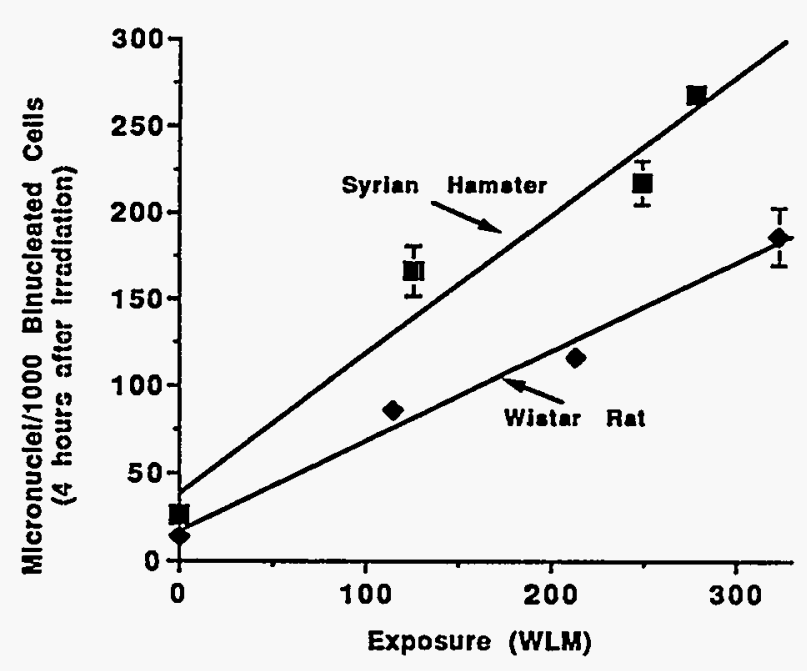

Figure 1. Comparison of Exposure-Response Relationships for Radon-Induced Micronuclei Between Wistar Rats and Syrian Golden Hamsters. Slope estimate for the Syrian Golden hamster was significantly higher $(P<0.05)$ than that estimated for the Wistar rat. 
et al. 1981). The current data show that, per WLM, more damage is present in the hamster lung than in the rat, and suggest that differences in sensitivity to the induction of lung cancer may not be related to the amount of initial chromosome damage induced, because this type of damage is usually lethal. The results of the mouse study are plotted in Figure 2. There were no significant differences observed in the frequency of micronuclei induced by radon in the 2 different strains of mice, even though $\mathrm{A} / \mathrm{J}$ mice are much more sensitive to chemically induced lung cancer. The frequency of induced micronuclei per unit exposure was $1.11 \pm 0.05$ and $1.12 \pm 0.03$ micronuclei/1000 binucleated cells/WLM for the A/J and C57BL/6J mice, respectively. This induced frequency is similar to that observed in the Chinese hamster and illustrates that the mouse is also less sensitive to the induction of initial genetic damage than the rat. It may be necessary to grow epithelial cells from the different species to resolve these differences.

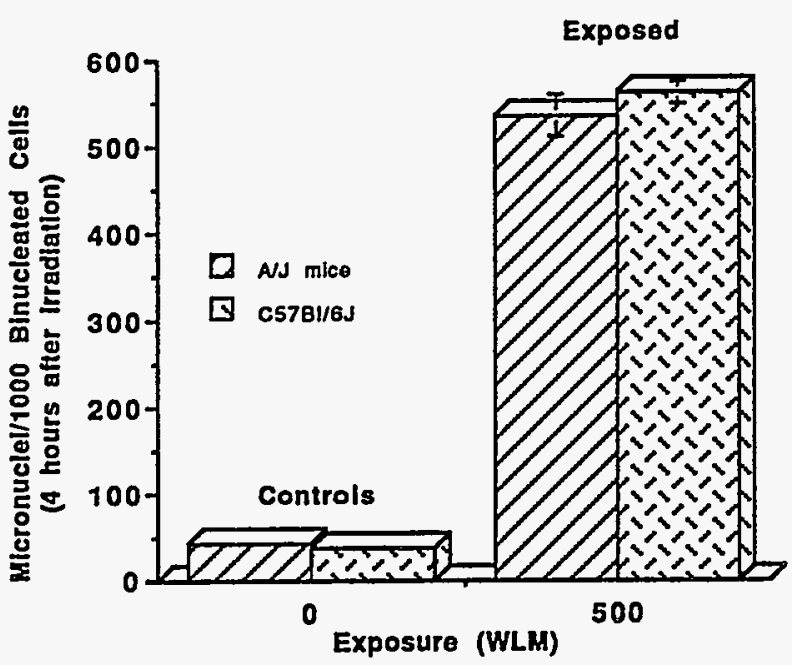

Figure 2. The Induction of Micronuclei by Radon Inhalation in the Deep-Lung Fibroblasts of 2 Different Strains of Mice (A/J and C57BL/6J). There were no significant differences observed between the two strains.
To evaluate the persistence of cytogenetic damage in the cell population, a comparison of the relative sensitivity per WLM of Wistar rats, Syrian Golden hamsters, and Chinese hamsters at all 3 sacrifice times was reported (Khan et al. in press); this comparison is shown in Figure 3. This figure suggests that the rat is the least sensitive of the 3 rodents, based on initial and sustained cytogenetic damage, and illustrates that the rate of loss of damage from the cell population is very similar for the rat, and Chinese and Syrian Golden hamster. These data further suggest that the between-species differences in sensitivity to cancer induction is not related to the rate of loss of the cells that contain cytogenetic damage from the cell population. This loss is probably related to cell death and cell proliferation, and seems not to be related to cancer induction sensitivity.

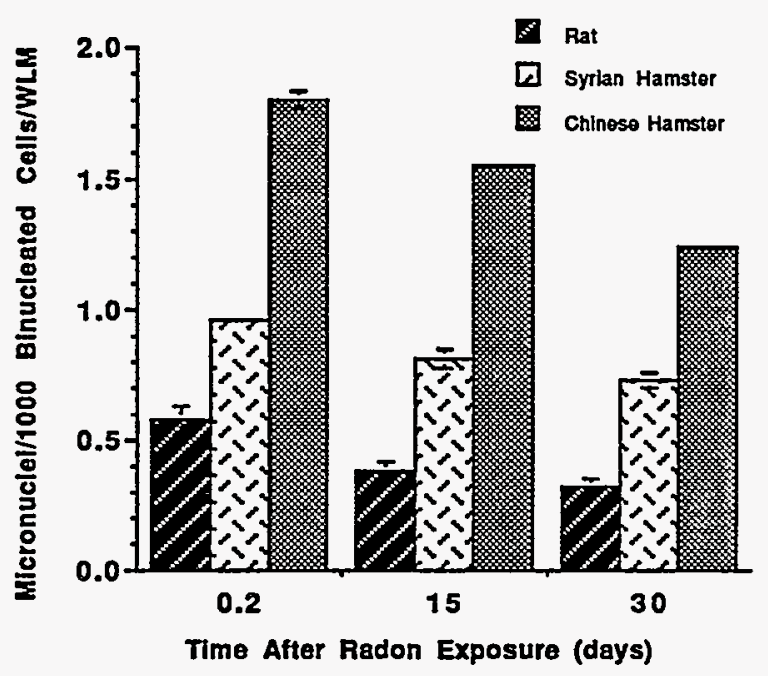

Figure 3. Comparison of Radon-Induced Micronuclei Frequency per WLM in Wistar Rat, Syrien Golden Hamster, and Chinese Hamster Lung Fibroblasts as a Function of Time (4 hours, and 15 and 30 days) Between the End of Radon Exposure and Sacrifice 


\section{Relative Biological Effectiveness Study}

To determine an RBE that is relevant to environmental radon exposures, it is necessary to develop low- and high-LET dose-response relationships at low dose and dose rates. We previously reported on the comparison of micronuclei induction for high dose-rate ${ }^{60} \mathrm{Co}$ gamma rays and radon, both in vivo and in vitro (Brooks et al. in press). The reported in vitro values reported indicate that radon is $10.9 \pm 2.6$ and $12.5 \pm 2.4$ times as effective as ${ }^{60} \mathrm{Co}$ in inducing micronuclei in primary rat lung fibroblasts and $\mathrm{CHO}-\mathrm{K} 1$ cells, respectively. For lung fibroblasts exposed by radon inhalation or by ${ }^{60} \mathrm{Co}$ gamma rays in vivo, radon was $10.6 \pm 1.0$ times as effective as acute whole-body ${ }^{60} \mathrm{Co}$ exposure. To make RBE comparisons that are more valid at environmental levels, where the dose rates are very low, it is necessary to establish the limiting dose rate for the exposure systems, especially for the low-LET radiation source. Figure 4 shows the dose-response relationship for the induction of micronuclei in vivo by ${ }^{60} \mathrm{Co}$ delivered over 3 different times. The dose-response relationships were fit with a linear least-squares analysis; they decreased as a function of increased exposure time. The equations that described the dose-response relationships (where $\mathrm{D}=$ dose in Gy) were micronuclei/binucleated cell $=$ $0.01+0.060 \mathrm{D}$ for acute exposure; micronuclei/ binucleated cell $=0.02+0.024 \mathrm{D}$ for exposures protracted 4 hours; and micronuclei/binucleated cell $=0.007+0.010 \mathrm{D}$ for exposures protracted 67 hours. If the damage produced by ${ }^{60} \mathrm{Co}$ and radon delivered over the same time are compared, the RBE value is estimated to be 65 . The dose-rate effectiveness factor for the induction of micronuclei was 6.0 when the highest dose rate was compared to the lowest dose rate.

\section{Carrier-Aerosol Study}

Studies have been conducted to determine if changing the radon-progeny carrier aerosol will change the dose and damage in the deep lung per WLM of exposure. Rats were exposed to similar total WLM exposure in association with a cigarette-smoke aerosol, a 0.2-mm-diameter wax aerosol, and a uranium ore-dust aerosol.

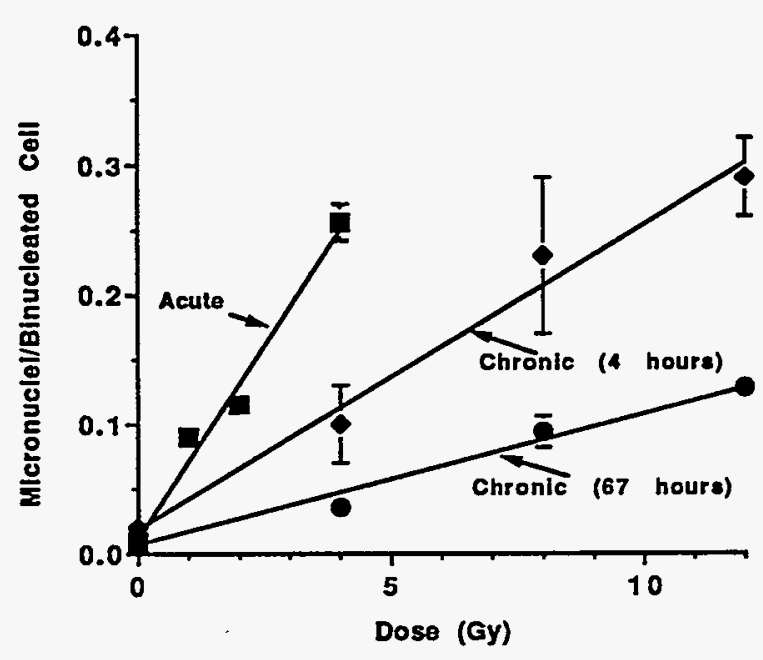

Figure 4. The Influence of Dose Rate on ${ }^{60}$ Co-Inducted Micronuclei in Deep-Lung Fibroblasts Exposed In Vivo

Figure 5 illustrates that the wax aerosol was the most effective (1.5 micronuclei/1000 binucleated cells/WLM) in inducing micronuclei in the deep lung, followed by the ore dust $(0.47$ micronuclei/1000 binucleated cells/WLM) and the cigarette-smoke aerosol ( 0.30 micronuclei/ 1000 binucleated cells/WLM). It should be noted that the dose rate of the animals exposed to the smoke aerosol was higher than that of the other 2 aerosols. The uniform size of the wax aerosol $(0.2 \mu \mathrm{m})$ seems to have had a marked infiuence on the actual amount of dose delivered to deep lung fibroblasts per WLM of exposure.

\section{Summary}

Studies have been conducted that demonstrate the usefulness of cellular damage as a biomarker of radiation dose to the lung. They suggest that initial cytogenetic damage in lung fibroblasts is a good measure of biological dose, but it is not related to the radiation or chemical sensitivity of animals for lung cancer induction. Similarly, the rate of loss of induced micronuclei from lung fibroblasts, which was used as a measure of tissue repair, does not appear to count for sensitivity for the induction of lung cancer among rodent species and strains, as expected, 


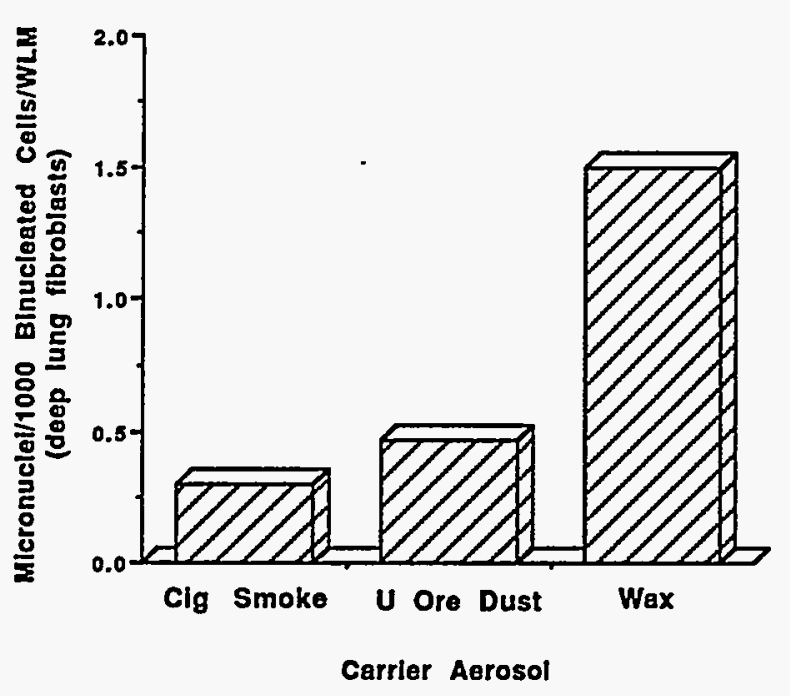

Figure 5. The Role of Aerosol Carriers (wax, uranium-ore dust, and cigarette-smoke particles) on the Induction of Micronuclei in the Deep Lung Following Inhalation of Radon and its Progeny

because removal of cells with potentially lethal damage may not affect cancer rates. In addition, an RBE of 65 was determined for low dose-rate radon-progeny exposure in vivo. This factor, combined with a rather high dose-rate effectiveness factor (6.0) for high vs. low dose-rate exposure, provide comparative risk estimations for cytogenetic damage. Finally, the influence of aerosol characteristics on dose and cytogenetic damage in deep lung fibroblasts was determined with 3 different aerosols. Further work is needed to characterize these aerosols, particularly in regard to the radon-progeny dose distribution in the respiratory tract. To make this research more useful for carcinoma risk evaluation, it is of prime importance to extend these studies to epithelial cells of the respiratory tract.

\section{References}

Brooks, A.L., M.A. Khan, A. Duncan, R.L. Buschbom, R.F. Jostes, and F.T. Cross. 1994. Effectiveness of radon relative to acute ${ }^{60} \mathrm{Co}$ gamma rays for induction of micronuclei in vitro and in vivo. Int. J. Radiat. Biol. (in press).

Cross, F.T., R.F. Palmer, R.H. Busch, R.E. Filipy, and B.O. Stuart. 1981. Development of lesions in Syrian Golden hamsters following exposure to radon daughters and uranium ore dust. Health Phys. 41:135-153.

Cross, F.T., R.F. Palmer, G.E. Dagle, R.H. Busch, and R.L.Buschbom. 1984. Influence of radon daughter exposure rate, unattachment fraction, and disequilibrium on occurrence of lung tumours. Radiat. Prot. Dosim. 7:381-384.

Khan, M.A., and J.A. Heddle. 1992. Optimization of the concurrent assay for gene mutation and chromosomal aberrations in vivo: Expression time in rats. Environ. and Mol. Mutagen. 20:165-171.

Khan, M.A., F.T. Cross, R. F. Jostes, E. Hui, J.E. Morris, and A.L. Brooks. 1994. Micronuclei induced by radon and its progeny in deep-lung fibroblasts of rats in vivo and in vitro. Radiat. Res. 139:53-59.

Khan, M.A., F.T. Cross, R.L. Buschbom, and A.L. Brooks. Inhaled radon-induced genotoxicity in Wistar rat, Syrian hamster, and Chinese hamster deep-lung fibroblasts in vivo. Mutat. Res. (in press). 
Publications and Presentations 


\section{Publications}

1993

Briant, J.K., and M. Lippmann. 1993.

Aerosol bolus transport through a hollow airway cast by steady flow in different gases. Aerosol Sci. Technol. 19:27-39.

Brooks, A.L., R.M. Kitchin, N.F. Johnson, and E.S. Gilbert. 1993. The role of cellular and molecular studies in evaluation of health effects from combined radiation and chemical exposure. Proceedings of the American Statistical Association Conference on Radiation and Health: Radiation Risk and Interactions.

Radiat. Res. 133:121-122.

Brooks, A.L., M.A. Khan, R.F. Jostes, and F.T. Cross. 1993. Metaphase chromosome aberrations as markers of radiation exposure and dose. In: The Laboratory and Epidemiology: The Development and Application of Biomarkers to the Study of Human Health Effects, L.E. Sever, ed., Proceedings of the 31st Hanford Symposium on Health and the Environment, October 19-23, 1992, Richland, Washington. J. Toxicol. Environ. Health 40:277-288.

Cross, F.T. 1993. A review of experimental animal radon health effects data. In: Radon Monitoring in Radiation Protection Environmental and/or Earth Sciences. G. Furlan and L. Tommasino, eds., pp. 34-43. World Scientific Publishing Co., Singapore.

Dagle, G.E., P. Fritsch, F.F. Hahn, J.R. Maisin, R. Masse, M. Morin, G. Patrick, C.L. Sanders. 1993. Report of joint U.S. Department of Energy Biological Effects Task Group and European Late Effects Project Group (BETG/EULEP) Workshop on Lung Pathology, October 12-13, 1992. In: European Late Effects Project Group Newsletter 73, pp. 24-30.

Evans, H.H., J. Mencl, G. Bakale, P.S. Rao, R.F. Jostes, T.E. Hui, F.T. Cross, and J.L. Schwartz. 1993. Interlaboratory comparison of the effects of radon on L5178Y cells: Dose contribution of radon daughter association with cells. Radiat. Res. 136:48-56.

Hui, T.E., F.T. Cross, A.C. James, R.F. Jostes, J.L. Schwartz, and K.L. Swinth. 1993. Evaluation of an alpha probe detector for in vitro cellular dosimetry. Health Phys. 64(6):647-652.

Hulla, J.E., Z.Y. Chen, and D.L. Eaton. 1993. Aflatoxin $B_{1}$-induced rat hepatic hyperplastic nodules do not exhibit a site-specific mutation within the $p 53$ gene. Cancer Res. 53:9-11.

Hulla, J.E., and R.P. Schneider. 1993. Structure of the rat p53 tumor suppressor gene. Nucleic Acids Res. 21(3):713-717.

Jostes, R.F. T.E. Hui, and F.T. Cross. 1993. Single-cell gel technique supports hit probability calculations. Health Phys. 64(6): 675-679.

Mahaffey, J.A., M.A. Parkhurst, A.C. James, F.T. Cross, M.C.R. Alavanja, J.D. Boice, S. Ezrine, P. Henderson, and R.C. Brownson. 1993. Estimating past exposure to indoor radon from household glass. Health Phys. 64(4):381-391.

Meznarich, H.K., L.S. McCoy, T.L. Bale, G.L. Stiegler, and M.R. Sikov. 1993. Brain fibronectin expression in prenatally irradiated mice. J. Toxicol. Environ. Health 40:263-275.

Miller, R.T., R.J. Douthart, and A.K Dunker. 1993. Learning an objective alphabet of amino acid conformation in protein. In: Techniques in Protein Chemistry, Vol. IV, p. 541-548. Plenum Publishing Corp., New York.

Miller, R.T., R.J. Douthart, and A.K. Dunker. 1993. An alphabet of amino acid conformation in protein. In: Proceedings of the 26th Annual Hawaii International Conference on Systems 
Science: Architecture and Biotechnology Computing, Vol. 5, pp. 689-698. IEEE Computer Society Press, Washington, DC.

Pelkey, J.E., G.S. Thomas, D.A. Thurman, V.B. Lortz, and R.J. Douthart. 1993. GnomeView: A tool for visual representation of human genome data. In: Proceedings of the 1993 ACM/SIGAPP Symposium on Applied Computing, pp. 127-136.

Sanders, C.L., K.E. Lauhala, K.E. McDonald, and G.A. Sanders. 1993. Lifespan studies in rats exposed to ${ }^{239} \mathrm{PuO}_{2}$ aerosol. I.

Dosimetry. Health Phys. 64:509-521.

Sever, L.E. 1993. Neuroepidemiology of intrauterine radiation exposure. In: Neuroepidemiology: Theory and Methods. Epidemiology of Neurological Disorders, C.A. Molgaard, ed., pp. 241-256. Academic Press, Orlando, Florida.

Sikov, M.R., R.J. Traub, T.E. Hui, H.K. Meznarich, and K.D. Thrall. 1993. Contribution of Maternal Radionuclide Burdens to Prenatal Radiation Doses. NUREG/CR-5631, PNL-7445, Rev. 1, Addendum 1. Prepared for the U.S. Nuclear Regulatory Commission, Washington, DC, by Pacific Northwest Laboratory, Richland, Washington.

Sikov, M.R., and T.E. Hui. 1993. Relationships between annual limits on intake and prenatal doses. In: Contribution of Maternal Radionuclide Burdens to Prenatal Radiation Doses. NUREG/CR-5631, PNL-7445, Rev. 1, Addendum 1. Prepared for the U.S. Nuclear Regulatory Commission, Washington, DC, by Pacific Northwest Laboratory, Richland, Washington.

Watson, C.R. 1993. SNODOG Glossary: Part 1, Introduction, and Part 2, Usage of Terms. PNL-8650, Pacific Northwest Laboratory, Richland, Washington.

Wolff, S.. V. Afzal, R. Jostes, and J.K. Wiencke. 1993. Indications of repair of radon-induced chromosome damage in human lymphocytes: An adaptive response induced by low doses of x rays. Environ. Health Perspect. Suppl. 101(Suppl. 3):73-77.

Zangar, R.C., D.L. Springer, and D.R. Buhler. 1993. Alterations in cytochrome P-450 levels in adult rats following neonatal exposure to xenobiotics. J. Toxicol. Environ. Health 38:43-55.

\section{4}

Akabani, G., A.C. James, and G.E. Dagle. 1994. Radon dosimetry of red bone marrow in beagle dogs using histological imaging. Health Phys. 6:S32.

Beach, C., A.F. Fuciarelli, and J.D. Zimbrick. 1994. Electron migration along 5-bromouracilsubstituted DNA irradiated in solution and in cells. Radiat. Res. 137:385-393.

Birchall, A., and A.C. James. 1994. A rapid method for modeling the kinetics of radioactive progeny applied to thorium in the lungs.

Health Phys. 67(2):162-169.

Birchall, A., and A.C. James. 1994. Uncertainty analysis of the effective dose per unit exposure from radon progeny and implications for ICRP risk-weighting factors. Radiat. Prot. Dosim. 53(1-4):133-140.

Brooks, A.L., M.A. Khan, A. Duncan, R.L. Buschbom, R.F. Jostes, and F.T. Cross.

1994. Effectiveness of radon relative to acute ${ }^{60} \mathrm{Co}$ gamma-rays for induction of micronuclei in vitro and in vivo. Int. J. Radiat. Biol. 66(6):801-808.

Cheng, X., R. Bakhtiar, S. Van Orden, and R.D. Smith. 1994. Charge-state shifting of individual multiply charged ions of bovine albumin dimer and molecular weight determination using an individual-ion approach. Anal. Chem. 66:2084-2087.

Cross, F.T. 1994. Invited commentary: Residential radon risks from the perspective of 
experimental animal studies. Am. J. Epidemiol. 140 (4):333-339.

Cross, F.T. 1994. Revision of ICRP Publication 30. Health Physics Society Newsletter 22(7):20.

Dagle, G.E., R.A. Gies, and F.T. Cross. 1994. Histopathology of radon-induced lung tumors in rats. Vet. Pathol. 31:586.

Douthart, R.J., J.E. Pelkey, and G.S. Thomas. 1994. Database integration and visualization of maps of the human genome using the GnomeView interface. In: Proceedings of the 27th Hawaii International Conference on System Sciences, Vol. 5, pp. 49-57. IEEE Computer Society, Los Alamitos, California.

Fuciarelli, A.F., E.C. Sisk, and J.D. Zimbrick. 1994. Electron migration in oligonucleotides upon $\gamma$-irradiation in solution. Int. J. Radiat. Biol. 65(4):409-418.

Fuciarelli, A.F., E.C. Sisk, J.H. Miller, and J.D. Zimbrick. 1994. Radiation-induced electron migration in nucleic acids. Int. $J$. Radiat. Biol. 66:505-509.

Gee, A., J.M. Specht, D. Kerk, J.D. Moore, A.S. Drum, and R.A. Elston. 1994. Disseminated neoplastic cells in Mytilus trossulus: Verification of host species origin by (16s-like) rRNA sequence comparison. Mol. Mar. Biol. Biotechnol. 3(1):7-12.

Hofstadler, S.A., J.E. Bruce, A.L. Rockwood, G.A. Anderson, B.E. Winger, and R.D. Smith. 1994. Isotopic beat patterns in Fourier transform ion cyclotron resonance mass spectrometry: Implications for high resolution mass measurements of large biopolymers. Intern. J. Mass Spectrom. Ion Proc. 132:109-127.

ICRP. 1994. Human Respiratory Tract Model for Radiological Protection. A Report of Committee 2 of the International Commission on Radiological Protection. ICPR Publication 66, International Commission on
Radiological Protection. Pergamon Press, Oxford, United Kingdom.

Jostes, R.F., E.W. Fleck, T.L. Morgan, G.L. Stiegler, and F.T. Cross. 1994. Southern blot and polymerase chain reaction exon analyses of HPRT mutations induced by radon and radon progeny. Radiat. Res. 137:371-379.

Khan, M.A., F.T. Cross, R.F. Jostes, T.E. Hui, J.E. Morris, and A.L. Brooks. 1994. Micronuclei induced by radon and its progeny in deep-lung fibroblasts of rats in vivo and in vitro. Radiat. Res. 139:53-59.

Mahaffey, J.A., J.S. Dukelow, Jr., R.D. Stenner, R.A. Kennedy, C.S. Glantz, C.R. Watson, L.H. Sawyer, J.K. Soldat, R.L. Buschbom, and B.L. Harper. 1994. Hanford Site's Integrated Risk Assessment Program: Screening-impacts of a no-intervention risk assessment. In: Spectrum '94: International Nuclear and Hazardous Waste Management. American Nuclear Society, La Grange Park IL.

Miller, R.T., R.J. Douthart, and A.K. Dunker. 1994. Identifying repeated structural elements in proteins. In: Proceedings of the 27th Hawaii International Conference on System Sciences, Vol. 5, pp. 235-244. IEEE Computer Society, Los Alamitos, California.

Rudolf, G., R. Köbrich, W. Stahlhofen, and A.C. James. 1994. Regional aerosol deposition in man-a statistic and algebraic model. In: Inhaled Particles VII, Proceedings of an International Symposium on Inhaled Particles Organized by the British Occupational Hygiene Society, September 16-22, 1991, J. Dodgson and R.L. McCallum, eds. Ann. Occup. Hyg. 38(Suppl. 1):1-14.

Solomon, S.B., R.S. O'Brien, M. Wilks, and A.C. James. 1994. Application of the ICRP's new respiratory tract model to an underground uranium mine. Radiat. Prot. Dosim. 53(1-4):119-125.

Thrall, B.D., D.B. Mann, M.J, Smerdon, and D.L. Springer. 1994. Nucleosome structure 
modulates benzo[a]pyrenediol epoxide adduct formation. Biochem. 33:2210-2216.

Weir, M.S., D.L. Springer, A.F. Fuciarelli, B.D. Thrall, and C.G. Edmonds. 1994. Characterization of the natural and radiation induced modification of histones. In: Techniques in Protein Chemistry V, pp. 115-122. Academic Press, New York, New York.

\section{5}

Cross, F.T. 1995. Evidence of cancer risk from radon experimental animal studies. In: Radiation and Public Perception, J. Young, ed., pp. 79-88. American Chemical Society Books, Washington, DC.

Fuciarelli, A.F., E.C. Sisk, R.M. Thomas, and D.L. Miller. 1995. Induction of base damage in DNA solutions by ultrasonic cavitation. Free Radical Biol. \& Med. 18(2):231-238.

\section{In Press}

Brooks, A.L. Chromosome aberrations. In: Encyclopedia of Toxicology (in press).

Brooks, A.L., K.E. McDonald, C. Mitchell, G.E. Dagle, and W.K. Yang. Role of ${ }^{239} \mathrm{Pu}-$ induced chromosome alterations and mutated $\mathrm{Ki}-\mathrm{V}$-ras oncogene during liver-cancer induction in Chinese hamsters and mice. In: International Seminar on Health Effects of Internally Deposited Radionuclides, Emphasis on Radium and Thorium. Heidelberg, Germany (in press).

Brooks, A.L., K.E. McDonald, C. Mitchell, D.S. Culp, A. Lloyd, N.F. Johnson, and R.M. Kitchin. The combined genotoxic effects of radiation and occupational pollutants. In: Current Topics in Occupational Health, T.S. Tenforde, ed., Proceedings of the 30th Hanford Symposium on Health and the Environment, Richland, Washington. Appl. Occup. Environ. Hyg. J. (in press).
Cross, F.T. Evidence of cancer risk from radon experimental animal studies. In: National Council of Radiation Protection and Measurements (NCRP) Scientific Committee 85 Report: Risk of Lung Cancer from Radon. (in press).

Cross, F.T., J. Lubin, R. Masse, J. Samet, and G.A. Swedjemark. Inputs to the quantification of risk. In: CEC/DOE Radon-Related Risk Recommendations Report, Chapter 4 (in press).

Khan, M.A., F.T. Cross, R.F. Jostes, and A.L. Brooks. Differences in radon-induced micronuclei between human bronchial epithelial cells and rat lung cells. In: Environmental Mutagens and Human Health, Proceedings of the 18th Annual Conference of the Environmental Mutagen Society of India, February 10-12, 1993, Madras, India (in press).

Khan, M.A., F.T. Cross, R.L. Buschbom, and A.L. Brooks. Inhaled radon-induced genotoxicity in Wistar rat, Syrian hamster, and Chinese hamster deep-lung fibroblasts in vivo. Mutat. Res. (in press).

Khan, M.A., R.F. Jostes, F.T. Cross, R.A. Gies, and A.L. Brooks. In vivo induction of micronuclei in rat and Chinese hamster lung fibroblasts from radon inhalation. In: Proceedings of the Annual Meeting of the Society of Toxicology, March 14-18, 1993, New Orleans, Louisiana, (in press).

Sanders, C.L., and G.E. Dagle. A threshold model of pulmonary carcinogenesis: Carcinoma in the rat after deposition of plutonium or quartz. In: Current Topics in Occupational Health, T.S. Tenforde, ed., 30th Hanford Symposium on Health and the Environment, Richland, Washington. Appl. Occup. Environ. Hyg. $J$. (in press).

Trumble, W.R., M. Huang, J.L. Reasoner, J.L. Huang, C.L. Wang, R.J. Douthart, and D.C. Birdsell. Gene synthesis and functional expression of a protein exhibiting mono-domain IgG Fc-binding. Protein Eng. (in press). 
Zhao, Z., J.H. Wahl, H.R. Udseth, S.A. Hofstadler, A.F. Fuciarelli, and R.D. Smith. On-line capillary electrophoresis-electrospray ionization mass spectrometry of nucleotides.

Electrophoresis (in press). 



\section{Presentations}

\section{3}

Birchall, A., and A.C. James. 1993. Sensitivity analysis of the effective dose per unit exposure from radon progeny using the new ICRP lung model. Presented at the workshop, Intakes of Radionuclides: Detection, Assessment, and Limitation of Occupational Exposure, September. 13-17, Bath, England.

Briant, J.K., and A.C. James. 1993. Modeling of aerosol deposition in human extrathoracic airways. Presented at the American Association for Aerosol Research, October 11-15, Oak Brook, Illinois.

Briant, J.K. 1993. Representation of the Aerosol Particle Size Spectrum by Deposition Diameter. Presented at the American Association for Aerosol Research, October 11-15, Oak Brook, Illinois.

Brooks, A.L., R.F. Jostes, M.A. Khan, and F.T. Cross. 1993. Radon-induced cytogenetic instability. Presented at the Sixth International Conference on Environmental Mutagens, February 21-26, Melbourne, Australia.

Brooks, A.L., and K.E. McDonald. 1993. The use of fluorescent in situ hybridization techniques in $A_{L}$ cells to define the kinetics and survival of radiation-induced chromosome aberrations. Presented at the Sixth International Conference on Environmental Mutagens, February 21-26, Melbourne, Australia.

Brooks, A.L. 1993. Overview of the cell and molecular research in the DOE/OHER Radon Program, Presented at the Principal Scientists' Meeting, February 28-March 1, Washington, D.C.

Brooks, A.L., R.F. Jostes, M.A. Khan, and F.T. Cross. 1993. Radon-induced cytogenetic instability. Presented at the 41st Annual Meeting of the Radiation Research Society, March 20-25, Dallas, Texas.
Brooks, A.L., M.A. Khan, R.F. Jostes, K.E. McDonald, and F.T. Cross. 1993. In vitro/in vivo radon-induced chromosome damage. Presented at the Environmental Mutagen Society Annual Meeting, April 17-22, Norfolk, Virginia.

Brooks, A.L. 1993. Radon awareness and disclosure Presented as testimony for the joint hearing before the Subcommittee on Health and the Environment and the Subcommittee on Transportation and Hazardous Materials of the Committee on Energy and Commerce, House of Representatives, Serial No. 103-139, July, Washington, D.C.

Brooks, A.L. 1993. The use of cellular and molecular changes to help understand exposuredose-response relationships for radon-induced damage. Presented at the National Academy of Sciences Meeting on Radon Risks, August 24, Washington, D.C.

Brooks, A.L. 1993. Realistic risk estimates: How they can be achieved. Presented at the DOE Contractor's Meeting, October 18-20, New York, New York.

Brooks, A.L. 1993. Cellular and molecular studies: How do they help define radon risk? Presented at the joint meeting of NIH/DOE/ EPA, October 29, Washington, D.C.

Bruce, J.E., S.A. Hofstadler, B.E. Winger, and R.D. Smith. 1993. Investigation of glycoprotein chemistry with electrospray ionization Fourier transform ion cyclotron resonance mass spectrometry. Presented at Sanibel Island Conference on MS of Carbohydrates, January 23-26, Sanibel Island, Florida.

Bruce, J.E., S. A. Hofstadler, G. A. Anderson, S.L. Van Orden, and R. D. Smith. 1993.

Time-dependent behavior of multiply charged electrosprayed ions tapped in a Fourier transform ion cyclotron resonance mass spectrometer. Presented at 41st ASMS Conference on MS and 
Allied Topics, May 30-June 4, San Francisco, California.

Cross, F.T. 1993. Radon interactions and the evidence on exposure rate effect from experimental animal studies. Presented at the National Research Council Radon: Molecular and Cellular Radiobiology Workshop, August 26-27, Washington, D.C.

Cross, F.T. 1993. Radon hazards in homes project. Presented at the U.S. DOE/OHER Radon Research Program Contractor's Meeting, October 17-19, New York, New York.

Douthart, R.J., J.E. Pelkey, and G.S. Thomas. 1993. A demonstration of the GnomeView interface. Presented at the DOE Human Genome Workshop, February 7-10, Sante Fe, New Mexico.

Douthart, R.J. 1993. GnomeView: A graphical inter face to the human genome. Presented at the DOE Human Genome Workshop, February 710, Sante Fe, New Mexico.

Douthart, R.J., J.E. Pelkey, G.S. Thomas, D.A. Thurman, and B.V. Lortz. 1993. GnomeView: A tool for visual representation of human genome data. Presented at the SIGAP 1993 Symposium on Applied Computing, February 14-16, Indianapolis, Indiana.

Durham, J.S., and A.C. James. 1993. Electron and beta dosimetry for the new ICRP respiratory tract model. Presented at the 38th Annual Meeting of the Health Physics Society, July 11-15, Atlanta, Georgia.

Edmonds, C.G., M.S. Weir, B.D. Thrall, J.E. Morris, and D.L. Springer. 1993. Evaluation of variable post- translational modification of human histones by electrospray ionization mass spectrometry and tandem mass spectrometry. Presented at the 41st ASMS Conference on Mass Spectrometry and Allied Topics, May 31-June 5, San Francisco, California.

Fuciarelli, A.F., E.C. Sisk, J.H. Miller, and J.D. Zimbrick. 1993. Electron migration in gamma-irradiated solutions of DNA. Presented at the Biophysical Society Meeting, February 1418, Washington, D.C.

Fuciarelli, A.F., E.C. Sisk, J.H. Miller, and J.D. Zimbrick. 1993. Electron migration in gamma-irradiated solutions of DNA. Presented at the 41st Annual Meeting of the Radiation Research Society, March 20-25, Dallas, Texas (invited plenary session).

Fuciarelli, A.F., E.C. Sisk, L.E. Matson, K. Miaskiewicz, J.H. Miller, and J.D. Zimbrick. 1993. Electron migration in gammairradiated solutions of DNA. Presented at the conference on DNA Damage: Effects on DNA Structure and Protein Recognition (New York Academy of Sciences), July 31-August 4, Burlington, Vermont.

Gies, R. A., F. T. Cross, and G. E. Dagle. 1993. A histopathological comparison of mixed exposures to radon progeny and uranium ore dust in rats. Presented at the 38th Annual Meeting of the Health Physics Society, July 11-15, Atlanta, Georgia.

Hofstadler, S. A., J. E. Bruce, B. E. Winger, and R. D. Smith. 1993. High-resolution precision mass measurements of noncovalently bound protein aggregates using electrosprayed ionization Fourier transform ion cyclotron resonance MS. Presented at 41st ASMS Conference of MS and Allied Topics, May 30June 4, San Francisco, California.

Hofstadler, S. A., J. H. Wahl, J. E. Bruce, and R. D. Smith. 1993. On-line high-performance separations with Fourier transform ion cyclotron resonance mass spectrometry. Presented at the 10th LC/MS and CE/MS Symposium, July 2124, Ithaca, New York.

Hofstadler, S.A., J.E. Bruce, J.H. Wahl, B.E. Winger, and R.D. Smith. 1993. High resolution precision mass measurements of biopolymers by electrospray ionization fourier transform ion cyclotron resonance mass spectrometry. Presented at 34th ORNL-DOE 
Conference on Analytical Chemistry in Energy Technology, October 4-6.

James, A.C. 1993. Application of the dog data to improve the human respiratory tract model for radiological protection. Presented at the DOE/ OHER Dog Workshop, February 16-18, Albuquerque, New Mexico.

James, A.C. 1993. An overview of the ICRP Task Group on the Human Respiratory Tract Model. Presented at the 33rd Annual Congress of the South African Association of Physicists in Medicine and Biology, University of the Orange Free State, March 8-10, Bloemfontein, South Africa.

James, A.C. 1993. The new ICRP lung model. Presented at the South African Association of Physicists in Medicine and Biology Joint Medical Physics and Radiation Protection Summer School, March 11-12, Allemanskraal Dam, South Africa.

James, A.C. 1993. Teach-in on the new ICRP lung model at the Atomic Energy Corporation of South Africa Ltd. Research Establishment, March 16, Pelindaba, Transvaal, South Africa.

James, A.C. 1993. Teach-in on the new ICRP lung model at the Koeberg Nuclear Power Station Establishment, March 18, Capetown, Cape Province, South Africa.

James, A.C. 1993. Dosimetric factors in evaluating radon risks. Presented at the National Research Council's Committee on Health Risks of Exposure to Radon (BEIR VI) Workshop, April 19, Albuquerque, New Mexico.

James, A.C. 1993. Physical factors affecting health risks from indoor radon. Presented at the CEC/USDOE/USEPA International Workshop on Indoor Radon Remedial Action, June 27July 2, Rimini, Italy.

James, A.C. 1993. Radon health effects data in animals and their relationship to human cancer. Presented to the Subcommittee on Environmental Carcinogenesis, National Cancer Advisory
Board, National Institutes of Health, September 20, Bethesda, Maryland.

James, A.C. 1993. The ICRP's new lung model for radiological protection. Presented at the American Nuclear Society's Topical Workshop on the Technical Basis for Measuring, Modeling, and Mitigating Toxic Aerosols, September 2730, Albuquerque, New Mexico.

James, A.C. 1993. The Dosimetry of Radon Progeny project. Presented at the DOE Contractor's Meeting, October 17-19, New York, New York.

James, A.C. 1993. New ICRP lung dosimetry and its risk implications for alpha emitters.

Presented at the symposium, Radiobiology of Inhaled Nuclides, November 9-10, Richland, Washington.

Jostes, R.F., T.E. Hui, A.L. Brooks, and F.T. Cross. 1993. Southern blot and PCR analysis of HPRT mutations induced by radon and its progeny. Presented at the Sixth International Conference on Environmental Mutagens, February 21-26, Melbourne, Australia.

Jostes, R.F., T.E. Hui, A.L. Brooks, and F.T. Cross. 1993. Use of the single-cell gel technique to support hit probability calculations in mammalian cells exposed to radon and radon progeny. Presented at the Sixth International Conference on Environmental Mutagens, February 21-26, Melbourne, Australia.

Jostes, R.F. 1993. Overview of the PNL Mechanisms of Radon Damage program. Presented at the Department of Radiobiology and Radiation Biology, Colorado State University, March 20, Fort Collins, Colorado.

Jostes, R.F., E.W. Fleck, T.L. Morgan, G. L. Stiegler, and F.T. Cross. 1993. Southern and PCR analysis of HPRT mutations induced by radon and its progeny. Presented at the 41 st Annual Meeting of the Radiation Research Society, March 20-25, Dallas, Texas. 
Jostes, R.F., E. W. Fleck, T. L. Morgan, G. L. Stiegler, and F.T. Cross. 1993. Southern and PCR analysis of HPRT mutations induced by radon and its progeny. Presented at the 17th Annual Meeting of the Cell Kinetics Society, April 15-18, Richland, Washington.

Jostes, R.F., F.T. Cross, R.A. Gies, T.E. Hui, A.D. Layton, L.C. Stillwell, and G.L. Stiegler. 1993. Update on the Mechanisms of Radon Damage project. Presented at the 1993 Annual Radon Contractor's meeting, October 17-19, New York, New York.

Khan, M.A., F.T. Cross, R.F. Jostes, and A.L. Brooks. 1993. Differences in radon-induced micronuclei between human bronchial epithelial cells and rat lung cells. Presented at the International Symposium on Environmental Mutagens and Human Health, February 10-12, Madras, India.

Khan, M.A., R.F. Jostes, J.A. Morris, and A.L. Brooks. 1993. The in vivo/in vitro induction of micronuclei in rat lung fibroblasts from radon exposure. Presented at the Sixth International Conference on Environmental Mutagens, February 21-26, Melbourne, Australia.

Khan, M.A., R.F. Jostes, F.T. Cross, R.A. Gies, and A.L. Brooks. 1993. In vivo induction of micronuclei in rat and Chinese hamster lung fibroblasts from radon inhalation. Presented at the Society of Toxicology Annual Meeting, March 14-18, New Orleans, Louisiana.

Khan, M.A., R.A. Gies, J.K. Briant, and A.L. Brooks. 1993. The induction of micronuclei in rat lung fibroblasts in response to radon inhalation with different carrier aerosols. Presented at the 10th Annual Meeting of the Pacific Northwest Association of Toxicologists, October 2223, Eatonville, Washington.

Leung, F.C., J.L. Helgeson, and D.R. Fisher. 1993. 131 I-EGF and 127 I-EGF are both cytotoxic to human A431 cervical cancer cells in vitro. Presented at the American Cancer Society 84th Annual Meeting of the American Associa- tion for Cancer Research, May 19-22, Orlando, Florida.

Mahaffey, J.A. 1993. Hanford's no-intervention risk assessment. Presented at the Society of Risk Analysis, December 5-8, Savannah, Georgia.

Miaskiewicz, K., J.H. Miller, R.L. Ornstein, A.F. Fuciarelli, J.D. Zimbrick, and J.A. Raleigh. 1993. DNA intramolecular crosslinks: Theory and experiment. Presented at the 41st Annual Meeting of the Radiation Research Society, March 20-25, Dallas, Texas.

Miller, R. T., R. J. Douthart, and A. K. Dunker. 1993. An alphabet of amino acid conformation in protein. Presented at the 26th Annual Hawaii International Conference on System Science, January 4-7, Maui, Hawaii.

Miller, R.T., R.J. Douthart, and A.K. Dunker. 1993. A set of distinguishable amino acid conformations. Presented at the Biophysical Society Meeting, February 18-22, New Orleans, Louisiana.

Miller, R.T., R.J. Douthart, and A.K. Dunker. 1993. Identifying repeated structures in proteins. Presented at the Seventh Annual Meeting of the Protein Society, June 23-26, San Diego, California.

Miller, R.T., R.J. Douthart, and A.K. Dunker. 1993. Identifying repeated structures in proteins. Presented at Genes, Macromolecules, and Computers III, August 17-22, Waterville, New Hampshire.

Murad, A.D., and D.L. Springer. 1993. Using Quantitative PCR to Measure Benzo[a]pyrene Diol Expoxide Adducts in Specific Sequences. Presented at the Tenth Annual Meeting of the Pacific Northwest Association of Toxicologists, October 22-23, Seattle, Washington.

Murad, A.O., B.D. Thrall, and D.L. Springer. 1993. Measuring benzo[a]pyrene diol epoxide adducts in specific sequences with defined chromatin structure and inducible transcription. 
Presented at the American Society for Cell Biology Annual Meeting, December 15, New Orleans, Louisiana.

O'Brien, R.S., S.B. Solomon, and A.C. James. 1993. Application of the ICRP Task Group's new lung model to an underground uranium mine. Presented at the workshop, Intakes of Radionuclides: Detection, Assessment, and Limitation of Occupational Exposure, September 13-17, Bath, England.

Park, J. F., and O. G. Raabe. 1993. Lung injury and cancer risks from inhaled ${ }^{239} \mathrm{PuO}_{2}$. Presented at the 38th Annual Meeting of the Health Physics Society, July 11-15, Atlanta, Georgia.

Pelkey, J.E., G.S. Thomas, and R.J. Douthart. 1993. GnomeView: A graphical interface to the human genome. Presented at the DOE Human Genome Workshop, February 7-10, Santa Fe, New Mexico.

Pelkey, J.E., G.S. Thomas, D.A. Thurman, V.B. Lortz, and R.J. Douthart. 1993. GnomeView: A tool for visual representation of human genome data. Presented at the 1993 ACM/ SIGAPP Symposium on Applied Computing, February 12-16, Indianapolis, Indiana.

Sikov, M.R., H.K. Meznarich, K.D. Thrall, and T.E. Hui. 1993. Use of data from experimental animals for dosimetry of radionuclides in the human embryo/fetus. Presented at the Teratology Society 1993 Annual Meeting, June 26-July 1, Tucson, Arizona.

Springer, D.L., B.D. Thrall, D.B. Mann, and M.J. Smerdon. 1993. Nucleosome modulation of benzo[a]pyrene diol epoxide adduct formation. Presented at the 15th Annual West Coast Chromatin and Chromosomes Meeting, December 9-12, Pacific Grove, California.

Strom, D.J., J.M. Selby, E.H. Carbaugh, M.M. Lardy, and T.P. Lynch. 1993. International dosimetry monitoring equipment-present and future. Presented at the Workshop on Intake of
Radionuclides, September 13-17, Bath, United Kingdom.

Thrall, B.D., and D.L. Springer. 1993. Reassembly of nucleosomes on a plasmid DNA model alters restriction enzyme accessibility. Presented at Society of Toxicology Annual Meeting, March 14-18, New Orleans, Louisiana.

Thrall, B.D., and D.L. Springer. 1993. Benzo[a]pyrene diol epoxide adduct formation on a reconstituted plasmid DNA system. Presented at the Environmental Mutagen Society Annual Meeting, April 17-22, Norfolk, Virginia.

Thrall, B.D., D.B. Mann, and D.L. Springer. 1993. Nucleosome structure modulates benzo[a]pyrene diol epoxide adduct formation. Presented at the 10th Annual Meeting of the Pacific Northwest Association of Toxicologists, October 22-24, Eatonville, Washington.

Thrall, K.D., T.E. Hui, and A.C. James. 1993. Physiologically based pharmacokinetic modeling of radon, thoron, and their short-lived progeny. Presented at the Society of Toxicology Annual Meeting, March 14-18, New Orleans, Louisiana.

Watson, C.R. 1993. Archival management of electronic information. Presented at the Archives Association of British Columbia Ancient Science Modern Machines, October 1-2, Vancouver, British Columbia, Canada.

Watson, C.R. 1993. National Radiobiology Archives. Presented at the 23rd General Assembly of the EULEP, March 7-11, Reisensberg, Germany.

Weir, M.S., D.L. Springer, A.F. Fuciarelli, B.D. Thrall, and S.G. Edmonds. 1993. Characterization of natural and radiation induced modifications of histones. Presented at the Seventh Symposium of the Protein Society, July 24-28, San Diego, Caifornia.

\section{4}

Akabani, G., A.C. James, and G.E. Dagle. 1994. Radon dosimetry of red bone marrow in 
beagle dogs using histological imaging. Presented at the Health Physics Society Annual Meeting, June 26-30, San Francisco, California.

Atencio, E.M., R.A. Gies, K.M. Groch, C.L. Sanders, F.T. Cross, and A.L. Brooks. 1994. Epithelial cell kinetics of the upper respiratory tract of Wistar rats following radon exposure. Presented at the 39th Annual Meeting of the Health Physics Society, June 26-30, San Francisco, California.

Bakhtiar, R.M., X. Cheng, S.L. Van Orden, and R.D. Smith. 1994. Charge state shifting of individual multiply charged ions of bovine albumin dimer and molecular weight. Presented at the American Society for Mass Spectrometry's 44th Conference on Mass Spectrometry and Allied Topics, May 29-June 3, Chicago, Illinois.

Brooks, A.L., W.K. Yang, K.E. McDonald, C. Mitchell, and G.E. Dagle. 1994. Role of ${ }^{239} \mathrm{Pu}-$ induced chromosome alterations and a mutated v$\mathrm{H}$-RAS oncogeny during liver cancer induction in mice. Presented at the International Symposium on Health Effects of Internally Deposited Radionuclides: Emphasis on Radium and Thorium, April 21, Heidelberg, Germany.

Brooks, A.L., M.A. Khan, A. Duncan, R.F. Jostes, and F.T. Cross. 1994. The effectiveness of radon relative to acute ${ }^{60} \mathrm{Co}$ for in vitro and in vivo induction of micronuclei. Presented at the 42nd Annual Radiation Research Society Meeting, April 29-May 4, Nashville, Tennessee.

Brooks, A.L., K.E. McDonald, and R.M. Kitchin. 1994. The influence of internally deposited alpha $\left({ }^{239} \mathrm{Pu}\right)$ or beta-gamma $\left({ }^{144} \mathrm{Ce}\right)$ emitting radionuclides on the sensitivity of Chinese hamster bone marrow cells to ${ }^{60} \mathrm{Co}$ induced chromosome aberrations. Presented at the Annual Meeting of the Environmental Mutagen Society, May 7-12, Portland, Oregon.

Bruce, J.E., G.A. Anderson, S:A. Hofstadler, and R.D. Smith. 1994. Single ion TRICS. Presented at the American Society for Mass Spectrometry's 44th Conference on Mass Spec- trometry and Allied Topics, May 29-June 3, Chicago, Illinois.

Cappas, M.A., K.D. Thrall, T.E. Hui, and J.A. Leonowich. 1994. A physiologically based pharmacokinetic model for methyl mercury in the pregnant and fetal rat. Presented at the American Industrial Hygiene Conference and Exposition, May 21-27, Anaheim, California.

Chen, R., D.W. Mitchell, X. Cheng, Q. Wu, S.A. Hofstadler, J.E. Bruce, and R.D. Smith. 1994. Charge and mass measurement of individual ions by ESI FT-ICR MS. Presented at the American Society for Mass Spectrometry's 44th Conference on Mass Spectrometry and Allied Topics, May 29-June 3, Chicago, Illinois.

Cheng, X., D.C. Gale, H.R. Udseth, and R.D. Smith. 1994. Charge state reduction of oligonucleotide negative ions from electrospray ionization. Presented at the American Society for Mass Spectrometry's 44th Conference on Mass Spectrometry and Allied Topics, May 29June 3, Chicago, Illinois.

Cheng, X., S.A. Hofstadler, D.C. Gale, Z. Zhao, and R.D. Smith. 1994. Advanced mass spectrometric methods for characterization of DNA. Presented at the 21st Annual Conference of the Federation of Analytical Chemistry and Spectroscopy Society, October 2-7, St. Louis, Missouri.

Cheng, X., D.C. Gale, H.R. Udseth, and R.D. Smith. 1994. Analysis of oligonucleotide mixtures by electrospray ionization-mass spectrometry. Presented at the Human Genome Workshop, November 13-18, Santa Fe New Mexico.

Dagle, G.E., R.E. Weller, C.R. Watson, and R.L. Buschbom. 1994. Effects of inhaled plutonium nitrate on bone and liver in dogs. Presented at the International Symposium on Health Effects of Internally Deposited Radionuclides: Emphasis on Radium and Thorium, April 20, Heidelberg, Germany. 
Dagle, G.E., and R.E. Filipy. 1994. Autoradiographic distribution of inhaled $\mathrm{Pu}$ in liver of dogs. Presented at Collaborative EULEP/BETG Liver Pathology Workshop, April 21, Heidelberg, Germany.

Dagle, G.E., R.A. Gies, and F.T. Cross. 1994. Histopathology of radon-induced lung tumors in rats. Presented at the Annual Meeting of the American College of Veterinary Pathologists, October 30-November 4, Montreal, Canada.

Edmonds, C.G., X. Cheng, R. Bakhtiar, S.L. Van Orden, R.D. Smith, S.L. Schlegel, and D.G. Camp III. 1994. Mass spectrometric evaluation of gas phase noncovalent quadruplex DNA obtained by electrospray ionization mass spectrometry. Presented at the American Society for Mass Spectrometry's 44th Conference on Mass Spectrometry and Allied Topics, May 29June 3, Chicago, Illinois.

Fuciarelli, A.F., E.C. Sisk, J.H. Miller and J.D. Zimbrick. 1994. Radiation-induced electron migration in oligonucleotides. Presented at the International Workshop on Radiation Damage in DNA, October 1-6, Gleneden, Oregon.

Gale, D.C., D.G. Camp, K.J. Wahl, S.L. Delinger, D.R. Goodlett, H.R. Udseth, and R.D. Smith. 1994. Analysis and characterization of oligonucleotide duplex-drug noncovalent complexes by electrospray ionization mass spectrometry. Presented at the American Society for Mass Spectrometry's 44th Conference on Mass Spectrometry and Allied Topics, May 29-June 3, Chicago, Illinois.

Gies, R.A., E.M. Atencio, A.L. Brooks, and F.T. Cross. 1994. Cell proliferation rates in the respiratory tract of rats following exposure to radon. Presented at the 42nd Ånnual Radiation Research Society Meeting, April 29-May 4, Nashville, Tennessee.

Hofstadler, S.A., G.A. Anderson, R. Bakhtiar, J.E. Bruce, R. Chen, X. Cheng, D.W. Mitchell, A.L. Rockwood, M.G. Sherman, H.R. Udseth, S. Van Orden, Q. Wu, and R.D. Smith. 1994. Mass analysis and reactions of large individual ions by electrospray ionization Fourier transform ion cyclotron resonance mass spectrometry. Presented at the International Mass Spectrometry Conference, August 29-September 2, Budapest, Hungary.

James, A.C. 1994. Dosimetry of inhaled radon and thoron progeny. Presented at the 1994 Summer School of the Health Physics Society, June 20-24, Davis, California.

Jostes, R.F., Stiegler, G.L., F.T. Cross, A.D. Layton, L.H. Lutze, and L.C. Stillwell. 1994. Sequence analysis of $\mathrm{LaCl}$ mutations obtained from lung cells of radon-exposed Big Blue ${ }^{\mathrm{ns}}$ transgenic mice. Presented at the 42nd Annual Radiation Research Society Meeting, April 29May 4, Nashville, Tennessee.

Khan, M.A., J.D. Saffer, K.M. Groch, and A.L. Brooks. 1994. Urethane and radon progeny-induced micronuclei in lung fibroblasts with $\mathrm{A} / \mathrm{J}$ and $\mathrm{C} 56 \mathrm{BL} / 6 \mathrm{~J}$ mice. Presented at the 34th Annual Meeting of the Society of Toxicology, March 5-9, Baltimore, Maryland.

Khan, M.A. R.A. Gies, J.K. Briant, A.C. James, and A.L. Brooks. 1994. Genotoxic response of rat lung fibroblasts to radon inhalation with different carrier aerosols. Presented at the 1994 Annual Meeting of the Society of Toxicology, March 13-17, Dallas, Texas.

Khan, M.A., F.T. Cross, R.A. Gies, and A.L. Brooks. 1994. Radon-induced micronuclei in lung fibroblasts in vivo: A comparative study of three rodent species. Presented at the 42 nd Annual Radiation Research Society Meeting, April 29-May 4, Nashville, Tennessee.

Khan, M.A., R.F. Jostes, F.T. Cross, and A.L. Brooks. 1994. Concurrent induction of micronuclei and gene mutations in rat lung fibroblasts in vivo following inhalation of radon and radon progeny. Presented at the 25th Meeting of the Environmental Mutagen Society, May 7-12, Portland, Oregon.

Layton, A.D., F.T. Cross, L.H. Lutze, G.L. Stiegler, L.C. Stillwell, and R.F. Jostes. 1994. 
Sequence analysis of LacI mutations obtained from lung cells of radon-exposed Big Blue ${ }^{\mathrm{Ts}}$ transgenic mice. Presented at the 25th Meeting of the Environmental Mutagen Society, May 712, Portland, Oregon.

Mahaffey, J.A. 1994. Will cleanup reduce health and ecological risks? Presented at the meeting of the American Society of Heating, Refrigeration, and Air Conditioning Engineers, February 23-26, New Orleans, Louisiana.

Schneider, R.P., L.C. Stillwell, G.E. Dagle, and F.T. Cross. 1994. Analysis of $p 53$ gene for mutations in radon-induced rat lung adenocarcinomas. Presented at the 42nd Annual Radiation Research Society Meeting, April 29May 4, Nashville, Tennessee.

Sisk, E. C., D. A. Jett, J. L. Grady, M. K. Bowman, J. D. Zimbrick, and A. F. Fuciarelli. 1994. Hydrogen atom donation in irradiated solutions of 5-BrU or 5-BrU-containing oligonucleotides. Presented at the 42nd Annual Meeting of the Radiation Research Society, April 29-May 4, Nashville, Tennessee.

Smith, R.D, G.A. Anderson, R. Bakhtiar, J.E. Bruce, X. Cheng, S.A. Hofstadler, A.L. Rockwood, and M.G. Sherman. 1994. Extension of mass spectrometry into the megadalton range by individual ion analysis. Presented at the ACS National Meeting and Symposium, March 13-18, San Diego, California.

Smith, R.D. 1994. Extension of mass spectrometry into the megadalton range by individual ion analysis. Presented at the Desorption '94 Meeting on Ion Formation, March 27-31, Sun River, Oregon.

Smith, R.D., S.A. Hofstadler, J.A. Bruce, X. Cheng, Q. Wu, and R. Chen. 1994. Fourier transform ion cyclotron resonance: The future of high-performance mass spectrometry? Presented at the Third International Meeting on Mass Spectrometry in the Life Sciences, September 13-17, San Francisco, California.
Smith, R.D., X Cheng, S.A. Hofstadler, J.A. Bruce, and C.G. Edmonds. 1994. High-speed sequencing of single DNA molecules in the gas phase by FTICR-MS. Presented at the Human Genome Workshop, November 13-18, Santa Fe, New Mexico.

Thrall, K.D., M.A. Cappas, and T.E. Hui. 1994. The role of physiologically based pharmacokinetic models in identifying biological data gaps and reducing uncertainties in risk assessment. Presented at the First Annual EPA/HERL Biological Mechanisms and Quantitative Risk Assessment Symposium, November 1-4, Research Triangle Park, North Carolina.

Thurston, S. J., K. M. Groch, A. L. Brooks, and J. D. Saffer. 1994. Analysis of gene expression following low-dose irradiation. Presented at the Annual Meeting of the Environmental Mutagen Society, May 7-12, Portland, Oregon.

Van Orden, S.L., R. Bakhtiar, J.E. Bruce, S.A. Hofstadler, and R.D. Smith. 1994. Investigations of charge state effects in transition metalprotein complexes by ESI-FTICR. Presented at the American Society for Mass Spectrometry's 44th Conference on Mass Spectrometry and Allied Topics, May 29-June 3, Chicago, Illinois.

Wahl, J.H.,S.A. Hofstadler, D.C. Gale, Z. Zhao, and R.D. Smith. 1994. On-line microseparations with Fourier transform ion cyclotron resonance mass spectrometry. Presented at the American Society for Mass Spectrometry's 44th Conference on Mass Spectrometry and Allied Topics, May 29-June 3, Chicago, Illinois.

Watson, C.R. 1994. Demonstration of a DBMS used to access information from the U.S. National Radiobiology Archives. Presented at the International Association for Social Science Information Service and Technology 20th Annual Conference on Data Archive and Library Professionals, May 3-6, San Francisco, California.

Weir-Lipton, M.S., A.F. Fuciarelli, D.L. Springer, B.D. Thrall, and C.G. Edmonds. 
1994. Radiation-induced modifications of peptide and histone models. Presented at the 42nd Annual Meeting of the Radiation Research Society, April 29-May 4, Nashville, Tennessee.

Weller, R.E. 1994. Complications of anticancer chemotherapy. Presented at the University of Chile Veterinary Oncology Post-Graduate Course, March 22-24, Santiago, Chile.

Weller, R.E. 1994. Diagnosis and management of endocrine gland neoplasms. Presented at the University of Chile Veterinary Oncology PostGraduate Course, March 22-24, Santiago, Chile.

Weller, R.E. 1994. Intrathoracic neoplasms in the dog and cat. Presented at the University of Chile Veterinary Oncology Post-Graduate Course, March 22-24, Santiago, Chile.

Weller, R. E. 1994. Primary bone neoplasms. Presented at the University of Chile Veterinary Oncology Post-Graduate Course, March 22-24, Santiago, Chile.

Weller, R.E. 1994. The significant humananimal bond: Pets with cancer. Presented at the University of Chile Veterinary Oncology PostGraduate Course, March 22-24, Santiago, Chile.

Weller, R.E. 1994. Urogenital tumors. Presented at the University of Chile Veterinary Oncology Post-Graduate Course, March 22-24, Santiago, Chile. 
Author Index 


\section{Author Index}

Brooks, A.L., 23, 47, 5357

Buschbom, R.L., 1, 19, 41

Cross, F.T., 41, 47, 53, 57

Dagle, G.E., 1, 41

Edmonds, C.G., 35

Eicher, E.M., 47

Fuciarelli, A.F., 35

Gies; R.A., 41, 47, 53

Gilbert, E.S., 1, 19

Groch, K.M., 23, 47, 57

Hill, R.L., 19

Hui, T.E., 53

Jostes, R.F., 23, 53, 57
Karagianes, M.T., 13

Khan, M.A., 47, 57

Ligotke, E.K., 13

Lutze, L.H., 53

Mann, D.B., 29

Miller, J.H., 35

Miller, R.C., 53

Murad, A.0., 29

Nelson, J.M., 53

O'Neill, J.P., 53

Park, J.F., 1

Petty, C.R., 41

Prather, J.C., 13
Saffer, J.D., 47

Sisk, E.C., 35

Smith, R.D., 35

Smith, L.G., 13

Smith, S.K., 13

Springer, D.L., 29, 35

Stillwell, L.C., 47, 53

Thrall, R.S., 47

Watson, C.R., 1, 13

Weller, R.E., 1

Wood, B., 23 


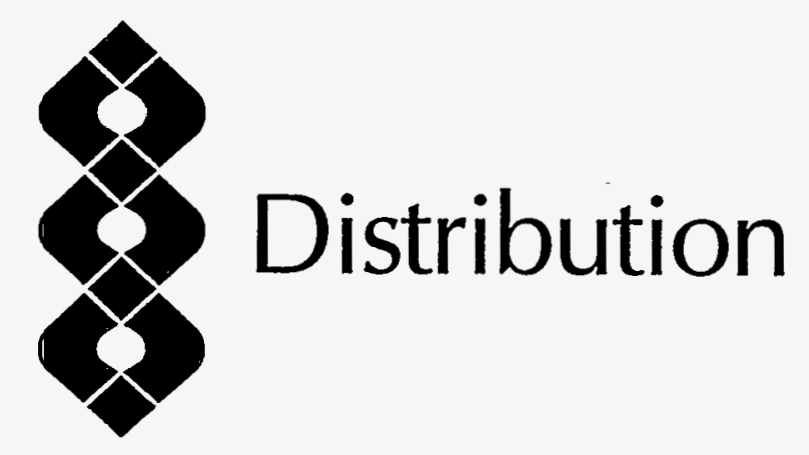




\section{Distribution}

\section{DOMESTIC}

S. Addison

Radiological Safety Division

University of Washington, GS-05

Seattle, WA 98105

R. E. Albert

Department of Environmental Health

University of Cincinnati Medical Center

3223 Eden Avenue

Cincinnati, $\mathrm{OH} \quad 45267-0056$

E. L. Alpen

University of California

230 Donner Laboratory

Berkeley, CA 94720

D. Anderson

ENVIROTEST

1108 NE 200th Street

Seattle, WA 98155-1136

G. Anderson

Department of Oceanography

University of Washington

Seattle, WA 98115

V. E. Archer

Rocky Mountain Center for Occupational

\& Environmental Health

University of Utah, , BIdg. 512

50 North Medical Drive

Salt Lake City, UT 84112
Assistant Secretary

Environment, Safety \& Health

EH-1, FORS

U.S. Department of Energy

Washington, DC 20585

O. Auerbach

VA Hospital

East Orange, NJ 97919

Auxier \& Associates

412 Executive Tower Dr., Suite 402

Knoxville, TN 37921

F. I. Badgley

13749 NE 41st Street

Seattle, WA 98125

R. E. Baker

8904 Roundleaf Way

Gaithersburg, MD 20879-1630

R. W. Barber

EH-33, GTN

U.S. Department of Energy

Washington, DC 20585

W. W. Barker, Chairman

Department of Biology

Central Washington University

Ellensburg, WA 98926

B. J. Barnhart

ER-72, GTN

U.S. Department of Energy

Washington, DC 20585 
PNL-10500, Pt. 1

UC-408

N. F. Barr

ER-72, GTN

U.S. Department of Energy

Washington, DC 20585

M. M. Bashor

ATSDR, Mail Stop E-28

1600 Clifton Road NE

Atlanta, GA 30333

J. W. Baum

Brookhaven National Laboratory

Bldg. 703-M

Upton, NY 11973

J. R. Beall

ER-72, GTN

U.S. Department of Energy

Washington, DC 20585

P. M. Beam

EM-431/TREV

U.S. Department of Energy

Washington, DC 20585-0002

S. Benjamin, Director, CRHL, Foothilis Campus

Colorado State University

Fort Collins, CO 80523

G. L. Bennett

NASA Headquarters

Code CT

Washington, DC 20546-0001

R. P. Berube

EH-20, FORS

U.S. Department of Energy

Washington, DC 20585
M. H. Bhattacharyya

Argonne National Laboratory

BIM Div., Bldg. 202

9700 South Cass Avenue

Argonne, IL 60439

R. W. Bistline

Rockwell International, Rocky Flats Plant

P. O. Box 464

Golden, CO 80401

B. B. Boecker

Lovelace Inhalation Toxicology

Research Institute

P. O. Box 5890

Albuquerque, NM 87185

V. P. Bond

Life Sciences, Chemistry and Safety

Brookhaven National Laboratory

P. O. Box 83 , Bldg. 460

Upton, NY 11973

R. Borders

Health Protection Division

U.S. Department of Energy

P.O. Box 5400

Albuquerque, NM 87115

Dr. H. Box, Director

Biophysics, Roswell Park Cancer Institute

Elm \& Carlton Streets

Buffalo, NY 14263-0001

J. D. Brain

Harvard University School of Public Health

665 Huntington Avenue

Boston, MA 02115 
B. D. Breitenstein

Brookhaven National Laboratory

P.O. Box 83

Upton, NY 11973

J. K. Briant

P. O. Box 3029

Richland, WA 99352

F. W. Bruenger

Division of Radiobiology

University of Utah, Bldg. 586

Salt Lake City, UT 84112

D. R. Buhler

Toxicology Program

Oregon State University

Corvallis, OR 97331

R. J. Bull

Washington State University

College of Pharmacy

Pullman, WA 99164-6510

G. Burley

Office of Radiation Programs, ANR-458

U.S. Environmental Protection Agency

Washington, DC 20460

L. K. Bustad

College of Veterinary Medicine

Washington State University

Pullman, WA 99163

C. E. Carter

National Institute of

Environmental Health Sciences

P.O. Box 12233

Research Triangle Park, NC 27709
H. W. Casey

School of Veterinary Medicine

Louisiana State University

Baton Rouge, LA 70803

R. J. Catlin

Health Science Center, University of Texas 13307 Queensbury Lane

Houston, TX 77079

Center for Devices \& Radiological Health

Office of Health Physics

2094 Gaither Road, HFZ-60

Rockville, MD 20851

N. Cohen

New York University Medical Center

P.O. Box 817

Tuxedo, NY 10987

D. A. Cool

Office of Nuclear Regulatory Research

Nuclear Regulatory Commission

Washington, DC 20585

D. K. Craig

Savannah River Laboratories

P.O. Box 616

Aiken, SC 29802

E. P. Cronkite

Medical Department

Brookhaven National Laboratory

Upton, NY 11973

J. Crowell

The Maxima Corporation

107 Union Valley Road

Oak Ridge, TN 37830

Distr.3 
PNL-10500, Pt. 1

UC-408

G. Davis

Medical Sciences Division

Oak Ridge Associated Universities

P.O. Box 117

Oak Ridge, TN 37830-0117

G. DePlanque, Director

U.S. Nuclear Regulatory Commission

Washington, DC 20555

G. P. Dix

3028 St. Tropex Street

Las Vegas, NV 89128

T. J. Dobry, Jr.

DP-6.2, GTN

U.S. Department of Energy

Washington, DC 20585

DOE/Office of Scientific \&

Technical Information (12)

Savannah River Operations Office

Environmental Division

U.S. Department of Energy

P.O. Box A

Aiken, SC 29801

H. Drucker

Argonne National Laboratory

9700 South Cass Avenue

Argonne, IL 60439

J. A. Louis Dubeau

Comprehensive Cancer Center

University of Southern California

P. O. Box 33800

Los Angeles, CA 90033-0800
A. P. Duhamel

ER-74, GTN

U.S. Department of Energy

Washington, DC 20585

D. Dungworth

Department of Veterinary Pathology

School of Veterinary Medicine

University of California

Davis, CA 95616

Dr. Patricia W. Durbin

Division of Biology and Medicine

Lawrence Berkeley Laboratory

University of California

Berkeley, CA 94704

K. F. Eckerman

Health and Safety Research Division

Oak Ridge National Laboratory

P.O. Box 2008

Oak Ridge, TN 37831-6383

C. W. Edington, Director

National Academy of Sciences, JH 554

2101 Constitution Avenue, NW

Washington, DC 20418

G. R. Eisele

Medical Division

Oak Ridge Associated Universities

P.O. Box 117

Oak Ridge, TN 37830

M. Eisenbud

711 Bayberry Drive

Chapel Hill, NC 27514 
N. B. Everett

Department of Biological Structure

University of Washington

School of Medicine

Seattle, WA 98105

H. Falk, M.D.

CDC, CEHIC/EHHE

1600 Clifton Road NE

Atlanta, GA 30333

K. P. Ferlic

DP-65, GTN

U.S. Department of Energy

Washington, DC 20585

B. H. Fimiani

Battelle Washington Operations

370 L'Enfant Promenade, Suite 900

901 D Street, SW

Washington, DC 20024

Dr. W. Michael Foster

Environmental Physiology, EHS

615 N. Wolfe St., No. 7006

Baltimore, MD 21205

M. E. Frazier

ER-72, GTN

U.S. Department of Energy

Germantown, MD 20875

H. L. Friedell

Biochemical Oncology

Case-Western Reserve University,

Wearn B21, 2058 Abington Road

Cleveland, $\mathrm{OH} 44106$
T. Fritz

Argonne National Laboratory

9700 South Cass Avenue

Argonne, IL 60439

D. J. Galas

Darwin Molecular Corp.

2405 Carillon Point

Kirkland, WA 98033

D. E. Gardner

Northrop Services, Inc.

P.O. Box 12313

Research Triangle Park, NC 27709

T. F. Gesell

Idaho State University

Campus Box 8106

Pocatello, ID 83209

R. D. Gilmore, President

Environmental Health Sciences, Inc.

9 Lake Bellevue Bldg., Suite 220

Bellevue, WA 98005

M. Goldman

Department of Radiological Sciences (VM)

University of California

Davis, CA 95616

R. Goldsmith

EH-42, GTN

U.S. Department of Energy

Washington, DC 20585

G. Goldstein

EH-42, GTN

U.S. Department of Energy

Washington, DC 20585

Distr.5 
PNL-10500, Pt. 1

UC-408

J. A. Graham

ECAO, Mail Drop 52

U.S. Environmental Protection Agency

Research Triangle Park, NC 27711

R. A. Griesemer, Director

National Toxicology Program

National Institutes of Health

P.O. Box 12233

Research Triangle Park, NC 27709

G. H. Groenewold

Energy and Mineral Research Center

University of North Dakota

Box 8123, University Station

Grand Forks, ND 58202

F. F. Hahn

Lovelace Inhalation Toxicology

Research Institute

P.O. Box 5890

Albuquerque, NM 87115

E. J. Hall

Radiological Research Laboratory

Columbia University

630 West 168th Street

New York, NY 10032

R. Hamlin

Department of Veterinary Physiology

The Ohio State University

1900 Coffey Road

Columbus, $\mathrm{OH} 43201$

J. W. Healy

51 Grand Canyon Drive

White Rock, NM 87544
C. H. Hobbs

Lovelace Inhalation Toxicology

Research Institute

P.O. Box 5890

Albuquerque, NM 87185

R. Hornung

DSHEFS, NIOSH

Robert A. Taft Laboratories

4676 Columbia Parkway

Cincinnati, $\mathrm{OH} 45220$

F. Hutchinson

Department of Therapeutic Radiology, Yale University School of Medicine 333 Cedar Street, HRT 315

New Haven, CT 06510-8040

H. Ishikawa, General Manager

Nuclear Safety Research Association

P.O. Box 1307

Falls Church, VA 22041

E. D. Jacobson

Center for Devices \& Radiological Health

U.S. Food \& Drug Administration

5600 Fishers Lane, HFZ-100

Rockville, MD 20857

A. W. Johnson

San Diego State University

6310 Alvardo Court, Suite 110

San Diego, CA 92120

R. K. Jones

The Lovelace Foundation for

Medical Education \& Research

Bldg. 9200, Area Y, Sandia Base

Albuquerque, NM 87108 
G. Y. Jordy

ER-41, GTN

U.S. Department of Energy

Washington, DC 20585

C. M. Kelly

Air Products and Chemicals, Inc.

P.O. Box 538

Allentown, PA 18105

M. Krebs

Office of Energy Research, ER-1, FORS

U.S. Department of Energy

Washington, DC 20585

W. Lowder

U.S. Department of Energy-EMEL

375 Hudson Street

New York, NY 10014-3621

W. M. Leach

U.S. Food \& Drug Administration

5600 Fishers Lane, HFZ-100

Rockville, MD 20857

Librarian

Documents Department, The Libraries

Colorado State University

Ft. Collins, CO 80523

Librarian

Electric Power Research Institute

P.O. Box 10412, 3412 Hillview Ave.

Palo Alto, CA 94303

Librarian

Health Sciences Library, SB-55

University of Washington

Seattle, WA 98195
Librarian

Los Alamos National Laboratory

Report Library, MS P364

P.O. Box 1663

Los Alamos, NM 87545

Librarian

Oregon Regional Primate Research Center 505 NW 185th Avenue

Beaverton, OR 97006

Library

Serials Department (\#80-170187)

University of Chicago

1100 East 57th Street

Chicago, IL 60637

Librarian

Washington State University

Pullman, WA 99164-6510

J. B. Little

Department of Physiology

Harvard School of Public Health

665 Huntington Avenue

Boston, MA 02115

R. Loesch

EH-411, GTN

U.S. Department of Energy

Washington, DC 20585

A. B. Lovins

Rocky Mountain Institute

1739 Snowmass Creek Road

Snowmass, CO 81654-9199

Distr.7 
PNL-10500, Pt. 1

UC-408

D. L. Lundgren

Lovelace Inhalation Toxicology

Research Institute

P.O. Box 5890

Albuquerque, NM 87185

O. R. Lunt

Laboratory of Biomedical

\& Environmental Sciences

University of California

900 Veteran Avenue

Los Angeles, CA 90024-1786

J. R. Maher

ER-65, GTN

U.S. Department of Energy

Washington, DC 20585

T. D. Mahony

750 Swift Boulevard

Richland, WA 99352

S. Marks

2500 Canterbury Lane E.

Apartment 201

Seattle, WA 98112-2564

D. R. Mason

Nuclear Safety Branch

U.S. Department of Energy

P.O. Box A

Aiken, SC 29801

W. H. Matchett

Graduate School

New Mexico State University, Box 3G

Las Cruces, NM 88003-0001
R. O. McClellan, President

Chemical Industry Institute of Toxicology

P.O. Box 12137

Research Triangle Park, NC 27709

J. F. McInroy

Los Alamos National Laboratory

P.O. Box 1663, MS K4-84

Los Alamos, NM 87545

Medical Officer

Monsanto Research Corp.

Mound Laboratory

P.O. Box 32

Miamisburg, OH 45342

T. Meinhardt

DSHEFS, NIOSH

Robert A. Taft Laboratories

4676 Columbia Parkway

Cincinnati, $\mathrm{OH} 45220$

C. B. Meinhold

National Council on Radiation Protection 7910 Woodmont Avenue, Suite 800

Bethesda, MD 20814

H. Menkes

Assistant Professor of Medicine \&

Environmental Medicine

The John Hopkins University

Baltimore, MD 21205

D. B. Menzel

Southern Occupational Health Center

University of California, Irvine

Irvine, $\mathrm{CA} 92717$

C. Miller

P.O. Box 180

Watermill, NY 11976 
S. Miller

Department of Radiobiology

University of Utah

Salt Lake City, UT 84112

K. Z. Morgan

113 Danbury Drive

Oakridge, TN 37830

P. E. Morrow

Department of Biophysics

Medical Center, University of Rochester

Rochester, NY 14642

O. R. Moss

Chemical Industry Institute of Toxicology

P.O. Box 12137

Research Triangle Park, NC 27709

W. F. Mueller

New Mexico State University

Box 4500

Las Cruces, NM 88003-4500

D. S. Nachtwey

NASA-Johnson Space Center

Mail Code SD-5

Houston, TX 77058

R. Nathan

Battelle Columbus Laboratory

505 King Avenue

Columbus, Ohio 43201

National Library of Medicine

TSD-Serials

8600 Rockville Pike

Bethesda, MD 20014
N. S. Nelson

Office of Radiation Programs, ANR-461

U.S. Environmental Protection Agency

$401 \mathrm{M}$ Street SW

Washington, DC 20460

P. Nettesheim

National Institutes of

Environmental Health Sciences

Research Triangle Park, NC 27711

W. R. Ney, Executive Director

National Council on Radiation

Protection and Measurements

7910 Woodmont Avenue, Suite 800

Bethesda, MD 20814

S. W. Nielsen

Department of Pathology

New York State Veterinary College

Cornell University

Ithaca, NY 14850

R. A. Nilan

Division of Sciences

Washington State University

Pullman, WA 99164

M. Nolan

10958 Rum Cay Court

Columbia, MD 21044

Nuclear Regulatory Commission

Advisory Committee on Reactor Safeguards

Washington, DC 20555

A. Patrinos, Director

Office of Health and Environmental Research

ER-70, GTN

U.S. Department of Energy

Washington, DC 20585

Distr.9 
PNL-10500, Pt. 1

UC-408

J.E. Pelkey

c/o Cray Computer Corp.

1110 Bayfield Drive

Colorado Springs, CO 80906

A. F. Perge

RW-43, FORS

U.S. Department of Energy

Washington, DC 20585

D. F. Petersen

Los Alamos National Laboratory

P.O. Box 1663

Los Alamos, NM 87545

G. R. Petersen

EH-421, GTN

U.S. Department of Energy

Washington, DC 20585

\section{H. J. Pettengill}

EH-40, GTN

U.S. Department of Energy

Washington, DC 20585

H. Pfuderer

Oak Ridge National Laboratory

P.O. Box X

Oak Ridge, TN 37830

O. G. Raabe

Laboratory for Energy-Related Health Research University of California

Davis, CA 95616

R. Rabson

ER-17, GTN

U.S. Department of Energy

Washington, DC 20585
D. P. Rall, Director

National Institutes of

Environmental Health Sciences

P.O. Box 12233

Research Triangle Park, NC 27709

R. D. Reed, Chief

Rocky Flats Area Office

Albuquerque Operations Office

U.S. Department of Energy

P.O. Box 928

Golden, CO 80402-0928

C. R. Richmond

Oak Ridge National Laboratory

$4500 \mathrm{~N}, \mathrm{MS}-62523$

P.O. Box 2008

Oak Ridge, TN 37831-6253

B. Robinson

Monsanto Research Corp.

Mound Laboratory

P.O. Box 32

Miamisburg, OH 45342

S. L. Rose

ER-72, GTN

U.S. Department of Energy

Washington, DC 20585

G. Runkle, Chief

U.S. Department of Energy

AL HPB/EHD

P.O. Box 5400

Albuquerque, NM 87115

G. Saccomanno

Pathologist and Director of Laboratories

St. Marys and V. A. Hospitals

Grand Junction, CO 81501 
U. Saffiotti

Laboratory of Experimental Pathology

National Cancer Institute

Bldg. 41, Room C-105

Bethesda, MD 20892

\section{Sagan}

Electric Power Research Institute

3412 Hillview Avenue

P.O. Box 10412

Palo Alto, CA 94304

M. Sage

CDC (F-28), CEHIC

1600 Clifton Road NE

Atlanta, GA 30333

J. M. Samet, M.D.

The Johns Hopkins University

School of Hygiene \& Public Health

615 N. Wolfe St., Suite 6039

Baltimore, MD 21205-2179

\section{L. Sanders}

Inhalation Toxicology Research Institute

P. O. Box 5890

Albuquerque, NM 87185

R. A. Scarano

Mill Licensing Section

Nuclear Regulatory Commission

Washington, DC 20585

\section{R. A. Schlenker}

Environmental Health and Safety Department

Argonne National Laboratory, Bldg. 201

9700 South Cass Avenue

Argonne, IL 60439
M. Schulman

ER-70, GTN

U.S. Department of Energy

Washington, DC 20585

T. M. Seed

Argonne National Laboratory, BIM 202

9700 South Cass Avenue

Argonne, IL 60439

R. B. Setlow

Brookhaven National Laboratory

P. O. Box 83

Upton, NY 11973

R. Shikiar

Battelle Seattle Research Center

4000 NE 41st Street

Seattle, WA 98105

H. P. Silverman

Beckman Instruments

2500 Harbor Blvd.

Fullerton, CA 92634

W. K. Sinclair

National Council on Radiation Protection

7910 Woodmont Avenue, Suite 800

Bethesda, MD 20814

D. H. Slade

ER-74, GTN

U.S. Department of Energy

Washington, DC 20585

D. A. Smith

ER-72, GTN

U.S. Department of Energy

Washington, DC 20585

Distr.11 
PNL-10500, Pt. 1

UC-408

G. S. Smith

New Mexico State University

Box 3-I

Las Cruces, NM 88003-0001

J. M. Smith

CDC, CEHIC

1600 Clifton Road NE

Atlanta, GA 30333

M. Smith

Department of Ecology

NUC Waste Library

PV-11 Bldg. 99, South Sound

Olympia, WA 98504

Dr. H. Spitz

Department of Mechanical, Industrial, \&

Nuclear Engineering, MS 072

University of Cincinnati

Cincinnati, OH 45267

J. N. Stannard

17441 Plaza Animado \#132

San Diego, CA 92128

R. J. Stern

EH-10, FORS

U.S. Department of Energy

Washington, DC 20585

E. T. Still

Kerr-McGee Corporation

P.O. Box 25861

Oklahoma City, OK 73125

D. Swanger

Biology Department

Eastern Oregon State College

La Grande, OR 97850
J. Swinebroad

PE-43, GTN

U.S. Department of Energy

Washington, DC 20585

M. Tanaka

Research Library

Brookhaven National Laboratory

Upton, NY 11973

G. N. Taylor

Division of Radiobiology, Bldg. 351

University of Utah

Salt Lake City, UT 84112

Technical Information Service

E. I. duPont de Nemours \& Co.

Savannah River Laboratory, Room 773A

Aiken, SC 29801

J. W. Thiessen

P.O. Box 399

Somers, MT 59932

R. G. Thomas

Argonne National Laboratory

Environmental Res. Bldg. 203

9700 South Cass Avenue

Argonne, IL 60439

T. Thomas

EH-41, GTN

U.S. Department of Energy

Washington, DC 20585

D. Thomassen

Health Effects Research Division

U.S. Department of Energy

ER-72, GTN

Germantown, MD 20874 
L. H. Toburen

National Academy of Sciences

Board of Radiation Research

2101 Constitution NW, NAS/Rm. 342

Washington, DC 20318

P. W. Todd

Chemical Engineering Dept.

University of Colorado, Campus Box 424

Boulder, CO 80309

Trend Publishing, Inc.

National Press Bldg.

Washington, D.C. 20045

G. E. Tripard

Acting Director, NRC

Washington State University

Pullman, WA 99164-1300

University of Washington School of Medicine Associate Dean, Scientific Affairs A-300 Health Sciences Ctr., MS: SC-64

Seattle, WA 98195

A. C. Upton

New York University Medical Center

Institute of Environmental Medicine

P. O. Box 817

Tuxedo, NY 10987

E. J. Vallario

15228 Red Clover Drive

Rockville, MD 20853

R. L. Van Citters, Dean

Research and Graduate Programs

University of Washington

Seattle, WA 98105
Dr. C. R. Vest

Marymount University

2807 North Glebe Road

Arlington, VA 22207

G. J. Vodapivc

DOE - Schenectady Naval Reactors Office

P.O. Box 1069

Schenectady, NY 12301

G. L. Voelz

Los Alamos National Laboratory

P.O. Box 1663, MS K4-04

Los Alamos, NM 87545

B. W. Wachholz

Radiation Effects Branch

National Cancer Institute

Executive Plaza North

6130 Executive Blvd.

Rockville, MD 20842

N. Wald

School of Public Health

University of Pittsburgh

Pittsburgh, PA 15213

A. Waldo

U.S. Department of Energy, (EH-231)

1000 Independence Avenue SW

Washington, DC 20585

P. Watson, Associate Professor

Department of Chemistry

Oregon State University

Corvallis, OR 97331

M. E. Weaver

University of Oregon Health Science Center

School of Dentistry

Portland, OR 97201

Distr.13 
PNL-10500, Pt. 1

UC-408

M. H. Weeks

U.S. AEHA, Bldg. 2100

Edgewood Arsenal

Aberdeen Proving Ground, MD 21014

I. Wender

Department of Chemical Engineering

1249 Benedum Hall

University of Pittsburgh

Pittsburgh, PA 15261

K. Wilzbach

Argonne National Laboratory

9700 South Cass Avenue

Argonne, IL 60439

F. J. Wobber

ER-75, GTN

U.S. Department of Energy

Washington DC 20585

R. W. Wood

ER-73, GTN

U.S. Department of Energy

Washington, DC 20585

M. E. Wrenn

Environmental Radiation \&

Toxicology Laboratory

University of Utah

1771 South 900 W. \#10

Salt Lake City, UT 84104

Dr. Chui-hsu Yang

NASA Johnson Space Center

NASA Road 1, Mail Code: SD4

Houston, TX 77058

Dr. S. Yaniv

18 Cedarwood Court

Rockville, MD 20852
P. L. Ziemer

EH-1, Forrestal

U.S. Department of Energy

Washington, DC 20585

J. D. Zimbrick

National Academy of Sciences/NRC

Board of Radiation Effects/342

2101 Constitution Ave., NW

Washington, DC 20418

FOREIGN

A. Aarkrog

Risø National Laboratory

ECO/ML, DK-4000 Roskilde

DENMARK

G. E. Adams, Director

Medical Research Council, Radiobiology Unit

Harwell, Didcot, Oxon OX11 ORD

ENGLAND
A. L. Alejandrino, Head
Biomedical Research, ARD
Republic of the Philippines
Philippine Nuclear Research Institute
P.O. Box 932, Manila
THE PHILIPPINES

M. Anderson, Library

Department of National Health \& Welfare

Ottawa, Ontario

CANADA

Atomic Energy of Canada, Ltd.

Scientific Document Distribution Office

Station 14, Chalk River Nuclear Laboratories

Chalk River, Ontario KOJ 1JO

CANADA 
D. C. Aumann

Institut für Physikalische Chemie

Universität Bonn, Abt. Nuklearchemie

Wegelerstraße 12, 5300 Bonn 1

GERMANY

M. R. Balakrishnan, Head

Library \& Information Services

Bhabha Atomic Research Centre

Bombay-400 085

INDIA

G. W. Barendsen

Laboratory for Radiobiology

AMC, FO 212, Meibergdreef 9

$1105 \mathrm{AZ}$ Amsterdam

THE NETHERLANDS

A. M. Beau, Librarian

Département de Protection Sanitaire

Commissariat à l'Énergie Atomique

BP 6, F-92265 Fontenay-aux-Roses

FRANCE

G. Bengtsson, Director-General

Statens Stralskyddsinstitut

Box 60204, S-104 01 Stockholm

SWEDEN

D. J. Beninson, Director

Licenciamento de Instalaciones Nulceares

Comisión Nacional de Energía Atómica

Avenida del Libertador 8250

$2^{\circ}$ Piso Of. 2330, 1429 Buenos Aires

ARGENTINA

\section{A. Bianco}

Via le Seneca, 65

10131 Torino

ITALY
J. Booz

KFA Jülich Institut für Medezin

Kernsforschungsanlage Jülich

Postfach 1913, D-5170 Jülich

GERMANY

M. J. Bulman, Librarian

Medical Research Council, Radiobiology Unit

Harwell, Didcot, Oxon OX11 ORD

ENGLAND

\section{Calamosia}

ENEA-LAB Fisica E Tossicologia Aerosol

Via Mazzini 2, I-40138 Bologna

ITALY

Cao Shu-Yuan, Deputy Head

Laboratory of Radiation Medicine

North China Institute of Radiation Protection

P.O. Box 120, Tai-yuan, Shan-Xi

PEOPLE'S REPUBLIC OF CHINA

\section{Carpentier}

Commission of the European Communities

200 Rue de la Loi, J-70 6/16

B-1049 Brussels

BELGIUM

M. W. Charles

Physics Department

University of Birmingham

Edgbastan, Birmingham B152TT

ENGLAND

Chen Xing-An

Laboratory of Industrial Hygiene

Ministry of Public Health

2 Xinkang Street, Deshengmenwai, Beijing

PEOPLE'S REPUBLIC OF CHINA

Distr.15 
PNL-10500, Pt. 1

UC-408

R. Clarke

National Radiological Protection Board

Harwell, Didcot, Oxon OX11 ORQ

ENGLAND

G. F. Clemente, Director

Radiation Toxicology Laboratory

Casaccia Centre for Nuclear Studies (CSN)

Casella Postale 2400, I-00100 Roma

ITALY

H. Coffigny

Institut de Protection et de Sûreté Nucléaire

Département de Protection Sanitaire

Service de Pathologie Expérimentale

BP 6, F-92265 Fontenay-aux-Roses

FRANCE

Commission of the European Communities

DG XII - Library SDM8 R1

200 Rue de la Loi, B-1049 Brussels

BELGIUM

M. S. Davies

Medical Research Council

20 Park Crescent, London W1N 4AL

ENGLAND

Deng Zhicheng

North China Institute of Radiation Protection

Tai-yuan, Shan-Xi

PEOPLE'S REPUBLIC OF CHINA

M. Di Paola

ENEA, PAS/VALEPID, C.R.E. Casaccia

Casella Postale 2400, I-00100 Roma

ITALY
Director

Commissariat à l'Énergie Atomique

Centre d'Etudes Nucléaires

Fontenay-aux-Roses (Seine)

FRANCE

Director

Laboratorio di Radiobiologia Animal

Centro di Studi Nucleari Della Casaccia

Comitate Nazionale per l'Energia Nucleare

Casella Postale 2400, I-00100 Roma

ITALY

M. Dousset

Health Ministry

Frue de la Gruerie

F-91190 Gifsur Yvette

FRANCE

J. Eapen

Biochemistry Division

Bhabha Atomic Research Centre

Bombay-400 085

INDIA

Esta $\widetilde{c}$ ao Agronómica

Nacional Biblioteca

2780 Oeiras

PORTUGAL

L. Feinendegen, Director

Institut für Medezin

Kernsforschungsanlage Jülich

Postfach 1913, D-5170 Jülich

GERMANY 
T. M. Fliedner

Institut für Arbeits-u. Sozialmedizin

Universität Ulm

Oberer Eselsberg M 24, 309

D-7900 Ulm

GERMANY

L. Friberg

The Karolinska Institute

Stockholm

SWEDEN

A. Geertsema

Sasol Technology (Pty), Ltd.

P.O. Box 1, Sasolburg 9570

REPUBLIC OF SOUTH AFRICA

T. Giuseppe

ENEA-PAS-FIBI-AEROSOL

Via Mazzini 2, I-40138 Bologna

ITALY

H. L. Gjørup, Head

Health Physics Department

Atomic Energy Commission

Research Establishment

Ris $ø$, Roskilde

DENMARK

C. L. Greenstock

Radiation Biology, AECL Research

Chalk River, Ontario, KOJ 1 JO

CANADA

R. V. Griffith

International Atomic Energy Agency

Wagramerstraße 5

P.O. Box 200, A-1400 Vienna

AUSTRIA
Y. Hamnerius.

Applied Electron Physics

Chalmers University of Technology

S-412 96 Göteborg

SWEDEN

G. P. Hanson, Chief

Radiation Medicine Unit

World Health Organization

CH-1211 Geneva 27

SWITZERLAND

\section{J. L. Head}

Department of Nuclear Science \& Technology

Royal Naval College, Greenwich

London, SE 10 9NN

ENGLAND

W. Hofmann

Division of Biophysics

University of Salzburg

Hellbrunner Str. 34, A-5020 Salzburg

AUSTRIA

J. Inaba, Director

Division of Comparative Radiotoxicology

National Institute of Radiological Sciences

9-1, Anagawa-4-chome, Chiba-shi 260

JAPAN

International Atomic Energy Agency

Documents Library, Attn: Mrs. Javor

Kaerntnerring 11, A-1010 Vienna 1

AUSTRIA

E. Iranzo, Jefe

División Protección Radiológica

Junta de Energia Nuclear

Ciudad Universitari, Madrid 3

SPAIN

Distr.17 
PNL-10500, Pt. 1

UC-408

W. Jacobi

Institut für Strahlenschutz

Post Schleissheim, Ingolstadter Landstrasse 1

D-8042 Neuherberg

GERMANY

A. M. Kellerer

Institut für Strahlen Biologie, GSF

Ingolstadter Landstrasse 1

D-8042 Neuherberg b. München

GERMANY

T. Kivikas

Studsvik Nuclear

S-611 82 Nyköping

SWEDEN

H.-J. Klimisch

BASF Aktiengesellschaft

Abteilung Toxikologie, Z470

D-6700 Ludwigshafen

GERMANY

H. E. Knoell

Battelle-Institut e.V.

Am Römerhof 35, Postfach 900160

D-6000 Frankfurt am Main 90

GERMANY

Dr. J. Lafuma

Department de Protection Sanitair

Commissariate a l'Energie Atomique

92260 Fontenay-Aux-Roses

FRANCE

J. R. A. Lakey

Department of Nuclear Science \& Technology

Royal Naval College, Greenwich

London, SE 10 9NN

ENGLAND
Li De-Ping, Professor \& Director

North China Institute of Radiation

Protection, NMI

P.O. Box 120, Tai-yuan, Shan-Xi

PEOPLE'S REPUBLIC OF CHINA

Librarian

Alberta Environmental Centre

Bag 4000, Vegreville, Alberta T9C 1 T4

CANADA

Librarian

Centre d'Etudes Nucléaires de Saclay

P.O. Box 2, Saclay, Fig-sur-Yvette (S\&O)

FRANCE

Librarian, HCS/EHE

World Health Organization

CH-1211 Geneva 27

SWITZERLAND

Librarian

Kernforschungzentrum, Karlsruhe

Institut für Strahlenbiologie

Postfach 3640, D-75 Karlsruhe 1

GERMANY

Librarian

Max-Planck Institut für Biophysics

Forstkasstraße

D-6000 Frankfurt/Main

GERMANY

Librarian

Medical Research Council

Radiobiology Unit

Chilton, Oxon OX11 ORD

ENGLAND 
Librarian

Ministry of Agriculture, Fisheries \& Food

Fisheries Laboratory

Lowestoft, Suffolk NR33 OHT

ENGLAND

Librarian

National Institute of Radiological Sciences

9-1, Anagawa-4-chome, Chiba-shi 260

JAPAN

Library

Atomic Energy Commission of Canada, Ltd.

Whiteshell Nuclear Research Establishment

Pinawa, Manitoba ROE 1LO

CANADA

\section{B. Lindell}

National Institute of Radiation Protection

Fack S-104 01, Stockholm 60

SWEDEN

A. M. Marko

9 Huron Street

Deep River, Ontario KOJ 1PO

CANADA

R. Masse

Institut de Protection et de Sûreté Nucléaire

Département de Protection Sanitaire

Service d'Etudes Appliquées de

Protection Sanitaire

BP 6, F-92260 Fontenay-aux-Roses

FRANCE

H. Matsudaira, Director General

National Institute of Radiological Sciences

9-1, Anagawa-4-chome, Chiba-shi 260

JAPAN
O. Matsuoka, Research Consultant

Abiko Research Laboratory

Central Research Institute of

Electric Power Industry

1646, Abiko, Abiko City, Chiba-ken 270-11

JAPAN

N. Matsusaka

Department of Veterinary Medicine

Faculty of Agriculture, Iwate University

Ueda, Morioka, Iwate 020

JAPAN

S. Mattsson

Department of Radiation Physics

Malmő General Hopsital

S-214 01 Malmö

SWEDEN

R. G. C. McElroy

Atomic Energy Commission of Canada, Ltd.

Dosimetric Research Branch

Chalk River, Ontario KOJ 1JO

CANADA

F.-I. S. Medina

Cytogenetics Laboratory

Biomedical Research Division, A.R.C.

Philippine Atomic Energy Commission

P.O. Box 932, Manila

THE PHILIPPINES

M. L. Mendelsohn

Radiation Effects Research Foundation

1-8-6 Nakagawa, Nagasaki 850

JAPAN

Distr.19 
PNL-10500, Pt. 1

UC-408

Meng Zi-Qiang

Department of Environmental Science

Shanxi University

Tai-yuan, Shan-xi

PEOPLE'S REPUBLIC OF CHINA

P. Metalli

ENEA-PAS, CRE Casaccia

Casella Postale 2400, I-00100 Roma

ITALY

H. J. Metivier

Institut de Protection et de Sûreté Nucléaire

Centre d'Études de Service de

Fontenay-aux-Roses

BP 6, F-92265 Fontenay-aux-Roses

FRANCE

A. R. Morgan

Biotechnology, Bldg. 353

AEA Technology

Harwell, Didcot, Oxfordshire OX11 ORA

ENGLAND

Y. I. Moskalev

Institute of Biophysics

Ministry of Public Health

Givopisnaya 46, Moscow

RUSSIA

J. Muller

7 Millgate Crescent

Willowdale, Ontario M2K 1 L5

CANADA

J. C. Nénot, Deputy Director

Département de Protection

Centre d' Etudes Nucléaires

BP 6, F-92260 Fontenay-aux-Roses

FRANCE
R. Osborne

Atomic Energy Commission of Canada, Ltd.

Biology and Health Physics Division

Chalk River Nuclear Laboratories

P.O. Box 62, Chalk River, Ontario KOJ 1 JO

CANADA

J. Pacha

Silesian Medical School, Fac. of Pharmacy

U1. Jagiellonska 4, 41-200 Sosnowiec

POLAND

H. G. Paretzke

GSF Institut für Strahlenschutz

Ingolstadter Landstraße 1

D-8042 Neuherberg

GERMANY

N. Parmentier

Département de Protection Sanitaire

Centre d'Etudes Nucléaires

BP 6, F-92260 Fontenay-aux-Roses

FRANCE

G. Patrick

Medical Research Council

Radiobiology Unit

Harwell, Didcot, Oxon OX11 ORD

ENGLAND

O. Pavlovski

Institute of Biophysics

Ministry of Public Health

Givopisnaya 46, Moscow D-182

RUSSIA

G. Premazzi

Commission of the European Communities

Joint Research Centre, Ispra Establishment

I-21020 Ispra

ITALY 
V. Prodi

Department of Physics

University of Bologna

Via Irnerio 46, I-40126 Bologna

ITALY

O. Ravera

Commission of the European Communities

I-21020 Ispra (Varese)

ITALY

Reports Librarian

Harwell Laboratory,

Bldg. 465, UKAEA

Harwell, Didcot, Oxon OX11 ORB

ENGLAND

\section{P. J. A. Rombout}

Inhalation Toxicology Department

National Institute of Public Health

and Environmental Protection

P.O. Box 1, NL-3720 BA Bilthoven

THE NETHERLANDS

\section{Roy}

Institut de Protection et de Sûreté Nucléaire

Département de Protection Sanitaire

Service d'Etudes Appliquées

de Protection Sanitaire

BP 6, F-92260 Fontenay-aux-Roses

FRANCE

\section{F. A. Sacherer \\ $\mathrm{GmbH}$}

Böttgerstrasse 2-6

D65439 Flörsheim Am Main

GERMANY
W. Seelentag, Chief Medical Officer

Radiation Health Unit

World Health Organization

CH-1211 Geneva 27

SWITZERLAND

J. Sinnaeve

Biology, Radiation Protection

Medical Research

Commission of the European Communities

200 Rue de la Loi, B-1049 Brussels

BELGIUM

H. Smith

International Commission on

Radiological Protection

P.O. Box 35, Didcot

Oxon OX11 ORJ

ENGLAND

J. W. Stather

National Radiological Protection Board

Bldg. 383, Chilton, Didcot

Oxon OX11 ORQ

ENGLAND

M. J. Suess

International Advisor for Health Hazards

26A Strandvejen, DK-2100 Copenhagen

DENMARK

Sun Shi-quan, Head

Radiation-Medicine Department

North China Institute of

Radiation Protection, MNI

P.O. Box 120, Tai-yuan, Shan-Xi

PEOPLE'S REPUBLIC OF CHINA 
PNL-10500, Pt. 1

UC-408

G. Tarroni

EHEA-AMB-BIO-FITS

Viale G. B. Ercolani 8

I-40138 Bologna

ITALY

D. M. Taylor

5 Branwen Close, The Sanctuary

Culverhouse Cross, Cardiff CF5 4NE

ENGLAND

K. H. Tempel

Institut für Pharmakologie,

Toxikologie und Pharmazie

Fachbereich Tiermedizin der

Universität München

Veterinärstraße 13, D-8000 München 22

GERMANY

J. T. Triffitt

MRC Bone Research Laboratory

Nuffield Orthopaedic Centre

Oxford OX3 7LD

ENGLAND

United Nations Scientific Committee

on the Effects of Atomic Radiation

Vienna International Center

P.O. Box 500, A-1400 Vienna

AUSTRIA

D. Van As

Atomic Energy Corporation

P.O. Box 582, Pretoria 0001

REPUBLIC OF SOUTH AFRICA

L. Verschaeve

V.I.T.O.

Boeretang 200, B-2400 Mol

BELGIUM
Vienna International Centre Library

Gifts and Exchange

P.O. Box 100, A-1400 Vienna

AUSTRIA

V. Volf

Kernforschungzentrum Karlsruhe

Institut für Genetik und

Toxikologie von Spaltstoffen

Postfach 3640, D-7500 Karisruhe 1

GERMANY

G. Walinder

Unit of Radiological Oncology

University of Agricultural Sciences

P.O. Box 7031, S-750 07 Uppsala

SWEDEN

\section{Wang Hengde}

North China Institute of Radiation Protection

P.O. Box 120, Tai-yuan, Shan-Xi

PEOPLE'S REPUBLIC OF CHINA

Wang Renzhi

Institute of Radiation Medicine

27\# Tai Ping Road, Beijing 100850

PEOPLE'S REPUBLIC OF CHINA

Wang Ruifa, Associate Director

Laboratory of Industrial Hygiene

Ministry of Public Health

P.O. Box 8018, 2 Xinkang Street

Deshengmenwai, Beijing 100088

PEOPLE'S REPUBLIC OF CHINA

Wang Yibing

North China Institute of Radiation Protection

P.O. Box 120, Tai-yuan, Shan-Xi

PEOPLE'S REPUBLIC OF CHINA 
Wei Lü-Xin

Laboratory of Industrial Hygiene

Ministry of Public Health

2 Xinkang Street, Deshengmenwai,

Beijing 100088

PEOPLE'S REPUBLIC OF CHINA

\section{J. Wells}

Radiobiology Laboratory

Radiation Biophysics, Nuclear Electric,

Berkeley Nuclear Laboratories

Berkeley, Gloucestershire GL 13 9PB

ENGLAND

B. C. Winkler, Director of Licensing

Raad Op Atomic, Atoomkrag Energy Board

Privaatsk X 256, Pretoria 0001

REPUBLIC OF SOUTH AFRICA

Wu De-Chang

Institute of Radiation Medicine

27\# Tai Ping Road, Beijing

PEOPLE'S REPUBLIC OF CHINA

Yao Jiaxiang

Laboratory of Industrial Hygiene

2 Xinkang Street, Deshengmenwai

Beijing 100088

PEOPLE'S REPUBLIC OF CHINA

Kenjiro Yokoro, Director

Research Institute for Nuclear Medicine \& Biology, Hiroshima University

Kasumi 1-2-3, Minami-ku, Hiroshima 734

JAPAN
Zhu Zhixian

China Research Institute of

Radiation Protection

Ministry of Nuclear Industry

P.O. Box 120, Tai-yuan, Shan-Xi

PEOPLES REPUBLIC OF CHINA

\section{ON-SITE}

\section{DOE Richland}

Operations Office (4)

D. D. Green K8-50

P. W. Kruger K8-50

D. R. Segna K8-50

Public Reading Room A1-65

WSU Tri-Cities

University Center

H. R. Gover, Librarian H2-52

Hanford Environmental Health Foundation

R. L. Kathren H2-52

\section{Pacific Northwest Laboratory} (157)

R. R. Adee P8-13

R. C. Adams K8-09

L. E. Anderson K4-28

R. W. Baalman K1-50 (20)

J. F. Bagley K1-66

W. J. Bair K1-50 (2)

L. A. Braby P8-47

A. L. Brooks P7-53

R. L. Buschbom P7-82

B. J. Chou K4-10

J. M. Christensen P7-58 (5)

J. A. Creim K4-28

F. T. Cross K4-13

G. E. Dagle P7-53

H. S. DeFord K4-16

R. J. Douthart K4-13

R. D. DuBois P8-47

C. G. Edmonds P8-19

Distr.23 
PNL-10500, Pt. 1

UC-408

J. J. Evanoff K6-79

D. R. Fisher K3-53

L. J. Florek K4-16

W. C. Forsythe K4-16

A. F. Fuciarelli P7-56

K. M. Gideon K4-10

R. A. Gies K4-13

A. W. Gieschen K4-16

E. S. Gilbert P7-82

M. F. Gillis K1-50

W. A. Glass K3-53

D. K. Hammerberg P8-29

B. K. Hayden K4-16

L. A. Holmes K1-29

M. G. Horstman K4-10

V. G. Horstman P7-58

T. E. Hui K3-70

A. C. James H2-52

A. E. Jarrell K4-12

J. R. Johnson K3-57

R. F. Jostes K4-13

M. Knotek K1-48

E. G. Kuffel K4-16

W. W. Laity K2-50

K. E. Lauhala P7-58

E. K. Ligotke P7-82

C. C. Lumetta BSRC

W. J. Madia K1-46

J. A. Mahaffey P7-82

D. D. Mahlum P7-56

D. B. Mann P7-56

J. C. McDonald P7-03

P. W. Mellick K4-10

D. L. Miller P7-53

J. H. Miller P8-47

M. C. Miller P7-41

R. A. Miller K4-10

J. E. Morris P7-53

J. M. Nelson P8-47

G. P. O'Connor K6-63

J. F. Park P7-52 (20)

M. A. Parkhurst K3-55

R. W. Perkins K6-48

H. A. Ragan K4-13

R. A. Renne K4-13
D. N. Rommereim P7-55

R. L. Rommereim K4-10

C. O. Romsos K4-10

E. J. Rossignol K4-16

S. E. Rowe K4-13

J. L. Ryan P7-25

L. B. Sasser P7-53

L. C. Schmid K1-34

R. P. Schneider P7-56

L. E. Sever BSRC

B. D. Shipp K8-28

M. R. Sikov P7-53

E. C. Sisk P7-56

L. G. Smith K4-16

S. K. Smith P7-82

D. L. Springer P7-56

J. G. Stephan K6-84

D. L. Stewart K6-96

L. C. Stillwell P7-56

G. M. Stokes K1-74

K. L. Swinth K3-53

T. S. Tenforde K1-50

R. M. Thomas P7-53

B. D. Thrall P7-56

K. D. Thrall K3-57

H. R. Udseth P8-19

B. E. Vaughan K1-66

R. A. Walters K1-50 (10)

C. R. Watson P7-82

R. E. Weller P7-52

R. B. Westerberg K4-16

R. E. Wildung P7-54

W. E. Wilson P8-08

Health Physics Department Library

Life Sciences Library (2)

Publishing Coordination

Technical Report Files (5) 